\title{
Benchmarking MELCOR 1.8.2 for ITER Against Recent EVITA Results
}

\author{
Brad J. Merrill
}

November 2007

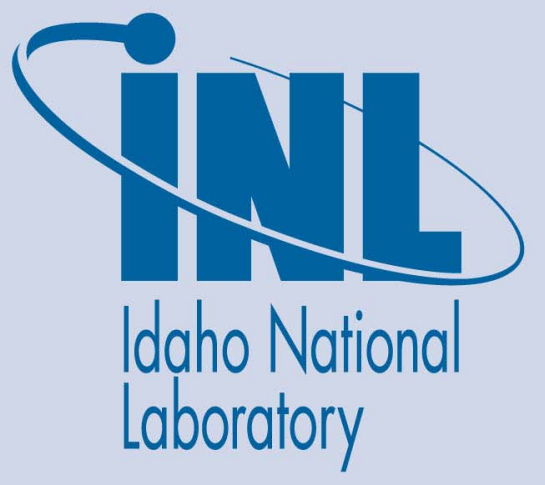

The INL is a U.S. Department of Energy National Laboratory operated by Battelle Energy Alliance 
INL/EXT-07-13521

\title{
Benchmarking MELCOR 1.8.2 for ITER Against Recent EVITA Results
}

\author{
Brad J. Merrill
}

November 2007

\begin{abstract}
Idaho National Laboratory
Idaho Falls, Idaho 83415
\end{abstract}

Prepared for the

U.S. Department of Energy

Office of Science

Under DOE Idaho Operations Office

Contract DE-AC07-05ID14517 


\title{
Benchmarking MELCOR 1.8.2 for ITER Against Recent EVITA Results
}

\author{
INL/EXT-07-13521
}

November 2007

Approved by
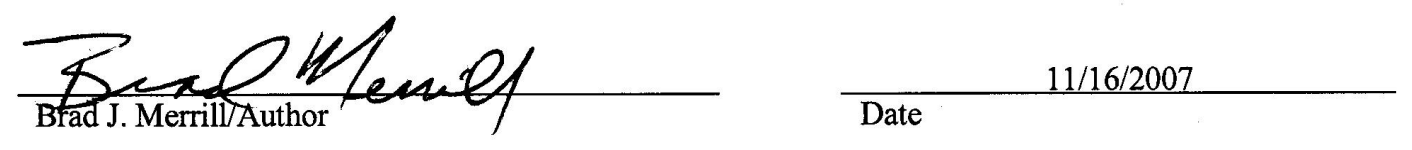

$\frac{\text { Xer C. Cadurallades }}{\text { Lee C. Cadwallader/Technical Checker }}$

$\frac{\text { Nov. 27,2007 }}{\text { Date }}$

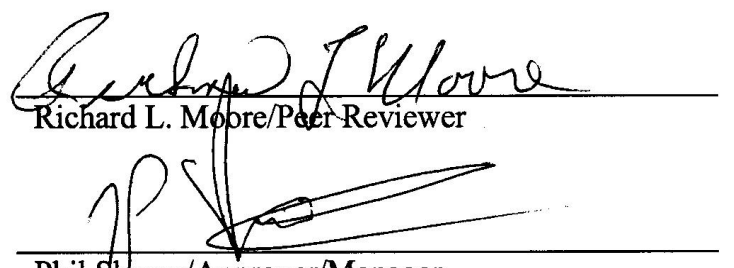

Phil Sharpe/Approver/Manager

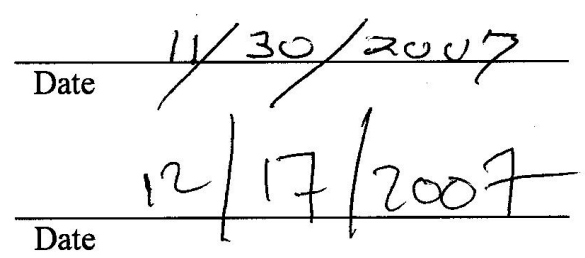




\begin{abstract}
A version of MELCOR 1.8.2, modified for use in International Thermonuclear Experimental Reactor (ITER) Preliminary Safety Report analyses, was validated against recent data from the European Vacuum Impingement Test Apparatus (EVITA) facility located in Cadarache, France. EVITA Test Series 7 was used for this study to verify MELCOR's ability to predict pressures, temperatures, cryoplate ice mass, and vacuum vessel (VV) condensate mass for test conditions in EVITA that included injections of steam, nitrogen, and water in to the EVITA VV after the VV walls had been heated to $165^{\circ} \mathrm{C}$ and the cryoplate had been cooled to $-193{ }^{\circ} \mathrm{C}$. In general, the ability of MELCOR to predict the VV pressure and wall temperatures for the steam only and water only injection tests was very good. Predicted ice layer masses were larger than reported for the EVITA cryoplate, in particular for the steam only injection tests ( $\sim 40 \%$ too high), and the predicted condensate masses were less that measured in EVITA. Both of these discrepancies can be explained by ice porosity. The modified MELCOR 1.8.2 over predicts the EVITA VV pressure for the co-injection tests (e.g., steam plus nitrogen, or water plus nitrogen injections) by almost a factor of two. Based on parametric runs that were made by increasing the predicted cryoplate condensation rate, it is believed that this pressure over prediction is a result of an under predicted cryoplate condensation rate. The details of this study are documented in this report as well as conclusions about the impact this study has regarding the use of this version of MELCOR for consequence analyses for ITER safety reports.
\end{abstract}




\section{ACRONYMS}

$\begin{array}{ll}\text { CV } & \text { Control Volume } \\ \text { EC } & \text { Enhanced Condensation } \\ \text { EVITA } & \text { European Vacuum Impingement Test Apparatus } \\ \text { FP } & \text { Flow Path } \\ \text { FR } & \text { Flow Rate } \\ \text { HS } & \text { Heat Structure } \\ \text { ICE } & \text { Ingress of Coolant Experiment } \\ \text { IEA } & \text { International Energy Agency } \\ \text { INL } & \text { Idaho National Laboratory } \\ \text { ITER } & \text { International Thermonuclear Experimental Reactor } \\ \text { IO } & \text { International Organization } \\ \text { PSR } & \text { Preliminary Safety Report } \\ \text { VV } & \text { Vacuum Vessel }\end{array}$




\section{CONTENTS}

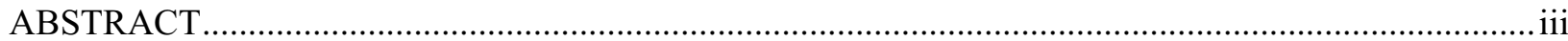

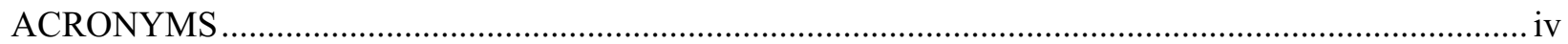

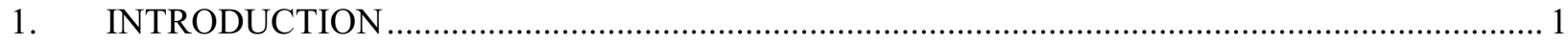

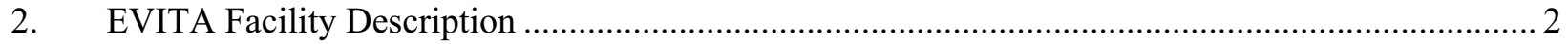

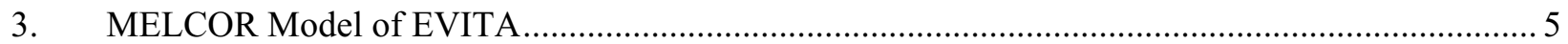

4. Modified MELCOR 1.8.2 Ice Layer Formation Model ............................................................ 7

5. EVITA Test Comparison to MELCOR Predictions ….............................................................. 9

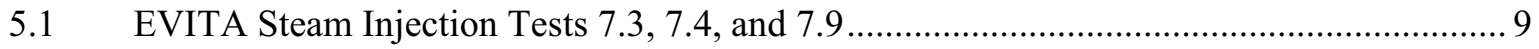



5.3 EVITA Steam and Nitrogen Co-injection Tests 7.1 and 7.2 ….................................... 18

5.4 EVITA Water and Nitrogen Co-injection Tests 7.5 and 7.6 ....................................... 24

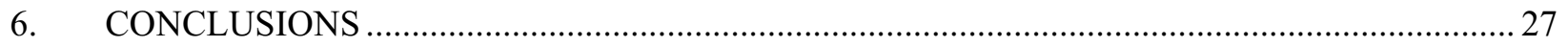

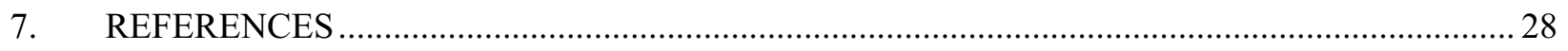

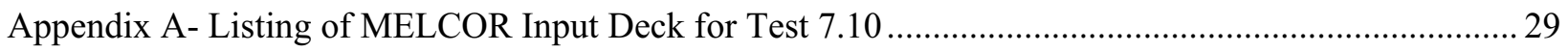

\section{FIGURES}

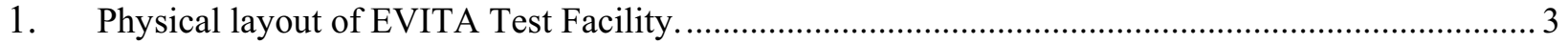

2. Schematic of MELCOR model of the EVITA VV and VV internals, showing control volumes

$(\mathrm{CV})$, flow paths (FP), and heat structures (numbers).

3. EVITA VV pressure, (a) Tests 7.3, 7.4, and 7.9, and (b) Comparison with MELCOR predictions.

4. EVITA VV wall temperatures, (a) Tests 7.3, 7.4, and 7.9, and (b) Comparison with MELCOR

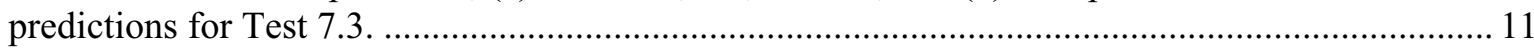

5. EVITA VV wall temperatures, (a) Comparison with MELCOR for Test 7.4, and (b) Comparison with MELCOR predictions for Test 7.9.

6. Ice and water masses for EVITA Tests 7.3, 7.4, and 7.9, (a) Cryoplate ice mass comparison with MELCOR predictions, and (b) VV condensate mass comparison with MELCOR predictions. 
7. EVITA VV wall thermocouple placement, (a) top of vessel, and (b) bottom of vessel.

8. EVITA VV pressure, (a) Tests 7.3, 7.4, and 7.9, and (b) Comparison with MELCOR predictions.

9. EVITA VV wall temperatures, (a) Tests 7.7, 7.8, and 7.10, and (b) Comparison with MELCOR predictions for Test 7.7.

10. EVITA VV wall temperatures, (a) Comparison with MELCOR for Test 7.8, and (b) Comparison with MELCOR predictions for Test 7.10.

11. Ice and water masses for EVITA Tests 7.7, 7.8, and 7.10, (a) Cryoplate ice mass comparison with MELCOR predictions, and (b) VV condensate mass comparison with MELCOR predictions........ 17

12. EVITA VV pressure, (a) Tests 7.1 and 7.2, and (b) Comparison with MELCOR predictions......... 20

13. EVITA VV wall temperatures, (a) Tests 7.1 and 7.2, and (b) Comparison with MELCOR predictions for Test 7.1.

14. EVITA Tests 7.1 and 7.2 comparisons, (a) Cryoplate ice mass comparison with MELCOR predictions, and (b) VV condensate mass comparison with MELCOR predictions.

15. EVITA Test 7.1 comparisons, (a) VV pressure with MELCOR and MELCOR with enhanced condensation (EC), and (b) VV wall temperature with MELCOR with EC.

16. EVITA Tests 7.1 and 7.2 comparison, (a) Cryoplate ice mass comparison with MELCOR with EC, and (b) VV condensate mass comparison with MELCOR with EC.

17. EVITA Test 7.1 comparisons, (a) VV pressure with MELCOR and experimental version (EV) of MELCOR with EC, and (b) VV wall temperature with EV of MELCOR with EC.

18. EVITA Tests 7.1 and 7.2 comparison, (a) Cryoplate ice mass comparison with EV of MELCOR with EC, and (b) VV condensate mass comparison with EV of MELCOR with EC.

19. EVITA VV pressure and temperatures, (a) Tests 7.5,7.6 and 7.8, MELCOR 7.5 and MELCOR 7.5 EC pressures, and (b) Test 7.5 VV wall and MELCOR and MELCOR EC temperatures..

20. EVITA Test 7.5 and 7.6 comparisons, (a) Cryoplate ice mass comparison with MELCOR EC, and (b) VV condensate mass comparison with MELCOR with EC.

\section{TABLES}




\section{Benchmarking MELCOR 1.8.2 for ITER Against Recent EVITA Results}

\section{INTRODUCTION}

The International Thermonuclear Experimental Reactor (ITER) Program has adopted a modified version of the MELCOR 1.8.2 code [Moore, 2007] for assessing the consequence of selected accidents on the ITER device. The results of these accident consequence analyses will be included in the ITER

Preliminary Safety Report (PSR). Because this ITER safety document is to be used in the licensing process for the ITER device, this modified version of MELCOR was validated against data from experiments that simulated accident conditions in ITER [Takase, 2001], [Tolpilski, 2001], [Sardain, 2005], [Sardain, 2006]. This report documents the results of a new validation study that benchmarks predictions from this modified MELCOR 1.8.2 code against the most recent data from the European Vacuum Impingement Test Apparatus (EVITA). This report was funded through an ITER Task Agreement for MELCOR Quality Assurance and Safety Analyses [Sauthoff, 2007].

The following section (Section 2) describes the physical layout and operation of the EVITA facility during the most recent test series in EVITA, Test Series 7. Section 3 describes the MELCOR input model developed to simulate the EVITA facility with the MELCOR code. Section 4 presents an overview of the ice formation model of the modified MELCOR 1.8.2 code, which is one of the MELCOR models being validated by this study. Section 5 gives a comparison of the results obtained from MELCOR with ten tests conducted in EVITA. The final section (Section 6) presents conclusions from this benchmarking study. 


\section{EVITA Facility Description}

A significant effort has been undertaken worldwide to validate thermal hydraulic codes that are used for the safety assessment of fusion reactors [Takase, 2001], [Tolpilski, 2001], [Sardain, 2005], [Sardain, 2006]. This work is conducted under a task on thermal hydraulic code validation through an International Energy Agency Implementing Agreement on the Environmental, Safety and Economic Aspects of Fusion Power (IEA-ESE/FP). Several programs, related to transient analysis in water-cooled fusion reactors, were run in order to assess the capabilities of these thermal hydraulic codes to treat the physical phenomena governing accident sequences related to water/steam discharge into a vacuum vessel or a cryostat. The phenomena studied were pressurization of a volume at low initial pressure, critical flow, water flashing, pressure relief into an expansion volume, condensation of vapor in a pressure suppression system, formation of ice on a cryogenic structure, and heat transfer between walls and fluid in various thermodynamic conditions. One of these programs was the EVITA facility, operated at Cadarache, France.

The EVITA facility simulates the ingress of coolant into the cryostat, i.e. into a volume at low initial pressure containing surfaces at cryogenic temperatures. A view of this test facility appears in Figure 1. In this figure is a flow schematic of the facility, a photo of various components of the facility showing the EVITA vacuum vessel (VV) interior, and photos of the cryoplate inside of the VV both prior to and during a test in EVITA. During a typical test in EVITA, the VV was evacuated to a very low pressure $(\sim 0.1$ mBar), the VV walls were heated to the desired test temperature $\left(\sim 165^{\circ} \mathrm{C}\right)$, the cryoplate was cooled by liquid nitrogen flow down to $80 \mathrm{~K}$, and either water $\left(40 \mathrm{bar}, 165^{\circ} \mathrm{C}\right)$ or steam $\left(7.5 \mathrm{bar}, 165^{\circ} \mathrm{C}\right)$ was injected into the VV for a set period of time. Once the injection time had been achieved, the injection of water or steam was terminated, the VV vented to atmosphere, the condensate drained from the bottom of the vessel (collect and measured), and then the VV was re-closed. After closing the VV, the cryoplate cooling was stopped, the plate allowed to return to room temperature, causing the ice layer on the cryoplate to melt, and the water from the ice layer melt collected and measured. Time-dependent measurements made during the test included:

- VV pressure

- VV atmosphere temperature at three locations

- VV wall temperature at nine locations

- Cryoplate temperatures at ten locations (including one for each plate face quadrant, both left and right surface)

- Injected water or steam flow rate and temperature

- Vaporized liquid nitrogen flow rate (from which plate heating was estimated)

- Liquid nitrogen system temperatures.

Table 1 contains a results summary supplied by [Ayrault, 2005] for some of the recent, successful EVITA tests. This table presents the test identifier, the injected water or steam flow rate, the co-injected flow rate of a non-condensable gas (nitrogen), the temperature conditions for the VV walls, the average power absorbed by the cryoplate during water or steam injection, the mass of water condensate at the bottom of the $\mathrm{VV}$ following water or steam injection, the duration of water or steam injection, the mass of ice that accumulates on the cryoplate, and the final pressure inside the VV at the end of injection. In addition to this information, each participant of the IEA Task Agreement received a report that documented the timedependent measurements [Ayrault, 2005] and the same time-dependent data in Excel spread sheet format. 

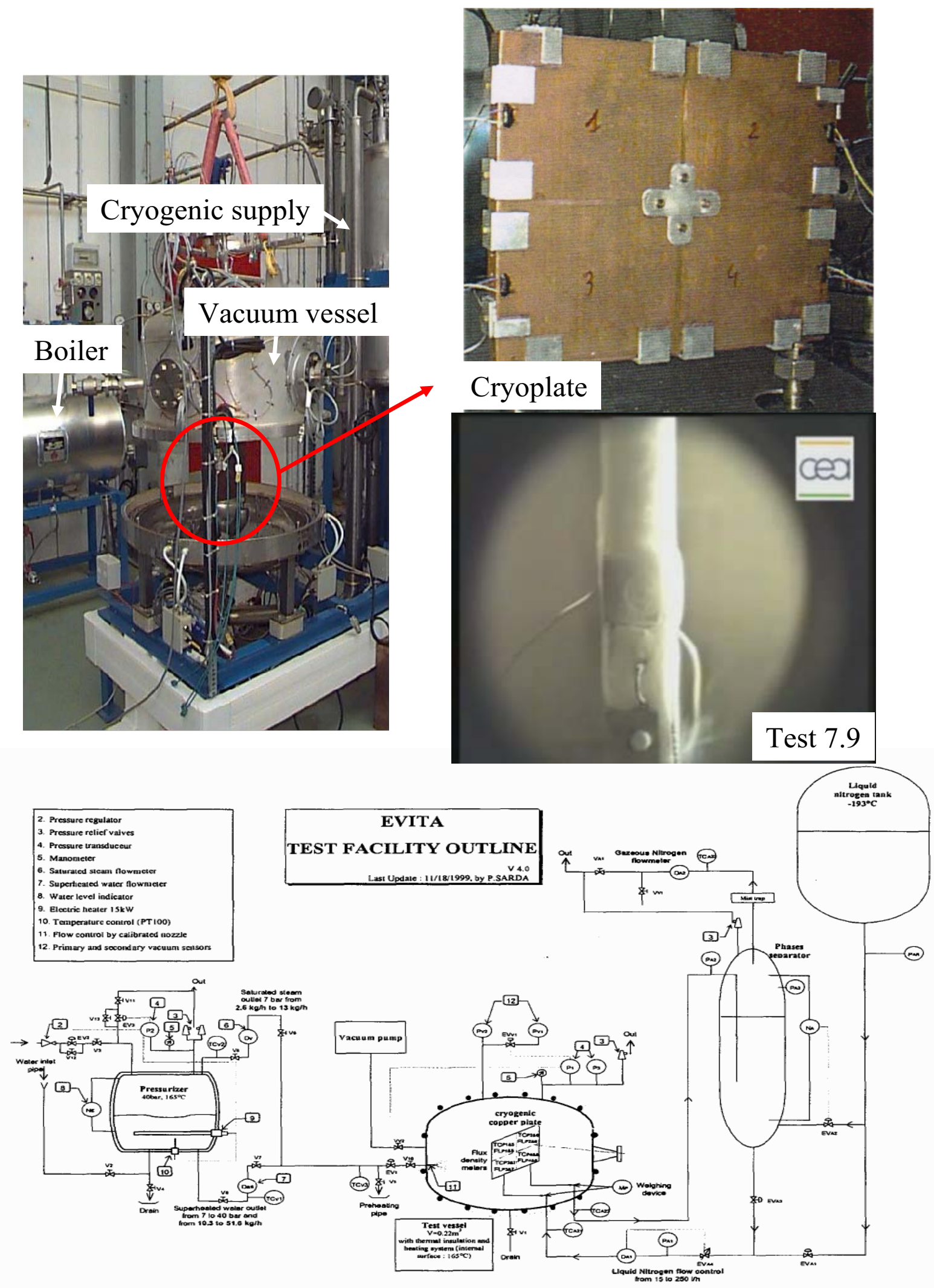

Figure 1. Physical layout of EVITA Test Facility. 
Table 1. Summary results from recent EVITA tests.

\begin{tabular}{|c|c|c|c|c|c|c|c|c|}
\hline Test & $\begin{array}{c}\text { Steam } / \text { water } \\
\text { FR }(\mathrm{g} / \mathbf{s})\end{array}$ & $\begin{array}{l}\text { Non-condensable } \\
\text { gas FR }(\mathrm{g} / \mathrm{s})\end{array}$ & VV-walls & $\begin{array}{l}\Delta \mathbf{P}_{\mathrm{N} 2} \\
(\mathbf{W})\end{array}$ & $\begin{array}{c}\text { Condensed } \\
\text { water (g) }\end{array}$ & $\begin{array}{l}\text { Duration } \\
\text { of test (s) }\end{array}$ & $\begin{array}{l}\text { Ice mass } \\
(\mathrm{g})\end{array}$ & $\begin{array}{l}\text { Final VV- } \\
\text { pressure } \\
\text { (abs bar) }\end{array}$ \\
\hline 7.1 & $\begin{array}{c}\text { Steam / } \\
2.1 \pm 0.018 \\
\end{array}$ & $1.540 \pm 0.013$ & Isothermal & 3896 & $180 \pm 2.9$ & $200 \pm 1$ & $118 \pm 11$ & $1.25 \pm 0.039$ \\
\hline 7.2 & $\begin{array}{c}\text { Steam / } \\
1.9 \pm 0.018\end{array}$ & $1.540 \pm 0.013$ & Isothermal & 3300 & $33 \pm 2.9$ & $120 \pm 1$ & $111 \pm 11$ & $1.04 \pm 0.039$ \\
\hline 7.3 & $\begin{array}{c}\text { Steam / } \\
2.04 \pm 0.015\end{array}$ & 0 & Isothermal & 4861 & $30 \pm 2.9$ & $120 \pm 1$ & $175 \pm 11$ & $0.295 \pm 0.039$ \\
\hline 7.4 & $\begin{array}{c}\text { Steam / } \\
1.9 \pm 0.015\end{array}$ & 0 & Isothermal & 4045 & $310 \pm 2.9$ & $300 \pm 1$ & $126 \pm 11$ & $0.995 \pm 0.039$ \\
\hline 7.5 & \begin{tabular}{|c} 
Water / \\
$2.45 \pm 0.011$ \\
\end{tabular} & $0.340 \pm 0.013$ & Isothermal & 3480 & $335 \pm 2.9$ & $300 \pm 1$ & $338 \pm 11$ & $0.57 \pm 0.039$ \\
\hline 7.6 & $\begin{array}{c}\text { Water / } \\
2.54 \pm 0.011\end{array}$ & $0.340 \pm 0.013$ & Isothermal & 3877 & $10 \pm 2.9$ & $80 \pm 1$ & $136 \pm 11$ & $\begin{array}{c}0.520 \pm \\
0.039\end{array}$ \\
\hline 7.7 & $\begin{array}{c}\text { Water / } \\
2.40 \pm 0.011\end{array}$ & 0 & Isothermal & 3876 & $0 \pm 2.9$ & $80 \pm 1$ & $165 \pm 11$ & $0.18 \pm 0.039$ \\
\hline 7.8 & $\begin{array}{c}\text { Water / } \\
2.72 \pm 0.011\end{array}$ & 0 & Isothermal & 4150 & $440 \pm 2.9$ & $300 \pm 1$ & $293 \pm 11$ & $0.64 \pm 0.039$ \\
\hline 7.9 & $\begin{array}{c}\text { Steam } \\
2.1 \pm 0.011\end{array}$ & 0 & $\begin{array}{l}\text { No VV- } \\
\text { heaters } \\
\text { during } \\
\text { injection }\end{array}$ & 4493 & $1050 \pm 2.9$ & $660 \pm 1$ & $205 \pm 11$ & $1.35 \pm 0.039$ \\
\hline 7.10 & $\begin{array}{c}\text { Water / } \\
2.45 \pm 0.011\end{array}$ & 0 & $\begin{array}{l}\text { No VV- } \\
\text { heaters } \\
\text { during } \\
\text { injection }\end{array}$ & 3220 & $1210 \pm 2.9$ & $720 \pm 1$ & $420 \pm 11$ & $0.63 \pm 0.039$ \\
\hline
\end{tabular}

From [Ayrault, 2005] 


\section{MELCOR Model of EVITA}

A modified version of the MELCOR code [Moore, 2007] was benchmarked against the EVITA experimental data described in the previous section. Figure 2 contains a schematic of the MELCOR input model used to calculate EVITA VV coolant flow, pressures and temperatures and VV wall and in-vessel component temperatures for this validation study. For this study, the EVITA VV and boiler were divided into four fluid volumes, connected by six fluid flow paths. Further nodalization of these volumes was not attempted at this time to allow for a fast running simulation of EVITA. It is known from previous validation studies that detailed flow estimates improve the agreement between tests and MELCOR predictions; however, there are not enough fluid velocity and temperature measurements from the EVITA facility to warrant a more detailed fluid flow model at this time. For this study, the injected flow rate for a given test was set to the measured value and was not calculated by MELCOR fluid conservation of momentum equations or flow choking correlations.

Based on previous attempts at modeling the EVITA facility [Sardain, 2005], heat transfer between the injected coolant and the cryoplate and VV walls plays a prominent role in predicting cryoplate ice formation and VV internal pressurization. An attempt at modeling the heat transfer between the liquid nitrogen and the cryoplate was not made in this model because of the added uncertainty that this would introduce into this validation study. Instead, the measured temperatures of the copper cryoplate were used as boundary conditions for the heat structures simulating the cryoplate in this model. Consequently, the cryoplate was simulated by eight heat structures, each location representing a portion of the cryoplate for which temperature measurements were made for the EVITA tests. In addition, the cryoplate coolant supply lines were modeled by four more heat structures to simulate the condensation that may have occurred on these structures.

The VV wall was divided into 10 heat structures, simulating poloidal rings at various axial locations of the bottom head, sidewall, and top head of the vessel. A more detailed segmentation of the vessel would have improved the MELCOR prediction, but it was not warranted because of the low number of VV temperature locations being monitored for these tests. However, the hemispherical bottom head was segmented in an attempt to simulate the heat transfer between any pool that might form at the bottom of the EVITA VV and the steel wall of the VV bottom head. Axial heat conduction between poloidal rings was included through user defined control functions in this model to simulate 2D heat conduction in the bottom head. Both the applied heater power during EVITA tests and the heat transfer between the VV wall and the ambient had to be estimated because the EVITA experimentalist did not record the heater power required to maintain the vessel at temperature. A request was also made to the experimentalists to bring the VV to temperature, and subsequent to achieving initial conditions to turn the heaters off without injecting coolant into the VV. The rate of wall temperature decay would have allowed modelers the opportunity to derive accurate over all heat loss coefficients for the VV to the environment, but the experimentalists did not attempt this test either. Because the EVITA experimenters did not record the heater power or perform a VV cool down test, an estimate to this power and heat loss had to be obtained by adjusting the ambient heat loss coefficient in the model to match the wall temperature trends measured for a test during which the heat power was switched off. This approach assumes that the jet heat transfer inside the vessel is being correctly simulated by MELCOR correlations. The test used to estimate the ambient heat loss was Test 7.10. A copy of the input deck used for Test 7.10 appears in Appendix A. Thermal properties for these cryo-components extend down to cryogenic temperatures for this analysis [SAD05]. 


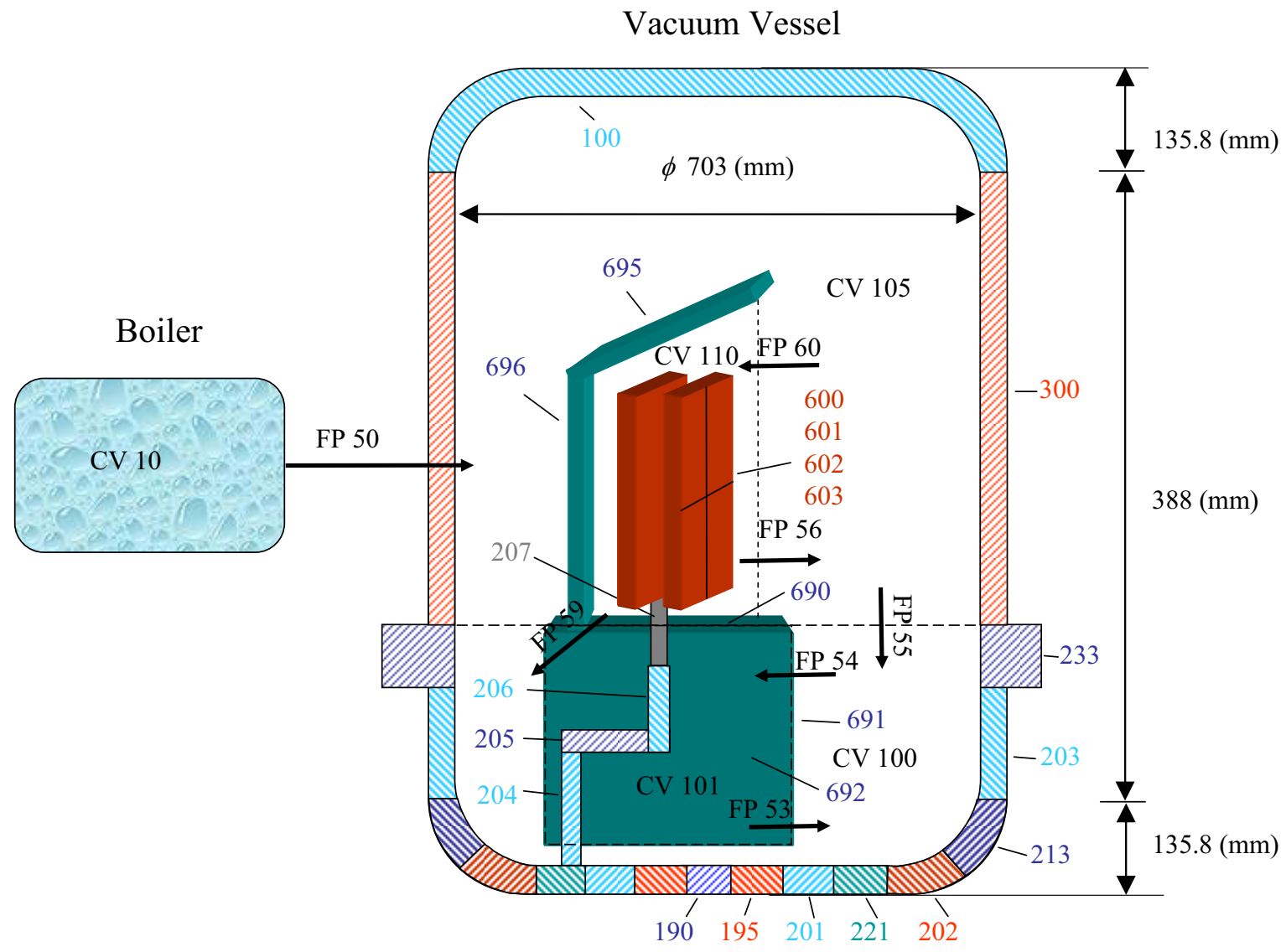

Figure 2. Schematic of MELCOR model of the EVITA VV and VV internals, showing control volumes $(\mathrm{CV})$, flow paths (FP), and heat structures (numbers). 


\section{Modified MELCOR 1.8.2 Ice Layer Formation Model}

The heat structure model in MELCOR 1.8.2 allows a film mass to develop on a heat structure whose surface remains at or below the dew point temperature (e.g. water saturation temperature associated with the steam partial pressure) given the predicted condensation rate at the surface [Gauntt, 2000]. The film is assumed to be at the same temperature as the heat structure surface. The energy associated with condensing steam and lowering the condensate temperature to that of the film mass on a given surface is conserved by passing this energy on to the heat structure beneath the film as a heat flux. The condensation rate for pure steam atmospheres is a modified Nusselt condensation correlation, which assumes that the limiting rate for condensation is the rate at which a flowing film, due to gravity, can conduct the condensation energy to the underlying surface. This rate is the film thermal conductivity divided by the film thickness as predicted by the Nusselt correlation.

When the atmosphere above the film contains a non-condensable gas, then the rate-limiting step for condensation is no longer the structure's ability to absorb the condensation heat flux but the rate at which steam can diffuse through a boundary layer of non-condensable gas that forms at the film surface. MELCOR employs the analogy between heat and mass transfer to predict this rate of diffusion or mass transfer through the boundary layer to the condensate film. This analogy is based on the fact that heat diffusion and mass diffusion through a surface boundary layer obey the same boundary layer conservation of mass, momentum, and energy equations. As a consequence, boundary layer mass transfer coefficients can be related to boundary layer heat transfer coefficients. The relationship used by MELCOR is the following Sherwood analogy:

$$
S h=N u S c^{1 / 3} / \operatorname{Pr}^{1 / 3}
$$

where

$$
\begin{array}{ll}
\mathrm{Nu} & =\text { Nusselt number (convective heat transfer) } \\
\mathrm{Sc} & =\text { Schmidt number (diffusive mass transfer) } \\
\mathrm{Pr} & =\text { Prandtl Number (convective heat transfer) }
\end{array}
$$

Once the Sherwood number has been determined by MELCOR, based on its convective heat transfer package, the mass transfer coefficient, $h_{m}(\mathrm{~m} / \mathrm{s})$, is calculated from this Sherwood number as follows:

$$
h_{m}=\operatorname{Sh} \frac{D}{L_{c}}
$$

where

$$
\begin{array}{ll}
D & =\text { the binary gaseous diffusion coefficient, } \mathrm{m}^{2} / \mathrm{s} \\
L_{c} & =\text { the heat structure characteristic dimension, } \mathrm{m}
\end{array}
$$

With this mass transport coefficient, the mass condensation rate, $\Gamma_{c}\left(\mathrm{~kg} / \mathrm{m}^{2}-\mathrm{s}\right)$, is evaluated from the following analytical solution for binary gaseous diffusion through the boundary:

$$
\Gamma_{c}=h_{m} \rho_{v} \ln \left(\frac{P-P_{s r f}}{P-P_{s t m}}\right)
$$


where

$$
\begin{array}{ll}
\rho_{v} & =\text { steam density, } \mathrm{kg} / \mathrm{m}^{3} \\
P & =\text { total pressure (e.g., steam plus non-condensable gas), } \mathrm{Pa} \\
P_{s r f} & =\text { steam saturation pressure at the surface temperature, } \mathrm{Pa} \\
P_{s t m} & =\text { steam partial pressure in the atmosphere above the surface, } \mathrm{Pa}
\end{array}
$$

The modification to the film model for this version of MELCOR 1.8.2 is in the growth of the film or ice layer, $\delta_{\text {ice }}(\mathrm{m})$, once the heat structure surface temperature falls below the triple point temperature, $T_{T P}$ $(\mathrm{K})$, of water [Merrill, 2000]. The growth of an ice layer with a surface temperature of $T_{T P}$ is calculated from the following conservation of energy equation:

$$
\rho_{i c e} h_{f u s} \frac{\partial \delta_{i c e}}{\partial t}=q_{c d}-q_{c v}-\Gamma_{c}\left(h_{v}-h_{l}\right)
$$

where

$$
\begin{array}{ll}
\rho_{\text {ice }} & =\text { ice density, } \mathrm{kg} / \mathrm{m}^{3} \\
\mathrm{~h}_{\text {fus }} & =\text { heat of fusion for forming ice, } \mathrm{J} / \mathrm{kg} \\
\mathrm{q}_{\mathrm{cd}} & =\text { ice layer conductive heat flux }=k_{\text {ice }}\left(T_{T P}-T_{s r f}\right) / \delta_{\text {ice }}, \mathrm{W} / \mathrm{m}^{2} \\
\mathrm{q}_{\mathrm{cv}} & =\text { vapor convective heat flux }=h_{c o n v}\left(T_{s t m^{-}} T_{T P}\right), \mathrm{W} / \mathrm{m}^{2} \\
\mathrm{~h}_{\mathrm{v}} & =\text { steam enthalpy, and } \mathrm{h}_{1} \text { is the liquid water enthalpy at the } T_{T P} \\
k_{\text {ice }} & =\text { ice thermal conductivity, } \mathrm{W} / \mathrm{m}-\mathrm{K} \\
T_{s t m} & =\text { steam temperature, }(\mathrm{K}) \\
T_{\text {srf }} & =\text { ice surface temperature, }(\mathrm{K}) \\
h_{\text {conv }} & =\text { heat transfer coefficient between the steam and the ice surface } \mathrm{W} / \mathrm{m}^{2}
\end{array}
$$

The maximum growth rate for this ice layer is evaluated from the following conservation of mass equation:

$$
\left.\rho_{\text {ice }} \frac{\partial \delta_{\text {ice }}}{\partial t}\right|_{\max }=\Gamma_{c}
$$

If the predicted growth rate from Equation 4 is less than this maximum growth rate (Eq. 5), the excess condensation flux is assumed to be drainage or runoff from the ice layer surface. If the predicted growth rate from Equation 4 is greater than the maximum growth rate (Eq.5), the growth rate is set equal to the maximum growth rate. The purpose for including this discussion in this report is not only to familiarize the reader with some of the models being validated, but to illustrate that in order for this modified version of the MELCOR 1.8.2 code to accurately simulate EVITA experiments, not only does the modeler have to develop a reasonably accurate model of the EVITA VV that accounts for vessel wall heat conduction, as discussed in the previous section, but the code needs to accurately simulate the heat transfer between steam or water and cryogenic or superheated walls, and account for any influence that a non-condensable gas has on steam condensation on cooler structures. 


\section{EVITA Test Comparison to MELCOR Predictions}

Only the Series 7 tests were selected for this validation study, primarily because these tests proved to have some degree of reproducibility among the results, which was not present in previous test series. As can be seen from Table 1, Series 7 tests involved the injection of steam or water at $165^{\circ} \mathrm{C}$ into the EVITA $\mathrm{VV}$, where an attempt was made to maintain the VV wall temperature at the same value (e.g., isothermal tests). However, the ability to maintain a uniform VV temperature at $165^{\circ} \mathrm{C}$ was lacking for the EVITA facility. Typically, temperatures ranged from $\sim 125^{\circ} \mathrm{C}$ at the bottom head to $\sim 180{ }^{\circ} \mathrm{C}$ at the top head, with one location on the sidewall at $\sim 165^{\circ} \mathrm{C}$. In addition, even on the side wall there was a $\sim 30{ }^{\circ} \mathrm{C}$ poloidal temperature variation at the wall locations measured. Besides the isothermal steam or water tests, tests were conducted with the co injection of a non-condensable gas (nitrogen) and with heater power turned off once coolant injection started. These tests plus comparisons with predictions from the modified MELCOR 1.8.2 appear in the following subsections.

\subsection{EVITA Steam Injection Tests 7.3, 7.4, and 7.9}

Figures 3 through 6 contain EVITA data and MELCOR comparisons for EVITA Tests 7.3, 7.4 and 7.9. These EVITA Tests are grouped together for this study because the test conditions for these tests are very similar. For example, the initial temperature conditions are virtually identical for these tests and the injected steam flow rate varies by only $\pm 5 \%$. Aside from switching off heater power for Test 7.9 , these tests should reproduce nearly the same EVITA response up to the time at which steam inject stopped. Figure 4a shows how the EVITA VV pressure changed during these tests. The steam injection rate for Test $7.3,7.4$, and 7.9 is $2.04 \mathrm{~kg} / \mathrm{s}, 1.9 \mathrm{~kg} / \mathrm{s}$, and $2.1 \mathrm{~kg} / \mathrm{s}$, respectively; and the steam and EVITA VV temperatures were as similar as one can expect from EVITA operation. However, it is interesting to note in Figure 3a that the pressurization rate for Test 7.3 is lower than for Test 7.4, which is counter intuitive since the VV pressurization rate should be directly proportional to the magnitude of steam injection rate. The pressurization trend of Test 7.4 makes sense when compared to Test 7.9, because the steam injection and VV pressurization are less than that of Test 7.9 until about $300 \mathrm{~s}$, when the heater power applied in Test 7.4 results in higher pressures in this test compared to Test 7.9.

Figure $3 \mathrm{~b}$ compares the prediction from the modified version of MELCOR 1.8.2 to the measured pressure histories of Test 7.3, 7.4, and 7.9. The relative trends in the MELCOR predictions make sense as they track with the magnitude of the injected steam flow rate. It can be seen that initially, the pressurization rate is faster in the MELCOR prediction than for EVITA, and that the final pressures for Test 7.4 and 7.9 are lower than those measured for EVITA. The higher initial pressurization rate suggests that the initial condensation rate (on the cryoplate or elsewhere in the VV) is higher in EVITA than what MELCOR predicts. At about $200 \mathrm{~s}$ into the Test 7.9 simulation, MELCOR is predicting that the cryoplate ice mass has achieved a thickness that results in the ice surface temperature reaching the triple point temperature at the condensation heat flux predicted by MELCOR (note the discussion in Section 3). At this time, $0{ }^{\circ} \mathrm{C}$ water is dripping from the cryoplate ice layer surface onto the protective lid and bottom head of EVITA. In the MELCOR prediction, either the predicted heat transfer between this ice water and the VV internals is too low or the predicted water temperature is too low. It actuality could be both. Accurately predicting the random formation of water droplets on the cryoplate ice surface and tracking the flow of these droplets as they drip from the cryoplate and find their way to the bottom of the vessel is beyond the capability of existing thermal hydraulic computer codes. In addition, as mentioned in Section 3, the heat structure film temperature in MELCOR 1.8.2 (e.g., ice layer for this analysis) is assumed to be at the surface temperature of the heat structure. Therefore, for MELCOR 1.8.2 to correctly maintain overall conservation of energy, the temperature of water dripping from the cryoplate surface is assumed to be at the same temperature as the cryoplate surface (e.g., $-80^{\circ} \mathrm{C}$ ). The MELCOR code's ability to track condensate flow and to predict film surface temperature has been improved in MELCOR 1.8.5. However even with this problem, the 
agreement between EVITA data and MELCOR 1.8.2 code prediction is good up to the point of water dripping, and after that point, the resulting deviation is at most only $20 \%$ in final pressure.

Figure 4a presents measured VV temperatures during Tests 7.3, 7.4 and 7.9 for comparison. This figure contains data from thermocouples TCE 20 (top head), TCE 25 (sidewall), and TCE 18 (bottom head) reported for these tests (see Figure 7 for thermocouple placement). The effect on wall temperature of switching off the heaters can be seen in the data of TCE 20 and 25 after $\sim 200 \mathrm{~s}$. It appears from this data that the heaters for the top head and sidewall are able to make up the power loss from the EVITA VV wall to the injected steam, which steam should cool during injection due to expansion and heat transfer with the cryoplate. The response of TCE 18 illustrates the difficulty that modeling EVITA poses for any computer code. First, this thermocouple is attached to the bottom head at a location that is situated between and slightly below the elevation of the double walled nitrogen feeder pipes for the cryoplate. Because of TCE 18 's proximity to the feeder pipes, this thermocouple could be reporting the lowest temperature of the bottom head. However, this thermocouple was used because it was the only thermocouple on the bottom head for which data was reported that also had the possibility of contacting any water pool forming at the bottom of the EVITA vessel. Second, TCE 18 is situated in the path that water dripping from the cryoplate would take when flowing to the bottom of the vessel by gravity for these particular tests. In this position, TCE 18 could either see an intermittent stream of cold water (plate runoff) that results in thermocouple wetting and subsequent dryout or continued thermal quench due to contact with a water pool forming at the bottom head. Interestingly enough, runoff quenching appears to have happened for Tests 7.3 and 7.9 but not for test 7.4.

Figures $4 \mathrm{~b}, 5 \mathrm{a}$, and $5 \mathrm{~b}$ show comparisons of MELCOR predicted EVITA VV wall temperatures and measurements from corresponding thermocouples for Test 7.3, 7.4, and 7.9. MELCOR's ability to simulate these temperatures appears reasonable given the uncertainty in EVITA heat losses to the ambient and the sparsity of thermocouple data. MELCOR heat structure 190 is at the very bottom of the vessel and is physically several $\mathrm{cm}$ from the actual location of TCE 18 . The quenching of this heat structure in MELCOR by runoff will continue until the condensate pool dries by heater power or axial heat conduction. This is not always the case for TCE 18.

Figures $6 \mathrm{a}$ and $6 \mathrm{~b}$ contain comparisons of the reported final values of cryoplate ice layer and bottom head condensate pool masses with the transient values predicted by the modified version MELCOR 1.8.2. The MELCOR predicted ice layer mass is larger than what was measured for Tests 7.4 and 7.7, but agrees with that reported for Test 7.3. In contrast, the predicted condensate mass is less for Tests 7.4 and 7.9 than what was measured by the same amount as the excess predicted for ice layer mass. When these two factors are taken together for Tests 7.4 and 7.9, it suggests that the cryoplate ice porosity for these tests was probably much higher, $\sim 40 \%$ to $60 \%$, than in the modified MELCOR 1.8.2 prediction, which assumes an ice porosity of zero. In addition, the porosity of the ice layers formed in Test 7.4 and 7.9 was much higher than the porosity of ice layer formed in Test 7.3, which indicates that the ice layer porosity should be nearly zero based on how well this test matched MELCOR predictions, which assumes an ice porosity of zero. 


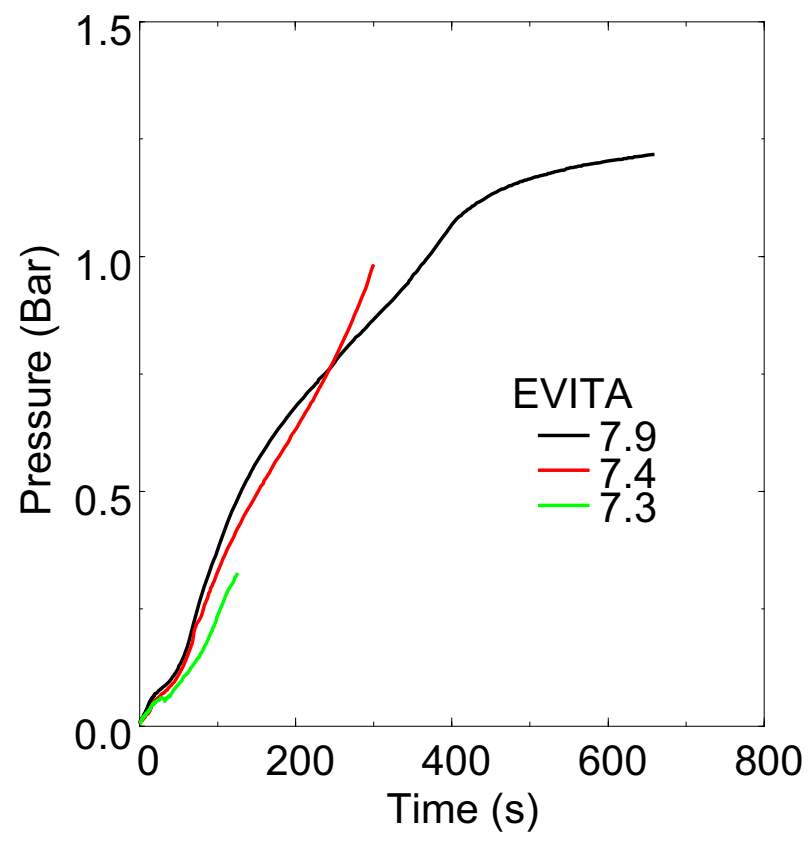

(a)

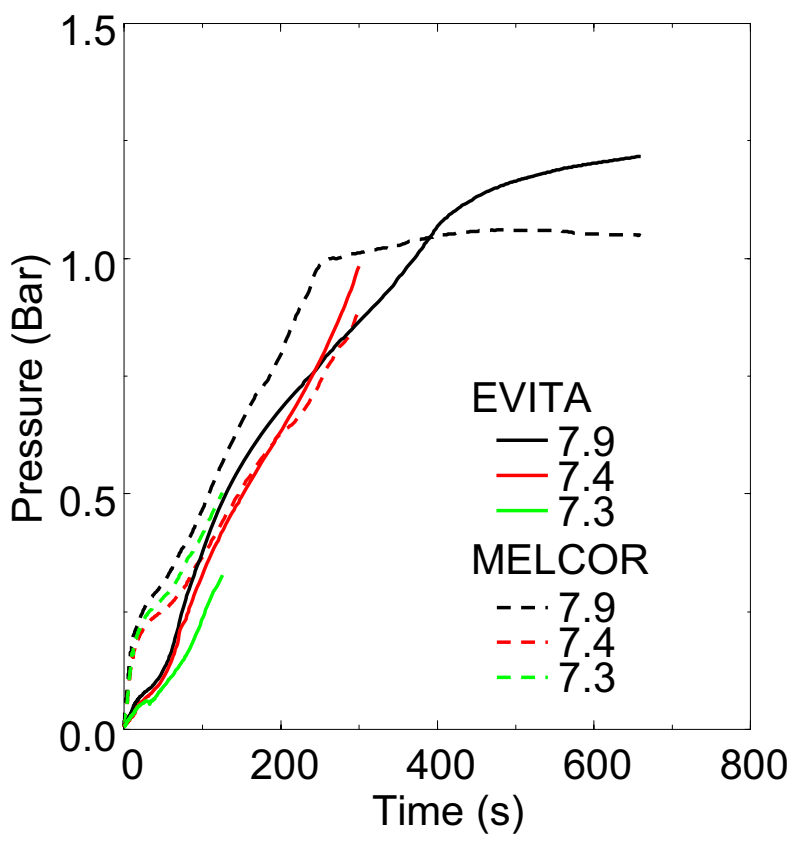

(b)

Figure 3. EVITA VV pressure, (a) Tests 7.3, 7.4, and 7.9, and (b) Comparison with MELCOR predictions.

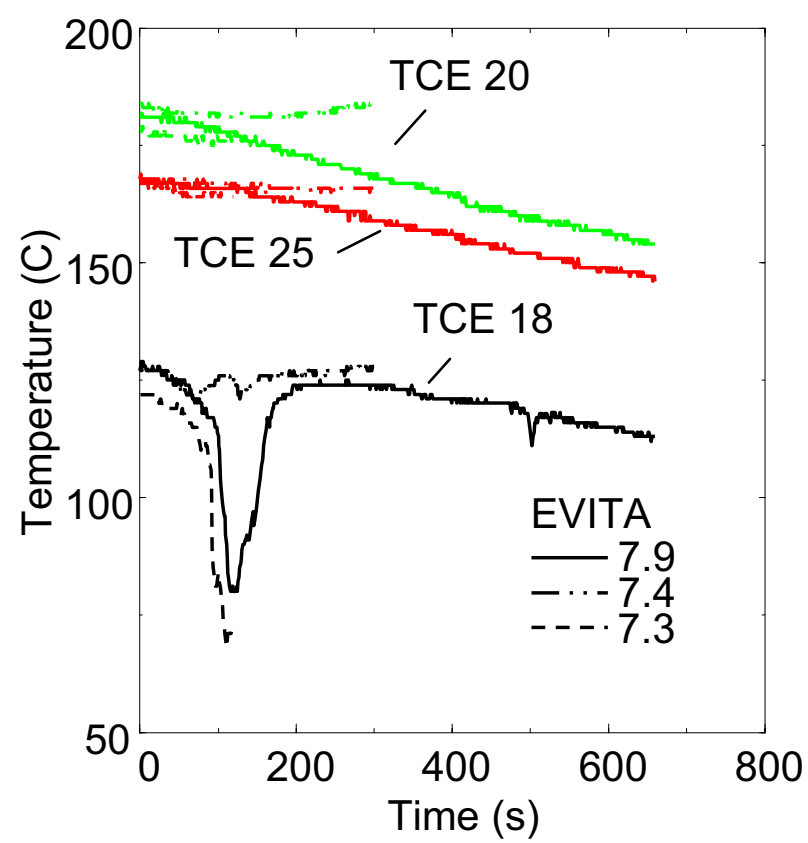

(a)

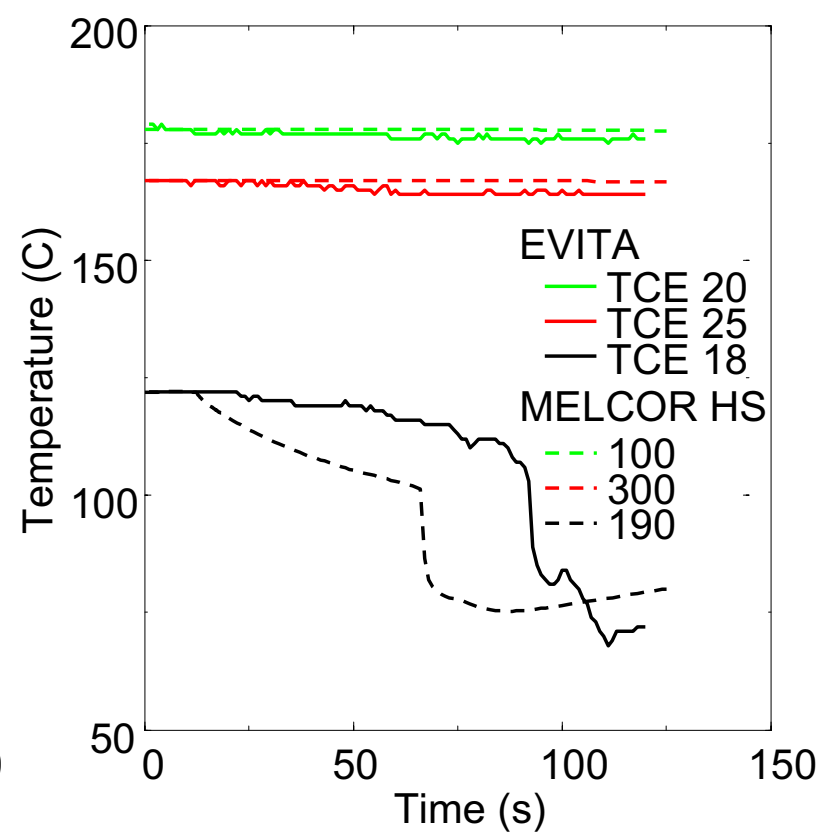

(b)

Figure 4. EVITA VV wall temperatures, (a) Tests 7.3, 7.4, and 7.9, and (b) Comparison with MELCOR predictions for Test 7.3. 


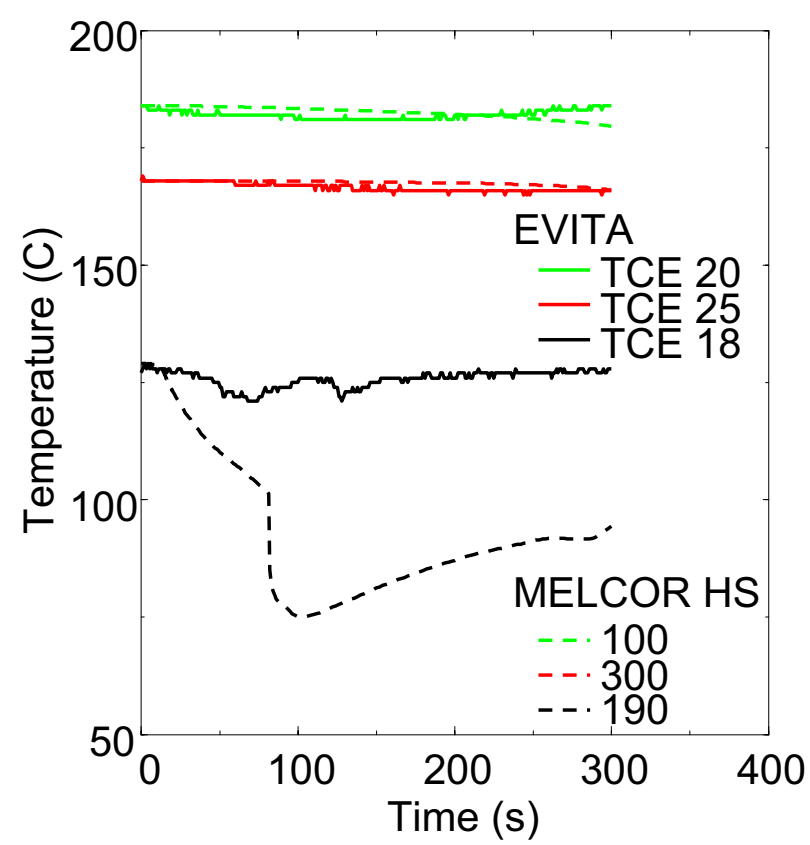

(a)

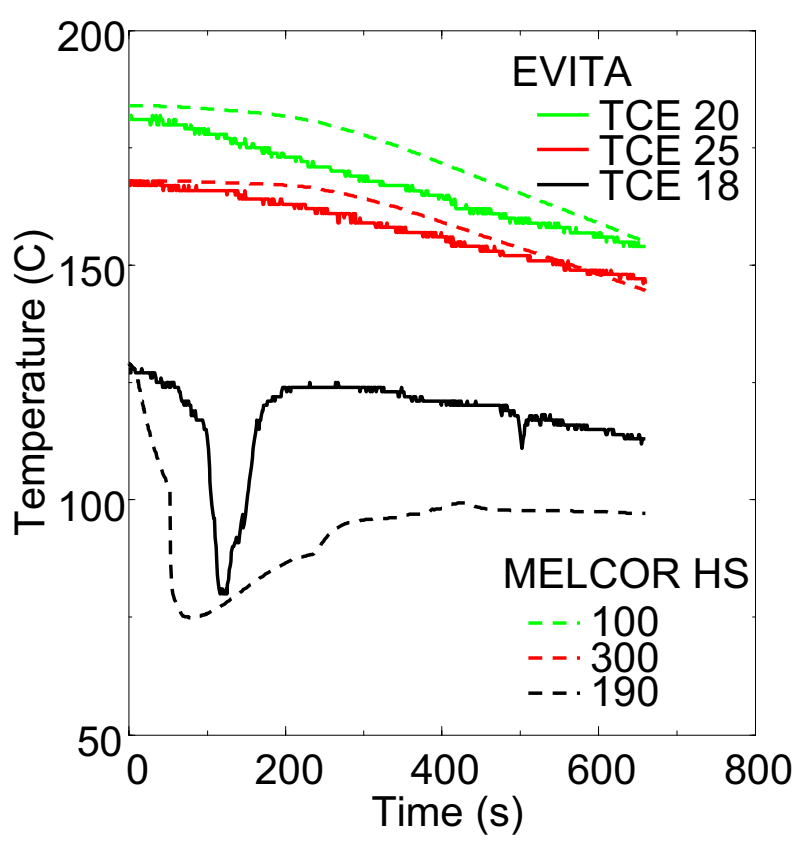

(b)

Figure 5. EVITA VV wall temperatures, (a) Comparison with MELCOR predictions for Test 7.4, and (b) Comparison with MELCOR predictions for Test 7.9.

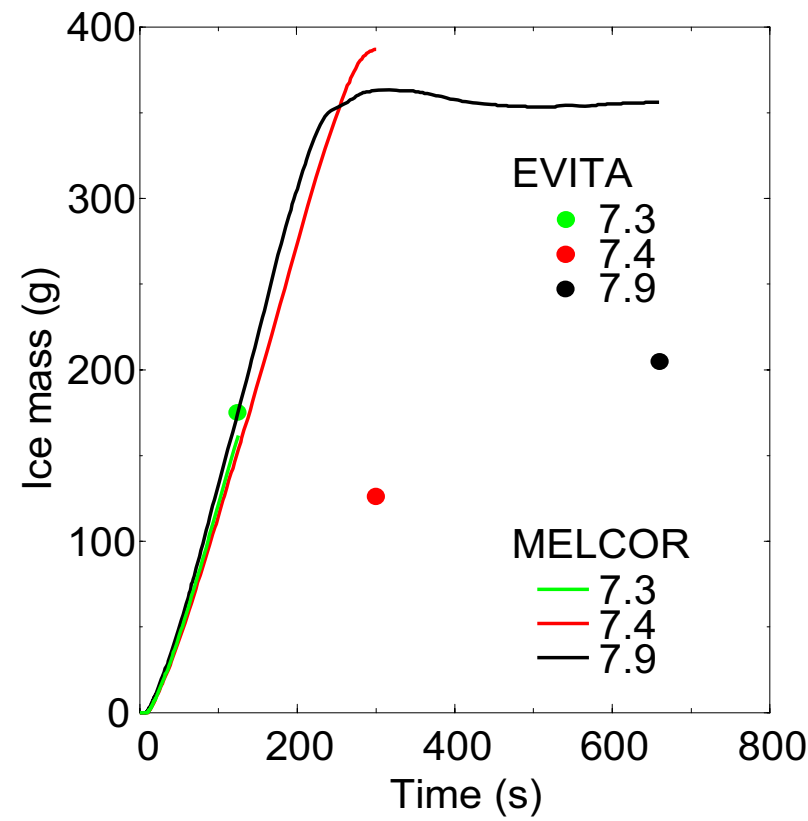

(a)

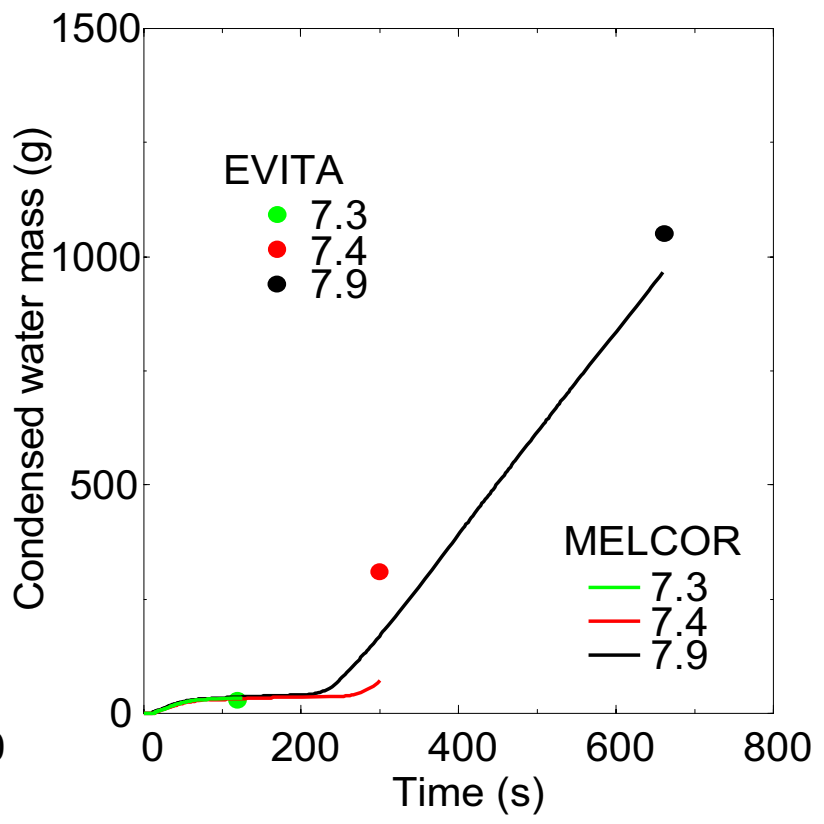

(b)

Figure 6. Ice and water masses for EVITA Tests 7.3, 7.4, and 7.9, (a) Cryoplate ice mass comparison with MELCOR predictions, and (b) VV condensate mass comparison with MELCOR predictions. 


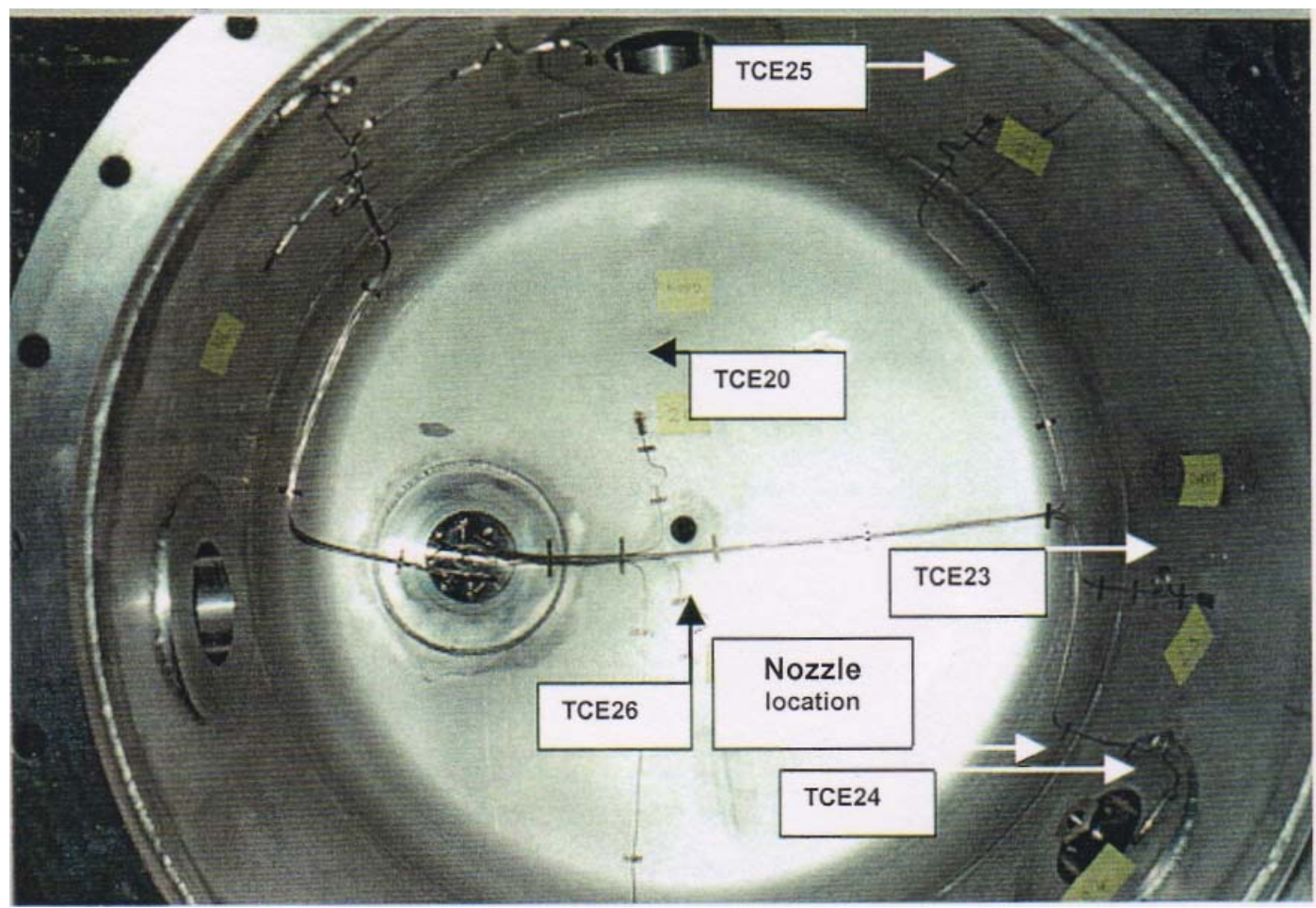

(a)

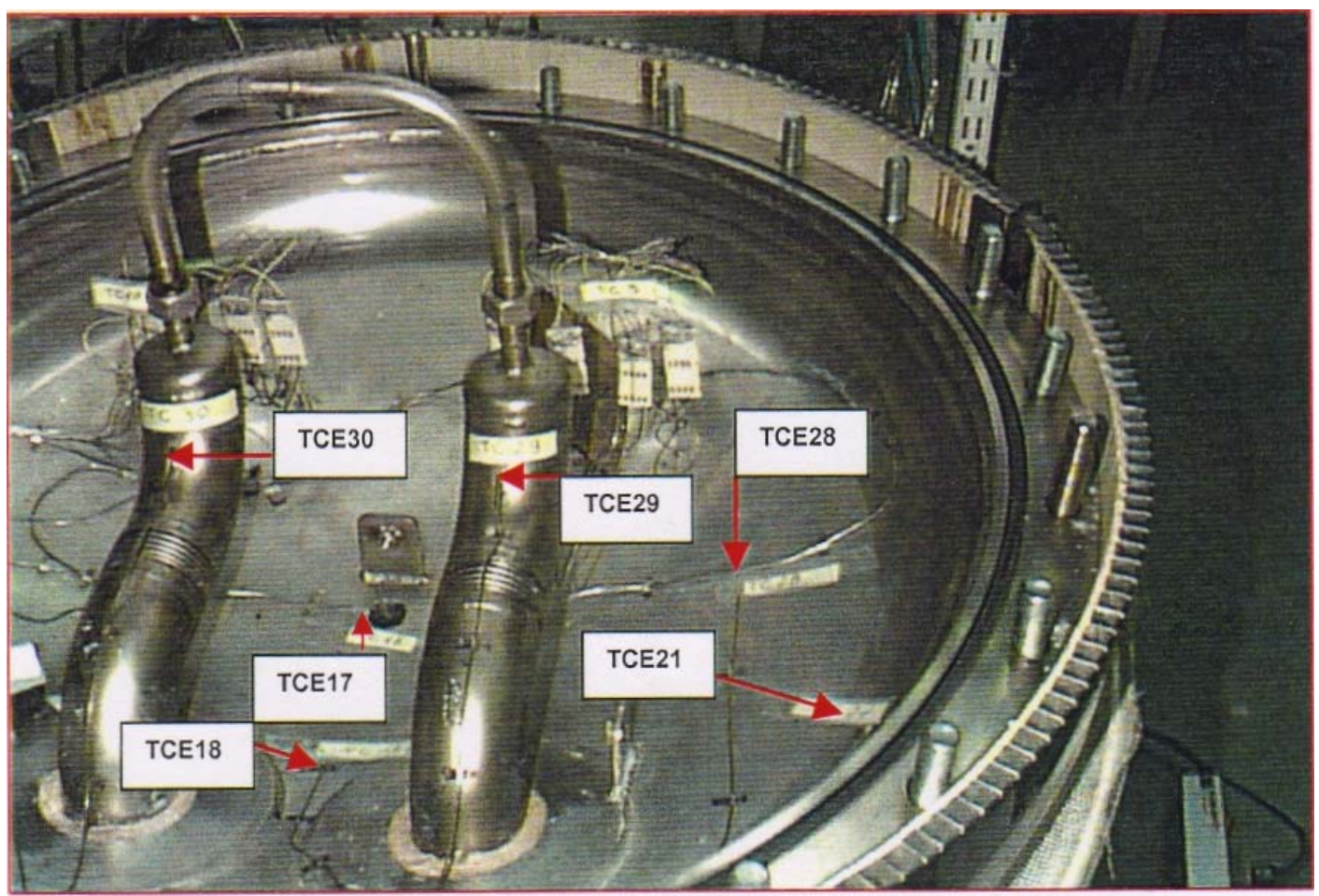

(b)

Figure 7. EVITA VV wall thermocouple placement, (a) top of vessel, and (b) bottom of vessel. 


\subsection{EVITA Water Injection Tests 7.7, 7.8, and 7.10}

Figures 8 through 11 contain EVITA data and MELCOR comparisons for EVITA Tests 7.7, 7.8 and 7.10. These EVITA Water Injection Tests have also been grouped together for this study because the test conditions for these tests are also very similar. For example, the initial temperature conditions are virtually identical for these tests and the injected water flow rate for Test 7.7 and 7.10 are nearly identical with Test 7.8 being only 13\% higher. Aside from switching of heater power for Test 7.10, these tests should produce nearly the same EVITA response up to the time at which water injection stops. The water injection rates for Test 7.7, 7.8, and 7.10 are $2.4 \mathrm{~kg} / \mathrm{s}, 2.72 \mathrm{~kg} / \mathrm{s}$, and $2.45 \mathrm{~kg} / \mathrm{s}$, respectively; and the injected water and EVITA VV temperatures are as similar as one can expect based on EVITA operation history.

Figure $8 \mathrm{a}$ shows that the VV pressurization rate for these tests is very similar up until $\sim 200 \mathrm{~s}$. Around $200 \mathrm{~s}$, the steam production from injected water flashing or water evaporation from quenching hot $\left(165^{\circ} \mathrm{C}\right.$ surfaces inside of EVITA appears to reach an equilibrium with the steam being lost to cryoplate ice formation and condensate runoff, which runoff drips back into the water pool forming at the bottom of the EVITA VV.

Figure $8 \mathrm{~b}$ compares the prediction from the modified version of MELCOR 1.8.2 to the measured pressure histories of Test 7.7, 7.8, and 7.10. The relative trends in the MELCOR predictions make sense, as the pressurization rate is nearly the same for the first $100 \mathrm{~s}$. This pressurization rate is not only due to water flashing as it enters the VV, but water contacting hot surfaces within the EVITA VV. Based on prior experience with the Japanese Ingress of Coolant Experiment (ICE) [Takase, 2001], where $150^{\circ} \mathrm{C}$ water was injected into a large evacuated vessel with walls heated to as high as $230^{\circ} \mathrm{C}$, the injected water jet becomes finely atomized at low vessel pressure and impinges on the vessel walls by either direct jet flow impingement or bulk flow swirling near walls. The impinged droplets undergo rapid boiling on impact with these surfaces, which not only produces enhanced water flashing but improves the wall heat transfer over that for steam flow alone. There is a noted downturn in the predicted VV pressure for Test 7.10 after $300 \mathrm{~s}$, due in part to the cryoplate ice surface runoff temperature being low in the MELCOR prediction as discussed in the previous sub-section. However, the agreement with the test pressures is good, varying by only $12 \%$ over the times these tests were conducted.

Figure 9a presents measured VV temperatures during Tests 7.7, 7.8 and 7.10 for comparison. This figure contains data from thermocouples TCE 20 (top head), TCE 25 (sidewall), and TCE 18 (bottom head) reported for these tests (see Figure 7 for thermocouple placement). As was the case for the steam injection tests, the effect on wall temperature of switching off the heaters can be seen in the data of TCE 20 and 25 after $\sim 200 \mathrm{~s}$. As mentioned in the previous sub-section and as can be clearly seen in this figure, TCE 18 experiences either an intermittent stream of cold water (cryoplate runoff) that results in thermocouple wetting and subsequent dryout or a continued thermal quench due to contact with a water pool that forms at the VV bottom head.

Figures $9 \mathrm{~b}, 10 \mathrm{a}$, and $10 \mathrm{~b}$ present comparisons of MELCOR predicted wall temperatures and measurements from EVITA thermocouples corresponding to these heat structure locations for Test 7.7, 7.8, and 7.10. MELCOR's ability to simulation these temperatures appears excellent given the uncertainty in EVITA heat losses to the ambient and the sparsity of EVITA VV thermocouple data. As mentioned in Section 3, to obtain this match an estimate of the VV heat loss to ambient had to be obtained. This estimate was obtained by adjusting the ambient heat loss coefficient for Test 7.10 (for which the experimenters did switch off the heaters) until a reasonable wall temperature match was obtained, assuming that the jet heat transfer inside the vessel is being correctly simulated by MELCOR correlations (this was the heat loss used for the simulations in this report). However, because MELCOR does not have an atomized jet heat transfer correlation the approach taken to simulate this heat transfer, and to match the thermocouple data of Test 
7.10, was to use the following a two-phase heat transfer coefficient, $h_{T P}\left(\mathrm{~W} / \mathrm{m}^{2}-\mathrm{K}\right)$, based on the MELCOR predicted steam mass fraction $(x)$, or quality, in the VV atmosphere:

$$
h_{T P}=x h_{\text {stm }}+(1-x) h_{d r o p}
$$

where $h_{s t m}\left(\mathrm{~W} / \mathrm{m}^{2}-\mathrm{K}\right)$ is the steam heat transfer coefficient predicted with the standard MELCOR heat transfer package, and $h_{\text {drop }}\left(\mathrm{W} / \mathrm{m}^{2}-\mathrm{K}\right)$ is the droplet impingement heat transfer coefficient. The droplet coefficient needed to match EVITA data for Test 7.10 was $1000 \mathrm{~W} / \mathrm{m}^{2}-\mathrm{K}$. The resulting enhancement in heat transfer $\left(\mathrm{h}_{\mathrm{TP}} / \mathrm{h}_{\mathrm{s}}\right)$ grew to $\sim 6$ by the end of the simulation, which according to the data in Figure 8 of [Hishida, 1980] is within reason for the predicted quality of $\sim 98 \%$.

Figures $11 \mathrm{a}$ and $11 \mathrm{~b}$ contain comparisons of the reported final values of cryoplate ice layer and bottom head condensate masses with the transient values predicted by the modified version of MELCOR 1.8.2. As was the case for the steam injection tests, the predicted ice layer mass is larger than what was measured for Tests 7.8 and 7.10, but not for 7.7. In contrast, the predicted condensate mass is less in Tests 7.7 and 7.10 than measured, by the same amount as the excess predicted for ice layer mass. When these two factors are taken together for Tests 7.8 and 7.10, it suggests that the ice porosity in these tests was probably much higher, $\sim 20 \%$ to $30 \%$, for these tests than in the modified MELCOR 1.8.2 prediction, which assumes an ice porosity of zero. These porosities are lower than those inferred from the steam injection tests and may suggest that the mist droplets play a role in ice layer formation during water injection tests in EVITA. Based on the results of Test 7.7, the ice layer formed more rapidly on the EVITA cryoplate at low pressures than predicted by MELCOR, and thereby produced the lower initial pressures measured in EVITA than predicted by MELCOR. 


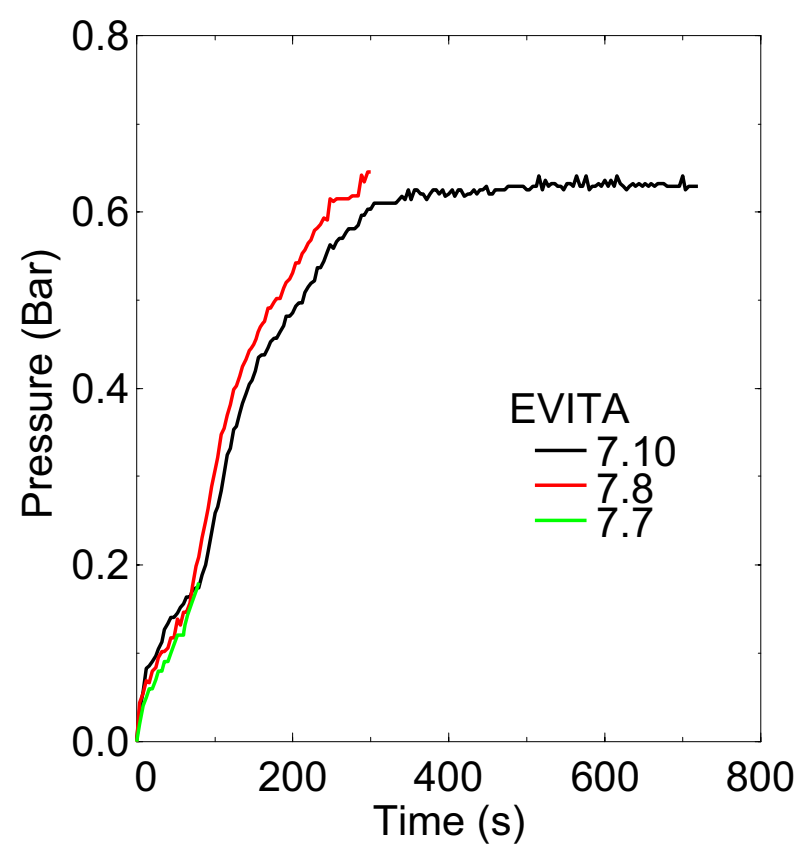

(a)

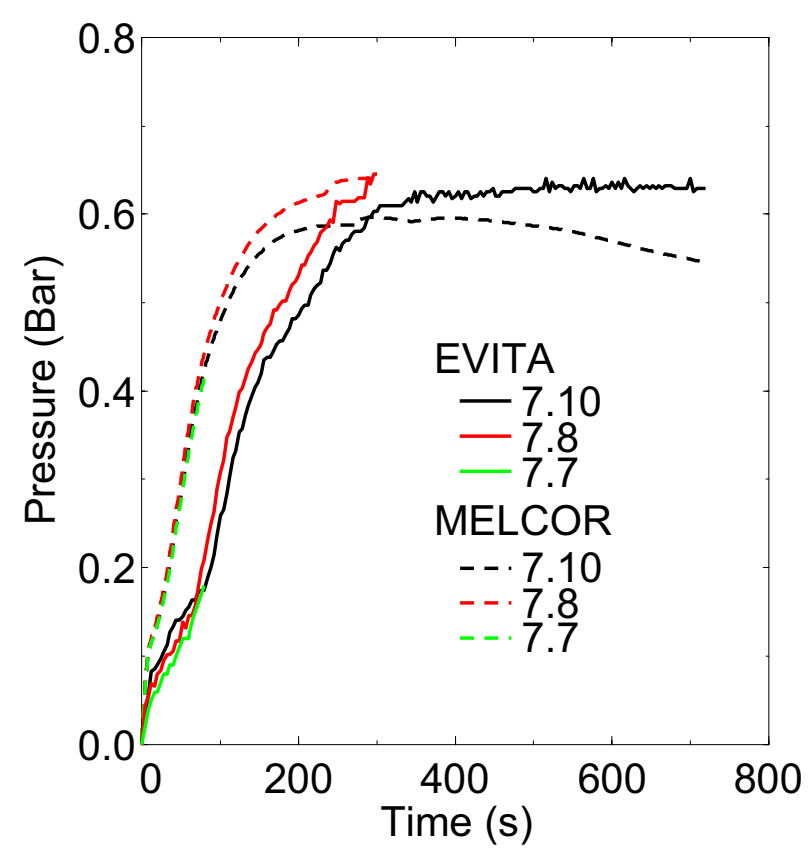

(b)

Figure 8. EVITA VV pressure, (a) Tests 7.3, 7.4, and 7.9, and (b) Comparison with MELCOR predictions.

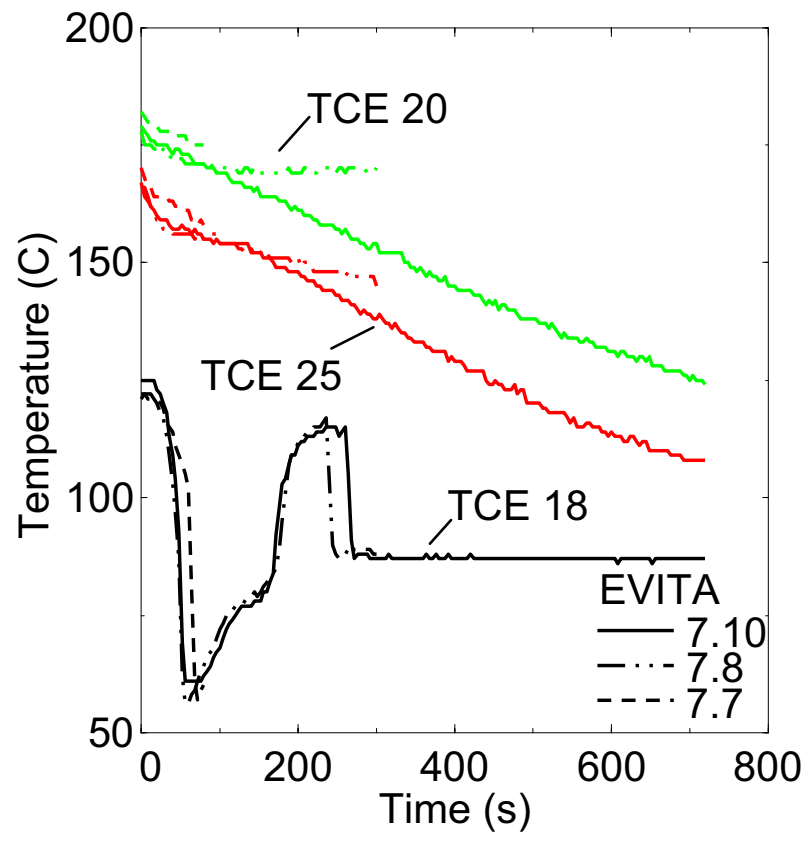

(a)

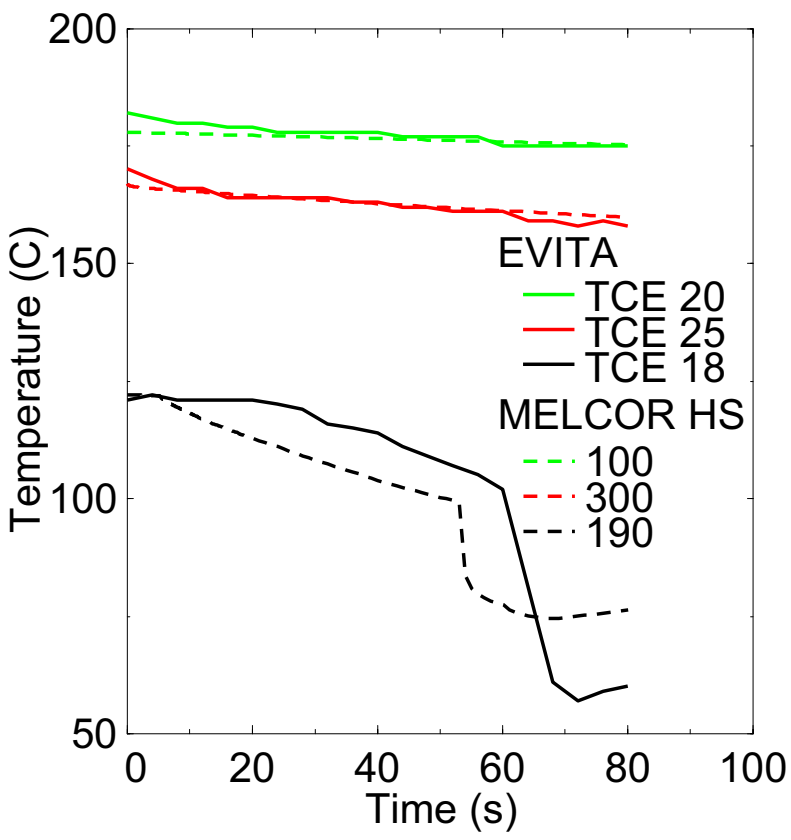

(b)

Figure 9. EVITA VV wall temperatures, (a) Tests 7.7, 7.8, and 7.10, and (b) Comparison with MELCOR predictions for Test 7.7. 


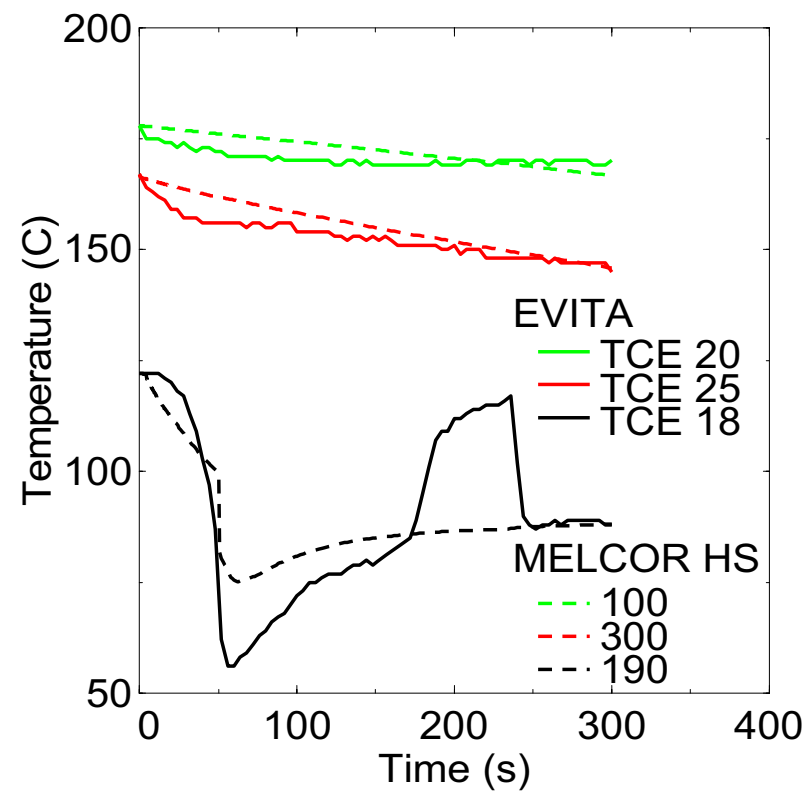

(a)

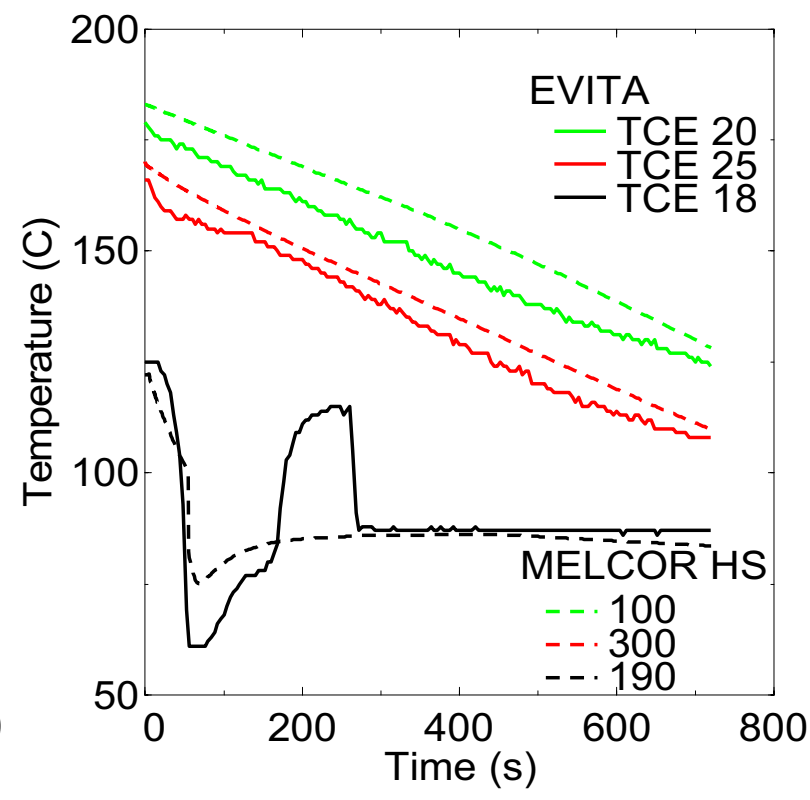

(b)

Figure 10. EVITA VV wall temperatures, (a) Comparison with MELCOR predictions for Test 7.8, and (b) Comparison with MELCOR predictions for Test 7.10.

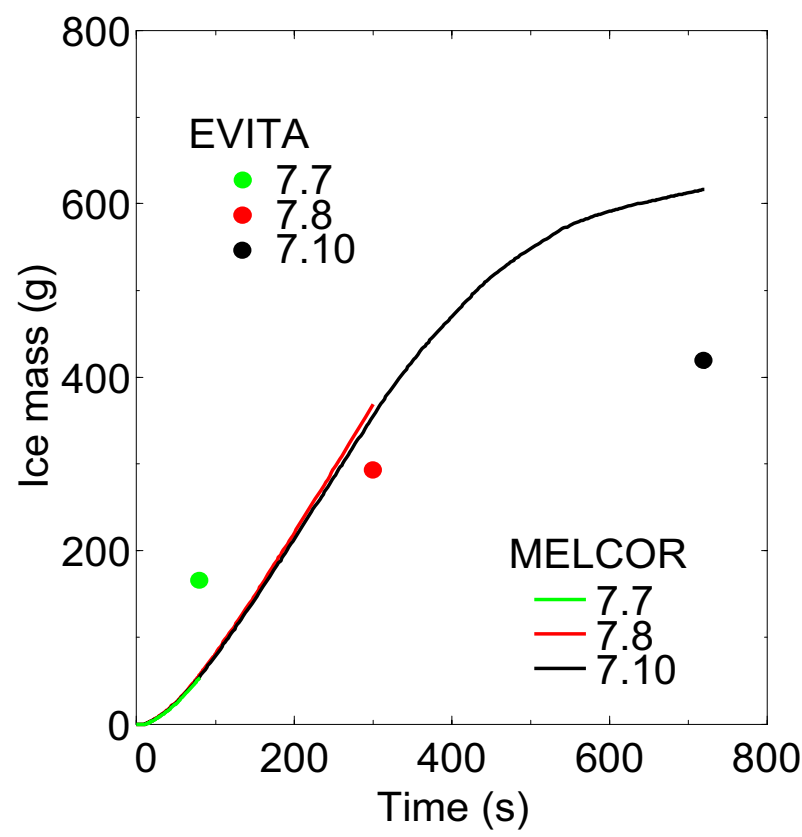

(a)

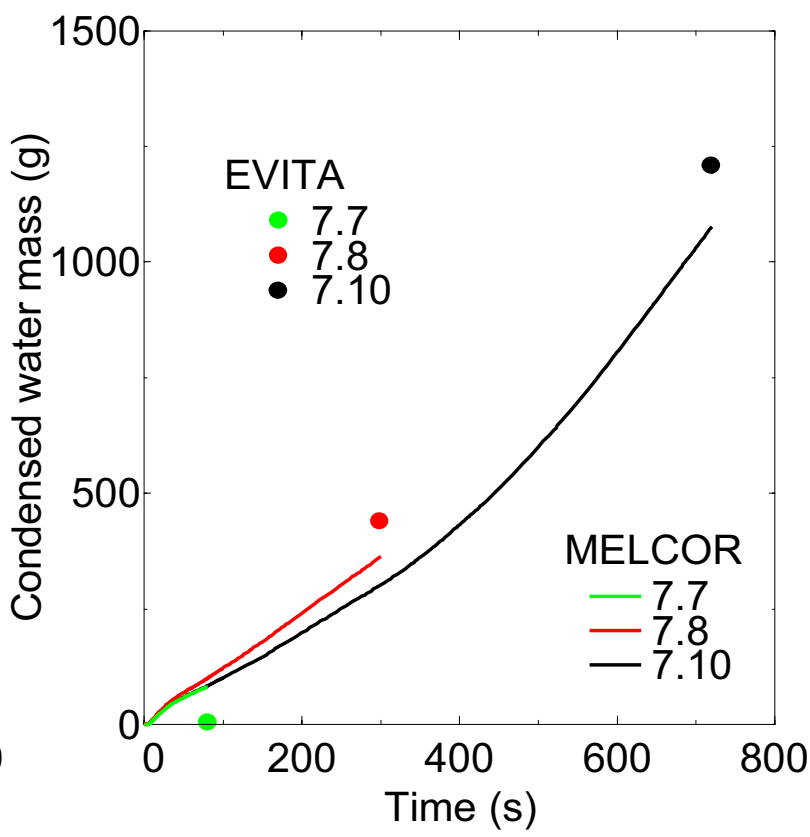

(b)

Figure 11. Ice and water masses for EVITA Tests 7.7, 7.8, and 7.10, (a) Cryoplate ice mass comparison with MELCOR predictions, and (b) VV condensate mass comparison with MELCOR predictions. 


\subsection{EVITA Steam and Nitrogen Co-injection Tests 7.1 and 7.2}

EVITA Tests 7.1 and 7.2 are steam and nitrogen co-injection tests. The objective of these tests is to study the impact of a non-condensable gas on cryoplate ice formation and VV pressurization during steam injection tests in EVITA. In theory, the impact should yield higher VV pressure as a result of two factors: 1) an indirect impact by reducing the cryoplate steam condensation rate (note Section 4) as a consequence of a non-condensable gas layer forming adjacent to the cryoplate, and 2) a direct impact by increasing VV pressure as a consequence of the additional partial pressure produced by the non-condensable gas in the VV atmosphere. If we were to assess the impact by examining the reported data of Table 1, there appears to be an inconsistency in the impact based on reported final pressures. For example, Tests 7.2 and 7.3 have the same steam injection time $(120 \mathrm{~s})$ and the same steam injection rate to within $7 \%$. The reported final pressure for the co-injection test (Test 7.2) is $\sim 3.5$ times higher than the steam only test (Test 7.3). If the partial pressure of the nitrogen ( $\sim 0.24$ Bar based on the ideal gas law $)$ is subtracted from the reported final pressure of Test 7.2, then the steam partial pressure at 120s for Test 7.2 is 2.7 times higher than for Test 7.3. In contrast, the recorded pressure for Test 7.4 (steam injection test) at $200 \mathrm{~s}$ is 0.7 Bar, while that for the Test 7.1 (co-injection test) is 1.25 Bar. If the nitrogen partial pressure is subtracted from Test 7.1 , the resulting steam partial pressure is $\sim 1$ Bar, which is only $\sim 1.4$ times higher than the pressure reported in Test 7.4, or one-half the impact seen between Tests 7.1 and 7.3. Most of the inconsistency can be attributed to the higher condensation rate inferred for the ice layer mass data of Test 7.3. In fact, the ice mass for Tests 7.1, 7.2 and 7.4 are within $15 \mathrm{~g}$ and at least $49 \mathrm{~g}$ less than the ice mass for Test 7.3. The reason for this inconsistency in EVITA tests is still not known.

Figures 12 through 13 contain EVITA data and pedigreed version of MELCOR 1.8.2 predictions for EVITA Tests 7.1 and 7.2. These tests have virtually identical initial conditions. The steam injection rate varies by only $\sim 10 \%$, at $2.1 \mathrm{~g} / \mathrm{s}$ for $200 \mathrm{~s}$ during Test 7.1 and $1.9 \mathrm{~g} / \mathrm{s}$ for $120 \mathrm{~s}$ during Test 7.2 . The nitrogen injection rate was $1.54 \mathrm{~g} / \mathrm{s}$ for $40 \mathrm{~s}$ for both tests. Figure 12a presents the measured EVITA VV pressure during these tests. As expected, the pressurization histories for these two tests are very similar. Figure $12 \mathrm{~b}$ contains a comparison between the MELCOR predicted pressures for these tests and the reported pressures for these tests. As can be seen, this modified version of MELCOR 1.8.2 over predicts the pressure in Test 7.1 at $200 \mathrm{~s}$ by a factor of $\sim 2$. The reason for this over prediction will be examined later in this section.

Figure 13a presents measured VV temperatures during Tests 7.1 and 7.2 for comparison. This figure contains data from thermocouples TCE 20 (top head), TCE 25 (sidewall), and TCE 18 (bottom head). As can be seen, the VV wall temperature histories are very similar for these tests and vary over the course of the test by only a few degrees. It is interesting to note that TCE 18 did not experience any significant thermal quenching during these tests, as compared to Tests 7.3 and 7.9 (note Figure 4a). However, the result is close to that obtained for Test 7.4, and may indicate an altered drip or runoff pattern for these tests. Figure 13b shows the agreement between MELCOR predicted temperatures and EVITA data for these thermocouples is excellent.

Figures 14a and 14b compare the reported final values of cryoplate ice layer and bottom head condensate pool masses with the transient values predicted by the modified version MELCOR 1.8.2. The predicted ice layer mass is larger than that measured for Tests 7.1 and less than that measured for Test 7.2. The predicted condensate mass for both tests is nearly zero, with any runoff in the prediction being immediately vaporized on contact with internal VV structures. However, both EVITA tests measured condensate at the bottom of the vessel, with $33 \mathrm{~g}$ and $180 \mathrm{~g}$ for Tests 7.2 and 7.1, respectively.

When the predicted ice layer and condensate masses are taken together with the predicted over pressure for these tests, they suggest that the modified MELCOR 1.8.2 predicted cryoplate condensation 
rates for these tests that were too low. To investigate this possibility, user sensitivity coefficient C4201(1) was adjusted by trial and error to achieve a reasonable match between MELCOR predictions and measured VV pressures. This sensitivity coefficient is a multiplier on the Sherwood correlation (note Equation 1), which will directly increase the predicted mass transport coefficient of the MELCOR condensation model and can be changed by user input. At a value of 4 for C2401(1), the pressure match shown in Figure 15a was achieved for Test 7.1 (note curve labeled MELCOR 7.1 EC for enhanced condensation). It is interesting to note that the increase in condensation mass flux predicted for this EC case was a factor of $\sim 2$ larger than the case without condensation enhancement, and that the resulting cryoplate condensation mass flux was nearly the same as that predicted for a steam only injection test, such as EVITA test 7.4. This suggests that the injected non-condensable gas had very little impact on the actual cryoplate condensation rate in EVITA.

Figure $15 \mathrm{~b}$ shows that by adjusting this sensitivity coefficient, the predicted VV wall temperature did not change significantly, except for the heat structure representing the lowest part of the EVITA lower head, which experience quenching from cryoplate runoff. Again, TCE 18 did not quench during these tests even though a significant condensate mass was measured for Test 7.1, which is likely due to the fact that TCE 18 is not located at the lowest point in the VV. Figures 16a and 16b contain predicated cryoplate ice and VV condensate masses for this EC case.

Figure 15 illustrate that a pressure match could be obtained by increasing the predicted cryoplate condensation rate. However, Figure 16 shows that the predicted condensation rate was not high enough to produce any significant ice layer melting or condensate pool formation by the ice surface runoff. As suggested in Section 5.1 of this report, the EVITA cryoplate ice layer has an inferred porosity of $\sim 40 \%$ for steam only tests. To investigate the impact ice porosity has on the modified MELCOR 1.8.2 code's predictions, an experimental version (EV) of the pedigreed MELCOR 1.8.2 code was developed that has an ice layer porosity of $40 \%$. Figures 17 and 18 contain the resulting prediction from this experimental version (curve labeled MELCOR 7.1 EC EV). As can be seen, the agreement is excellent.

While it can be argued that the jet like flow inside the EVITA VV does not allow a stable or effective non-condensable boundary layer to develop adjacent to the EVITA cryoplate and that the ice layers that form on cryogenic surfaces typically produce internal voids [Na, 2004], it may be too preliminary to suggest that this is what has happened in these EVITA tests. Based on video recordings of the ice layer during steam only tests, it appears that the cryoplate ice layer is opaque (note Figure 1), confirming the possibility of a porous ice layer. However, the actual 3D velocity distribution in EVITA is unknown at this time so it is not possible to confirm an unstable non-condensable boundary adjacent to the EVITA cryoplate. 


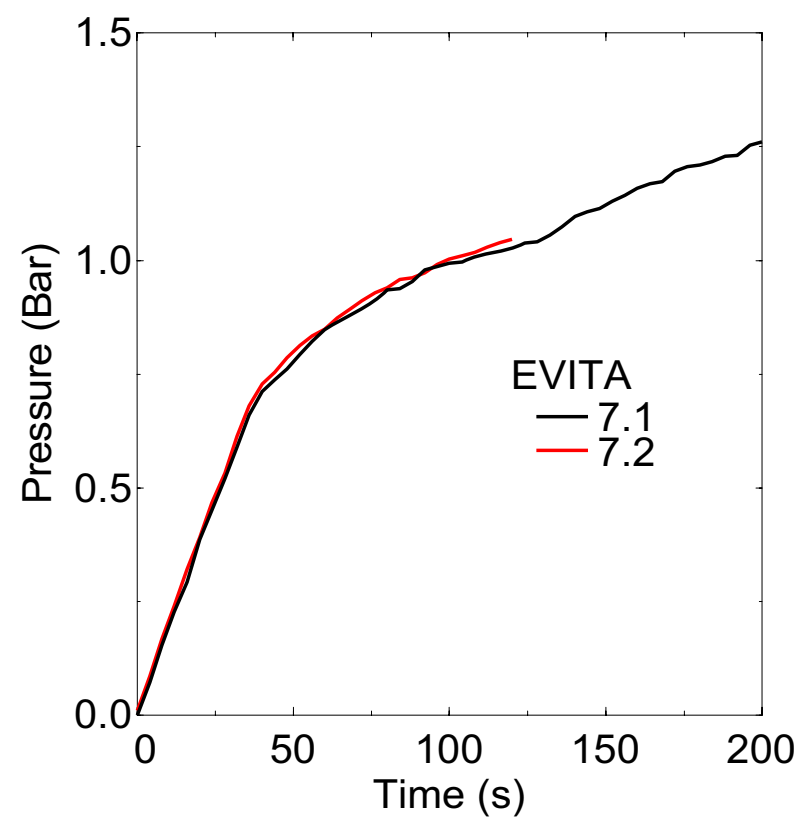

(a)

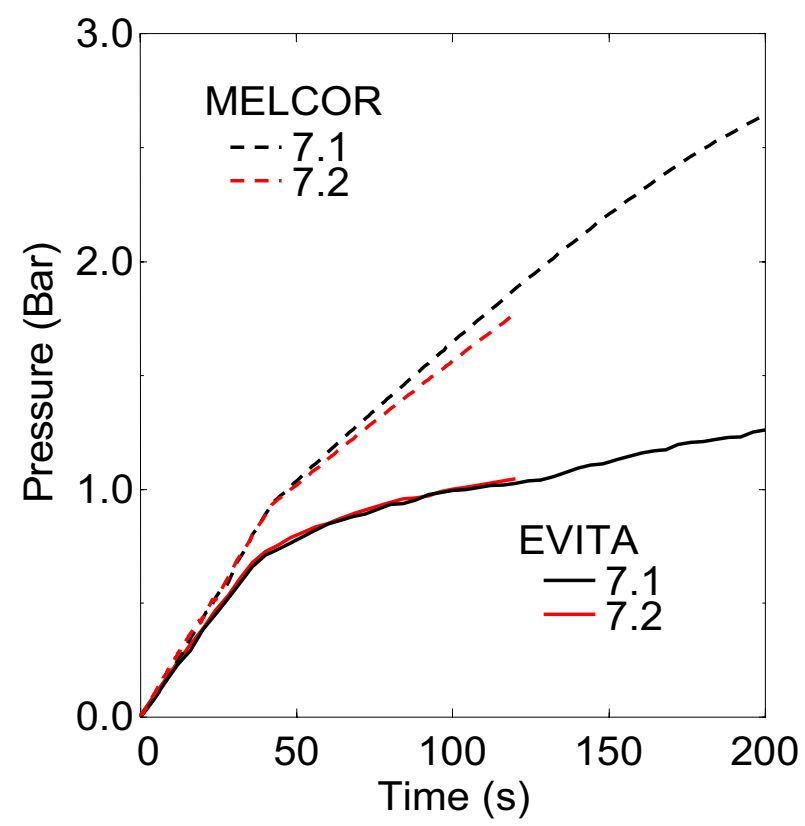

(b)

Figure 12. EVITA VV pressure, (a) Tests 7.1 and 7.2, and (b) Comparison with MELCOR predictions.

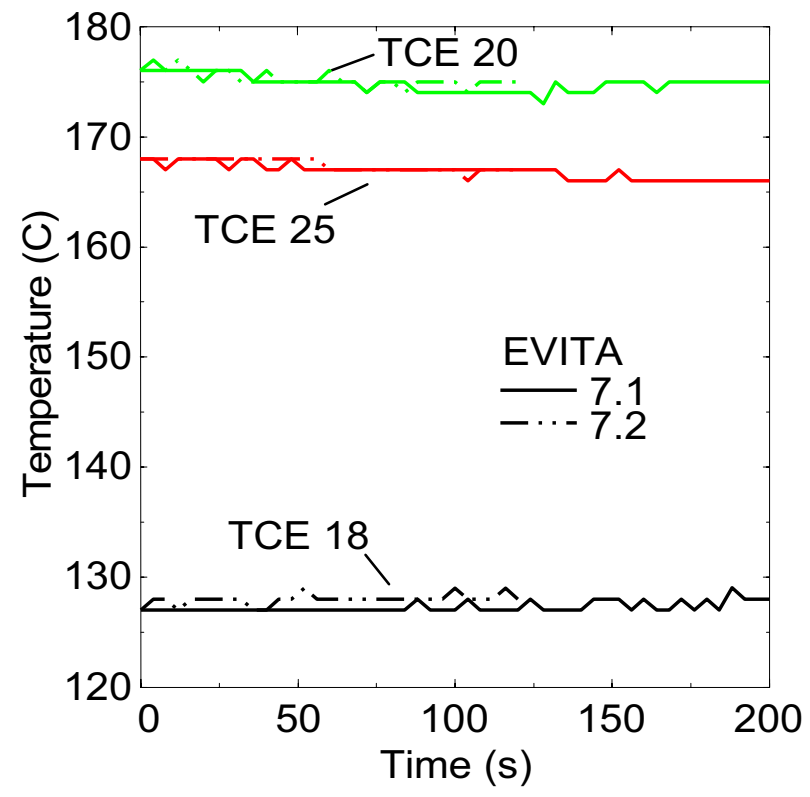

(a)

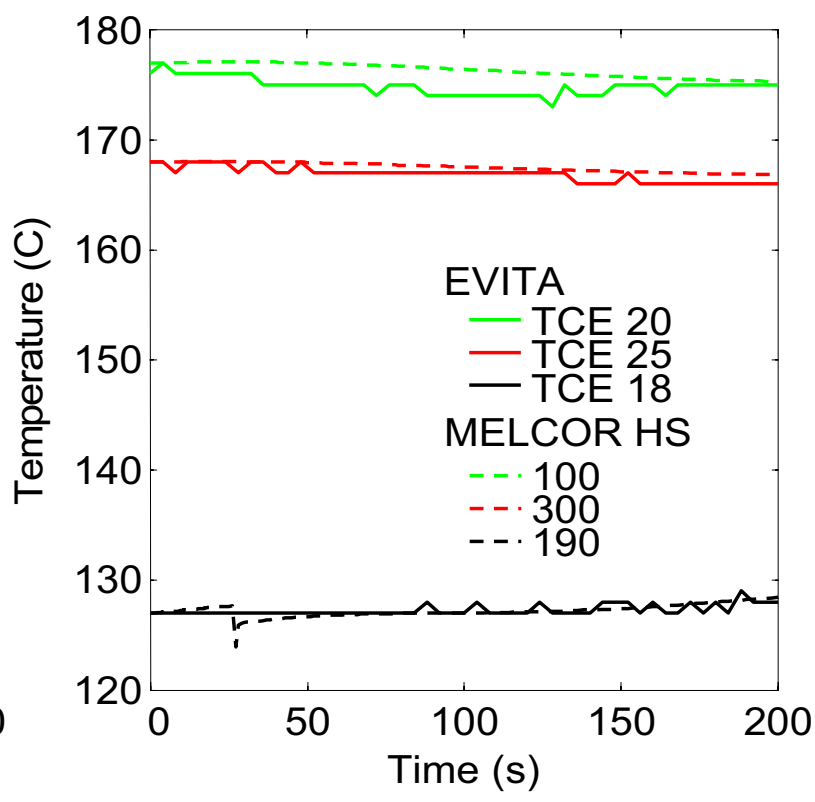

(b)

Figure 13. EVITA VV wall temperatures, (a) Tests 7.1 and 7.2, and (b) Comparison with MELCOR predictions for Test 7.1. 


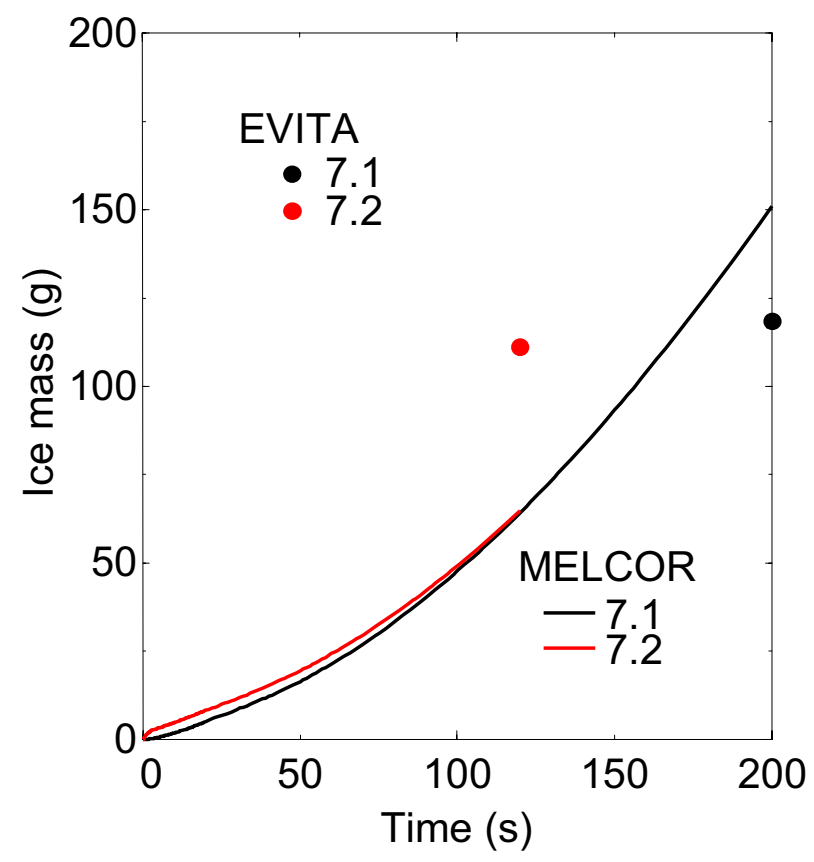

(a)

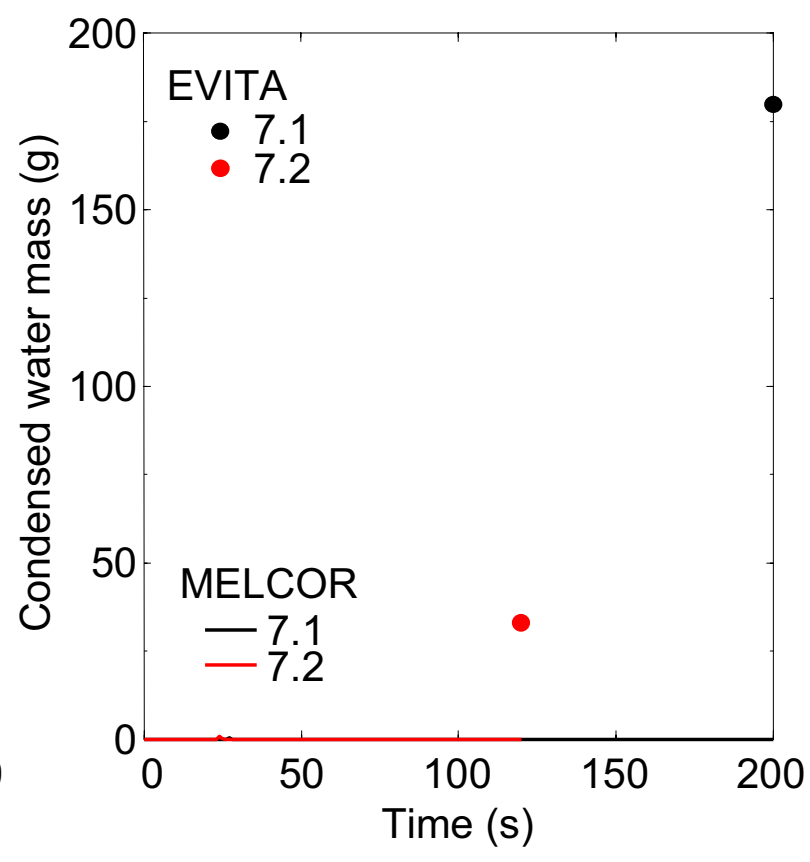

(b)

Figure 14. EVITA Tests 7.1 and 7.2 comparisons, (a) Cryoplate ice mass comparison with MELCOR predictions, and (b) VV condensate mass comparison with MELCOR predictions.

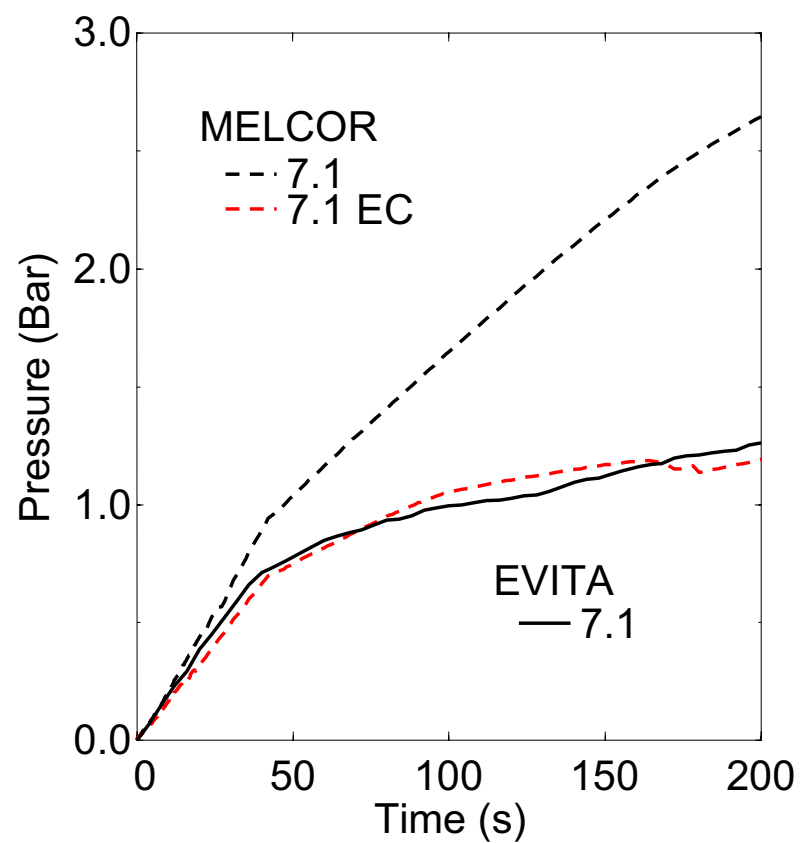

(a)

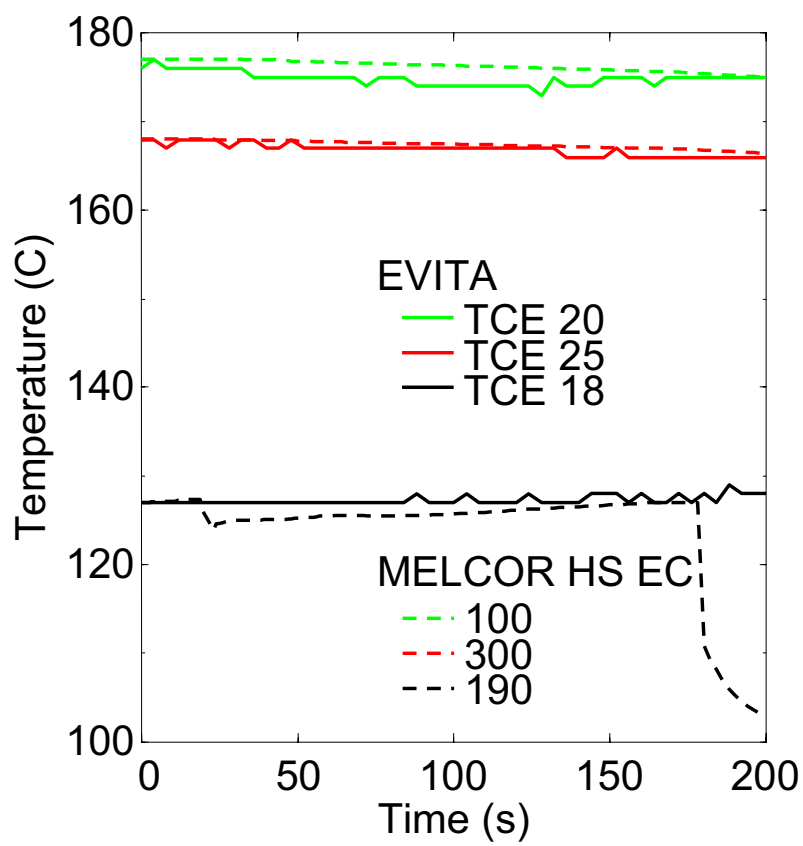

(b)

Figure 15. EVITA Test 7.1 comparisons, (a) VV pressure with MELCOR and MELCOR with enhanced condensation (EC) predictions, and (b) VV wall temperature with MELCOR with EC predictions. 


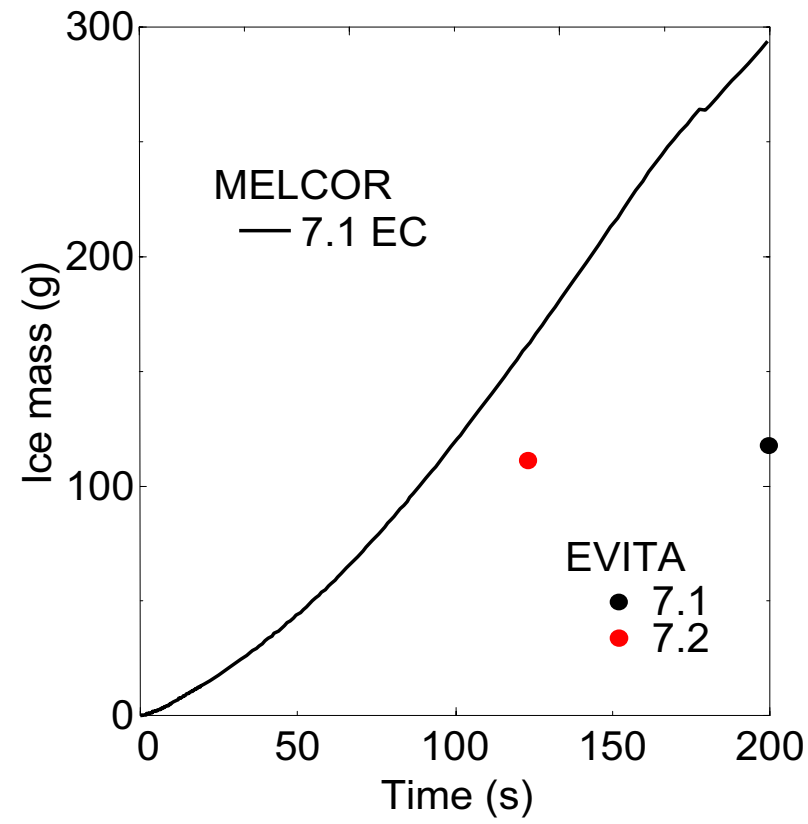

(a)

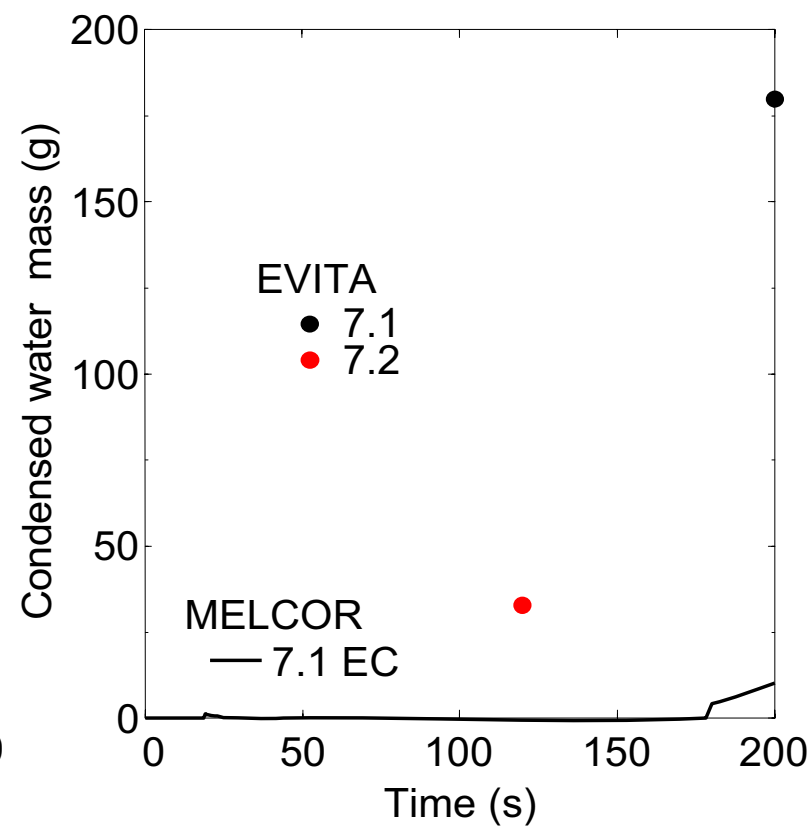

(b)

Figure 16. EVITA Tests 7.1 and 7.2 comparison, (a) Cryoplate ice mass comparison with MELCOR predictions with EC, and (b) VV condensate mass comparison with MELCOR predictions with EC.

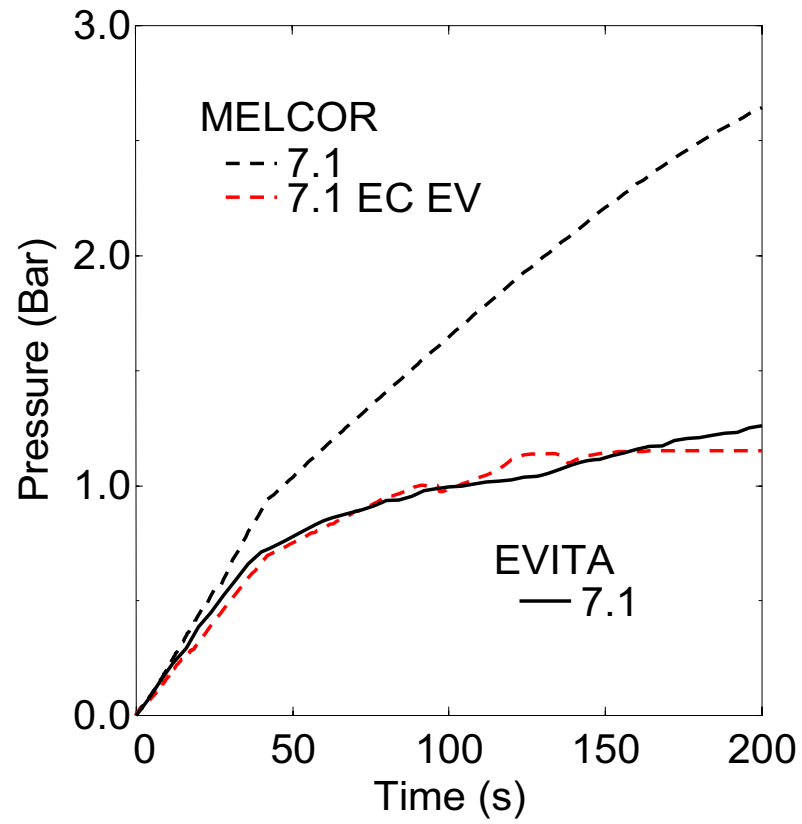

(a)

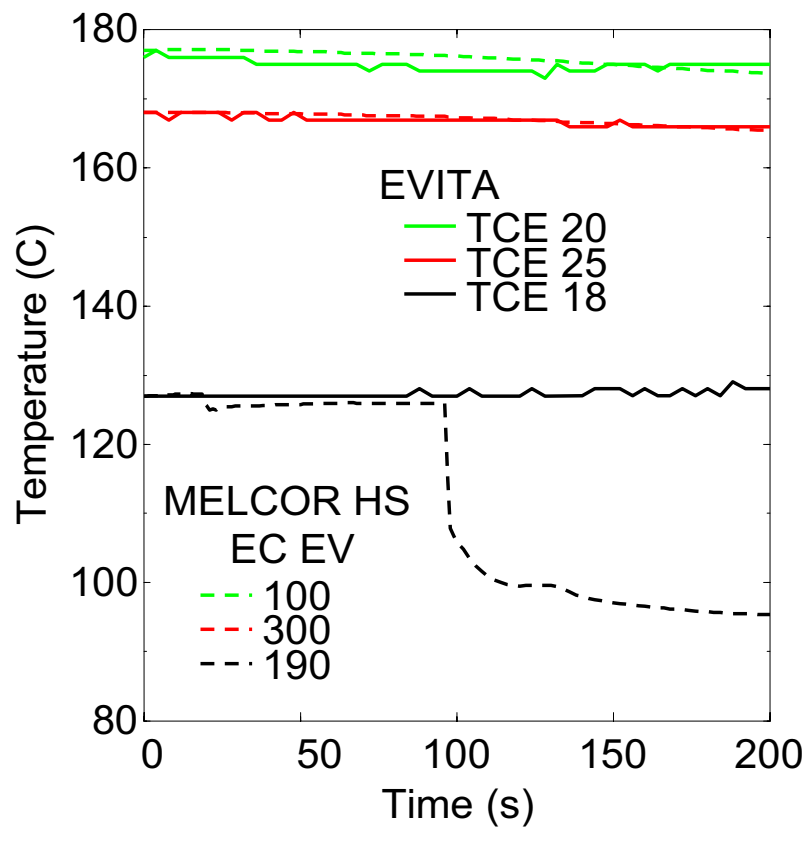

(b)

Figure 17. EVITA Test 7.1 comparisons, (a) VV pressure with MELCOR and experimental version (EV) of MELCOR with (EC) predictions, and (b) VV wall temperature with EV of MELCOR with EC predictions. 


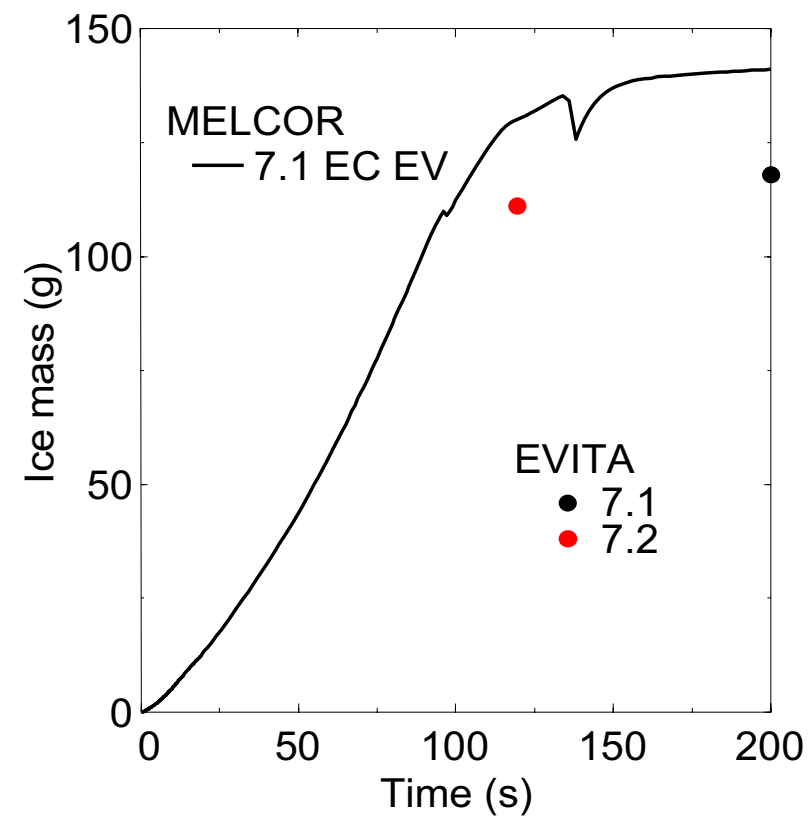

(a)

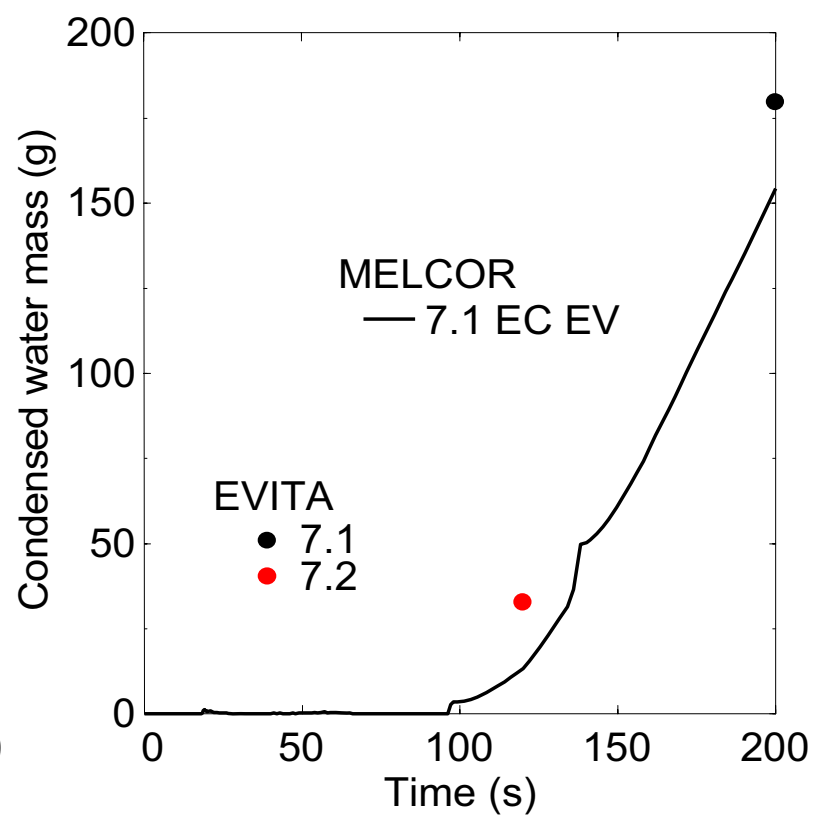

(b)

Figure 18. EVITA Tests 7.1 and 7.2 comparison, (a) Cryoplate ice mass comparison with EV of MELCOR predictions with EC, and (b) VV condensate mass comparison with EV of MELCOR predictions with EC. 


\subsection{EVITA Water and Nitrogen Co-injection Tests 7.5 and 7.6}

EVITA Tests 7.5 and 7.6 are water and nitrogen co-injection tests. The objective of these tests is to study the impact of a non-condensable gas on cryoplate ice formation and VV pressurization during water injection tests in EVITA. In theory, the impact should yield higher VV pressure as a result of two factors: 1) an indirect impact by reducing the cryoplate steam condensation rate (note Section 4) as a consequence of a non-condensable gas layer forming adjacent to the cryoplate, and 2) a direct impact by increasing VV pressure as a consequence of the additional partial pressure produced by the non-condensable gas in the VV atmosphere.

Figures 19 and 20 contain EVITA data and predictions from the pedigreed version of MELCOR 1.8.2 for EVITA Tests 7.5 and 7.6. The initial conditions for this test are similar to the Series 7 tests already discussed in previous sections. The water injection rate is $2.45 \mathrm{~g} / \mathrm{s}$ for $300 \mathrm{~s}$ and $2.54 \mathrm{~g} / \mathrm{s}$ for $80 \mathrm{~s}$ for Test 7.5 and 7.6, respectively, and the nitrogen injection rate for both tests is $0.34 \mathrm{~g} / \mathrm{s}$ for $40 \mathrm{~s}$. Figure 19a presents the measured EVITA VV pressure during these tests, plus predictions for the modified version of MELCOR 1.8.2. As was the case for the steam and nitrogen co-injection tests in the previous section, MELCOR over predicts the VV pressure for these tests because the standard condensation model under predicts the cryoplate condensation rate. Included in Figure 19a is a MELCOR prediction for Test 7.5 with EC. Pressure agreement was achieved by adjusting SC C4201(1) to a value of 2.5. At this condensation enhancement, the predicted condensation rate for the cryoplate in Test 7.5 (a co-injection test) was very similar to that predicted for water only injection test, Test 7.8 (within 10\%). The measured pressure history for Test 7.8 (a water only injection test) has been included in Figure 19a for comparison. Surprisingly, the ratio in final pressure between Test 7.8 and Test $7.5(=1.12)$ is nearly identical to the water injection rate ratio $(=1.11)$ for these tests, even with the added partial pressure of the non-condensable gas $(=0.05$ Bar $)$ for Test 7.5. This would suggest that to within the accuracy of the tests conducted in EVITA, the $13.6 \mathrm{~g}$ of nitrogen injected in Test 7.5 had little to no affect. It is also notable that the pressure results, EVITA data or MELCOR predictions, for Test 7.5 (first $80 \mathrm{~s}$ ) and Test 7.6 are the nearly the same.

Figures 20a and 20b compare the reported final values of cryoplate ice layer and bottom head condensate pool masses with the transient values predicted by the modified version MELCOR 1.8.2 with EC. The predicted ice layer mass is larger than that measured for Tests 7.5 by $35 \mathrm{~g}$ and the condensate mass is $43 \mathrm{~g}$ less than that measured for Test 7.5, which is excellent agreement. This result also suggests that the ice formed on the cryoplate in Test 7.5 had a very low porosity $(\sim 10 \%)$. It also appears from comparing MELCOR predictions for Test 7.6 that the cryoplate steam condensation and water flashing/wall evaporation rates were higher in Test 7.6 than predicted by MELCOR. However, the over predicted condensate mass is nearly equal to the under predicted ice mass for this test.

As mentioned in the previous section, the reason for the under prediction in the condensation rate for these co-injection tests is not known. It could be due to the jet like flow inside the EVITA VV preventing the formation of a stable or an effective non-condensable boundary layer adjacent to the EVITA cryoplate. However, it is too preliminary to suggest that this is what has happened in this EVITA test. It is interesting to note that the video recording of the cryoplate for Test 7.5 showed visible steam (a mist) near the plate that visually indicates a downward flow condition near the plate, which would be expected from natural convection arguments, but this flow pattern was sporadic and even appears to be upward at times.

Why an enhancement of 2.5 was needed for MELCOR to agree with measurements from these water/nitrogen co-injection tests when an enhancement of 4.0 was required for the steam/nitrogen coinjection tests is an unresolved issue at this time. However, whether the tests were water or steam injection tests the injected coolant mass flow rate was nearly the same. Because the injected steam produces the impetus for the EVITA VV gaseous flow patterns and because not all of the injected water will flash to 
steam during a water injection test, it is conceivable that the steam injection tests produce a more turbulent flow pattern near the cryoplate. A higher turbulence near the cryoplate would produce a less stable noncondensable gas boundary layer next to the cryoplate and consequently require a larger MELCOR condensation enhancement factor to match the data. In addition, the nitrogen mass injected in the water coinjection tests was only $1 / 5^{\text {th }}$ that injected during the steam co-injection tests. If the EVITA cryoplate steam condensation rate was approximately the same for both types of co-injection tests, due to turbulence, then as the injected nitrogen mass increases the MELCOR predict condensation rate would deviate more from the actual condensation rate (note Eq. 3), also requiring a greater enhancement to match the data. 


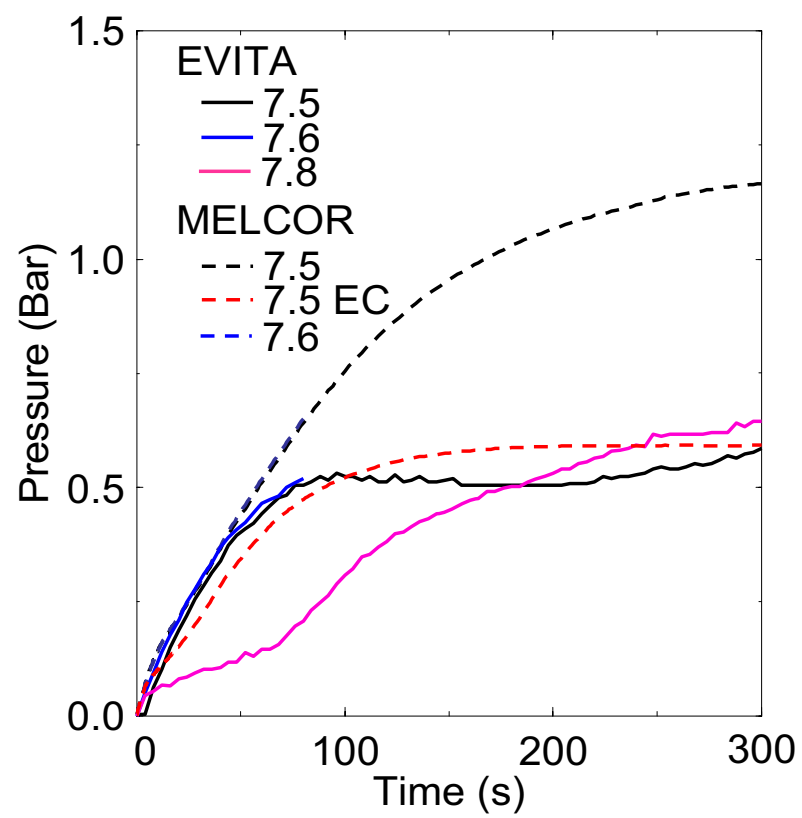

(a)

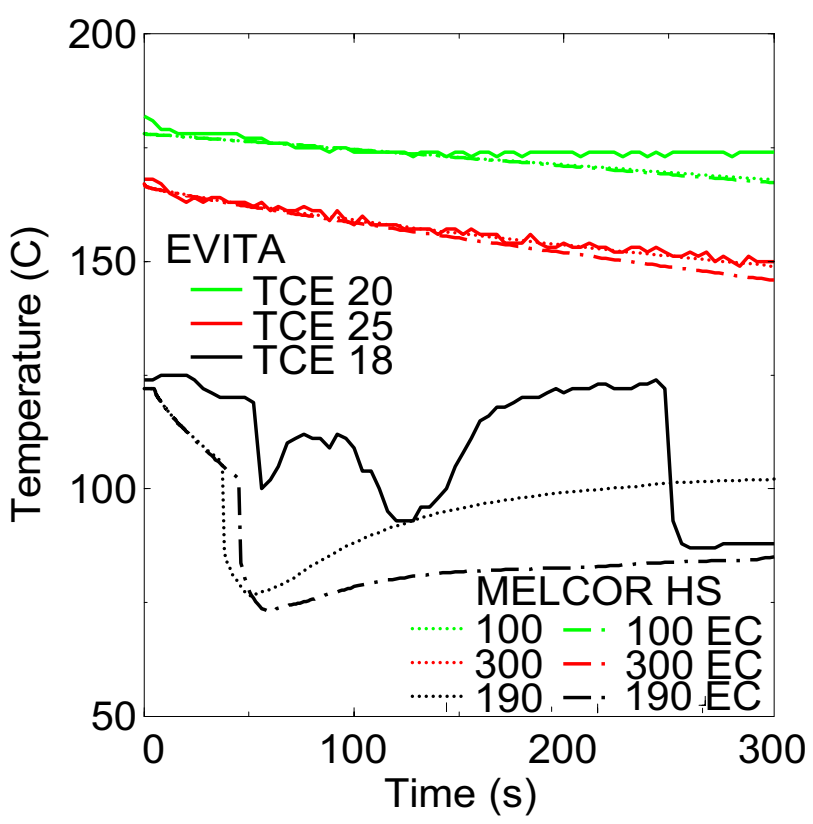

(b)

Figure 19. EVITA VV pressure and temperatures, (a) Tests 7.5, 7.6 and 7.8, MELCOR 7.5 and MELCOR 7.5 EC pressures, and (b) Test 7.5 VV wall and MELCOR and MELCOR EC heat structure temperatures.

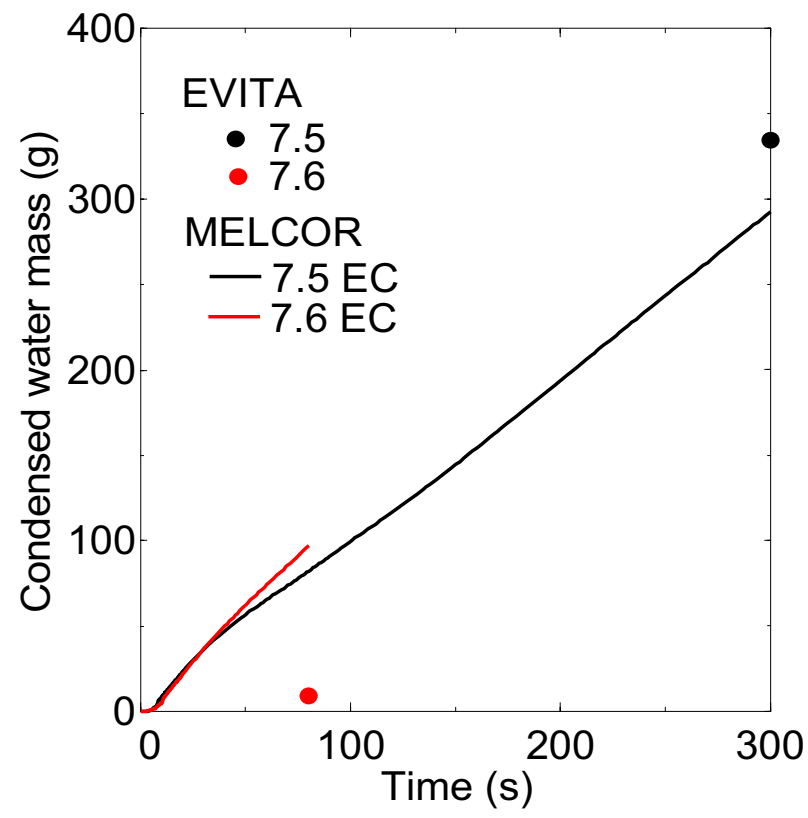

(a)

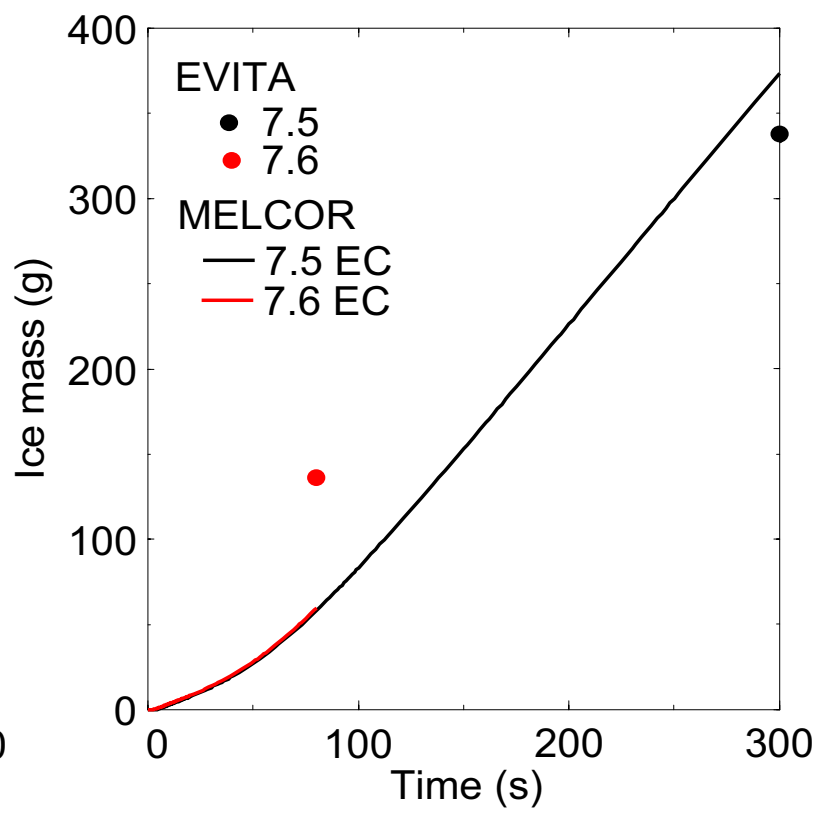

(b)

Figure 20. EVITA Test 7.5 and 7.6 comparisons, (a) Cryoplate ice mass comparison with MELCOR EC predictions, and (b) VV condensate mass comparison with MELCOR EC predictions. 


\section{CONCLUSIONS}

A version of MELCOR 1.8.2 modified for use in ITER PSR analysis was benchmarked against recent data from the EVITA facility located in Cadarache, France. EVITA Test Series 7 was used for this study to validate MELCOR's ability to predict the pressures, temperatures, cryoplate ice mass, and VV condensate mass for test conditions in EVITA that include injections of steam, nitrogen, and water in to the EVITA VV after the walls had been heated to $165^{\circ} \mathrm{C}$ and the cryoplate had been cooled to $-193{ }^{\circ} \mathrm{C}$. In general, MELCOR results showed the proper trends and agreed well with the EVITA data trends. This agreement should lend confidence to the modeling of water ingress events in ITER's cryostat and suggest that the MELCOR code is predicting the physical phenomena well.

The ability of MELCOR to predict the VV pressure and wall temperatures for the steam only and water only injection tests was very good. The largest deviation in pressure from EVITA was less than $20 \%$. The predicted wall temperatures were within a few percent of the measured values, but for the most part this agreement results for the VV ambient energy loss rate found for the input model by trial and error that matched Test 7.10 data, a test for which the heater power was switched off during water injection. Predicted ice layer masses where larger than reported for the EVITA cryoplate, in particular for the steam only injection tests ( $40 \%$ too high), and the predicted condensate masses were less that measured in EVITA. Both of these discrepancies can be explained by ice porosity. It is believed that the actual ice layer on the EVITA cryoplate has a porosity that varies from 20 to $40 \%$, where as the MELCOR model assumes an ice porosity of zero. When a porosity was introduced into the modified MELCOR 1.8.2 ice formation model, the predicted ice layer mass condensate masses were in agreement with EVITA data.

The modified MELCOR 1.8.2 code over predicts the EVITA VV pressure for the coinjection tests (e.g., steam plus nitrogen, or water plus nitrogen injections) by almost a factor of two. Based on parametric runs that where made by increasing the predicted cryoplate condensation rate, it is believed that the over prediction in pressure is a result of an under prediction in cryoplate condensation rate. The reason for this under prediction could be attributed to a vapor flow distribution inside of the EVITA VV that does not allow a stable non-condensable gas (nitrogen) layer to form at the surface of the cryoplate ice layer. However, there is no way of directly verifying this hypothesis at this time and there may be other explanations for the under predicted condensation rate.

Based on the results of this study, it may be concluded that to the extent that the EVITA facility simulates coolant leaks into the cryostat of ITER that this version of MELCOR 1.8.2 modified for use in ITER could over predict the cryogenic structure ice layer mass for steam and water leaks into the cryostat, and in addition could over predict the cryostat pressure if there is a co-injection of a non-condensable gas, such as air or helium. Both of these factors will more than likely result in a conservative prediction regarding the consequence of this type of accident in ITER. 


\section{REFERENCES}

Ayrault, 2005. L. Ayrault, "EVITA: Results of the cryogenic tests 7.xx - Kinetics of the ice layer formation," CEA Technical Note, DTN/STPAL/LTCG (2005).

Gauntt, 2000. R. O. Gauntt, et al., "MELCOR Computer Code Manuals Vol. 2: Reference Manuals Version 1.8.5," NUREG/CR-6119, Vol. 2, Rev. 2, SAND 2000-2417/2, Sandia National Laboratories, Albuquerque, NM, May 2000, pages HS-RM-60-62.

Hishida, 1980. K. Hishida, et al., "Heat Transfer from a Plate in Two-component Mist Flow," Heat Transfer, 102, August (1980), p 515-518.

Merrill, 2000. B. J. Merrill, R. L. Moore, S. T. Polkinghorne, D. A. Petti, "Modifications to the MELCOR code for application in fusion accident analyses," Fusion Engineeering and Design, 51-52 (2000) 555-563.

Moore, 2007. R. L. Moore, "Pedigree Analysis of the MELCOR 1.8.2 Code to be Used for ITER's Report Preliminary on Safety," Idaho National Laboratory Report, INL/EXT-07-12856, June (2006).

Na, 2004. B. Na, and R. L. Webb, "Mass Transfer on and Within a Frost Layer," International Journal of Heat and Mass Transfer, 47, (2004), p. 899-911.

Takase, 2001. K. Takase, H. Akimoto, L.N. Topilski, "Results of two-phase flow experiments with an integrated Ingress-of-Coolant Event (ICE) test facility for ITER safety," Fusion Engineering and Design, 54 (2001) 593-603.

Tolpilski, 2001. Topilski, L. N., et al., "Validation and benchmarking in support of ITER-FEAT safety analysis," Fusion Engineering and Design, 54 (2001) 627-633.

SADL, 2005. Topilski, L., et al., "Safety Analysis Data List,” ITER Report, ITER D 24LSAE, version 5.2, May 29 (2005).

Sardain, 2005. P. Sardain, L. Ayrault, F. Challet, L.B. Marie, B. Merrill, M.T. Porfiri, G. Caruso, "The EVITA programme: Experimental and numerical simulation of a fluid ingress in the cryostat of a water-cooled fusion reactor," Fusion Engineering and Design, 75-79 (2005) 1265-1269.

Sardain, 2006. P. Sardain, et al., "Validation of thermal hydraulic codes for fusion reactors safety," (Proceedings of 24th Symposium on Fusion Technology), Warsaw Poland, September 11th-15th, 2006.

Sauthoff, 2007. N. Sauthoff, "Support and assistance for MELCOR Quality Assurance and Safety Analyses,” ITER Task Agreement, ITA 81-18, TN C81TD30FU, June 3 (2007). 


\section{Appendix A}

Listing of MELCOR Input Deck for Test 7.10 


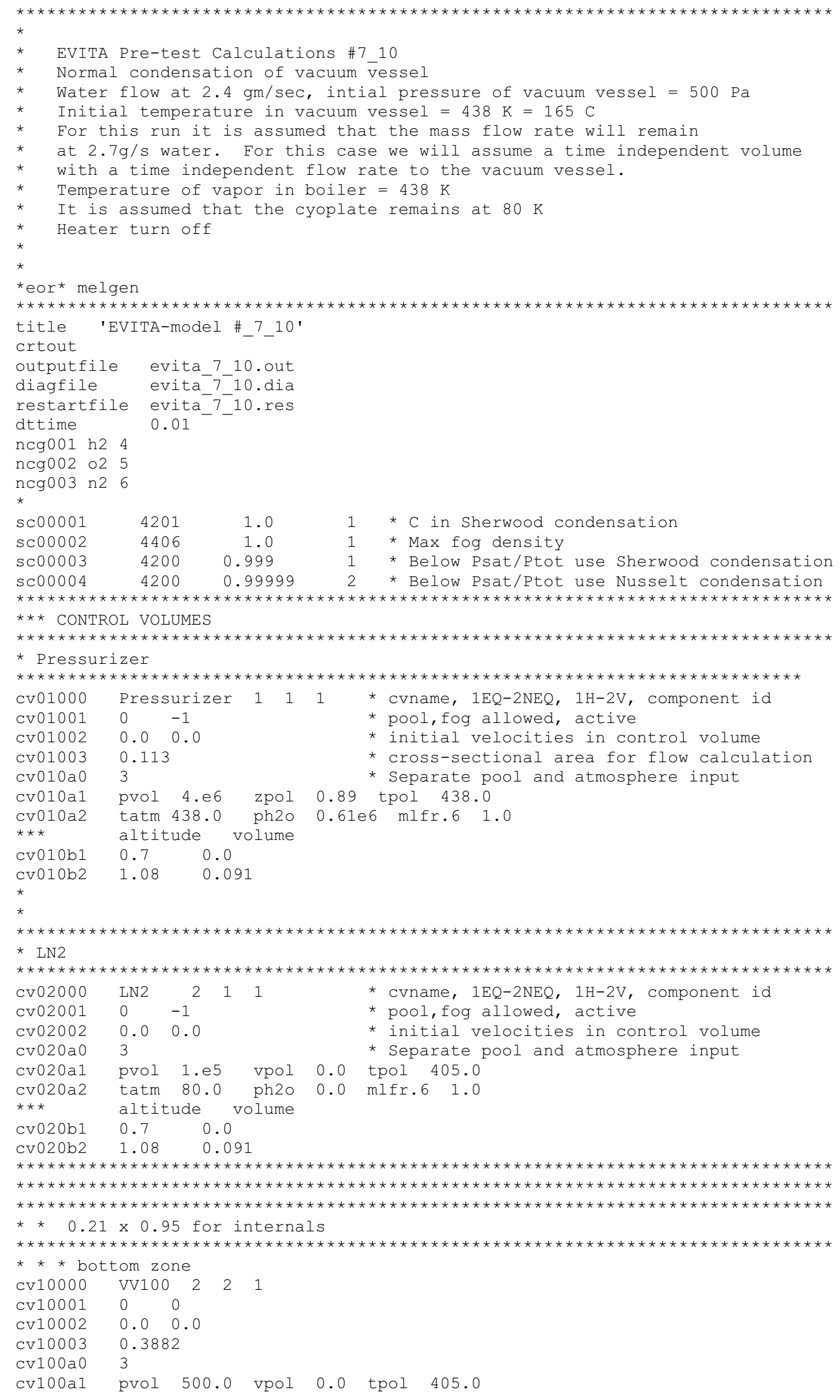




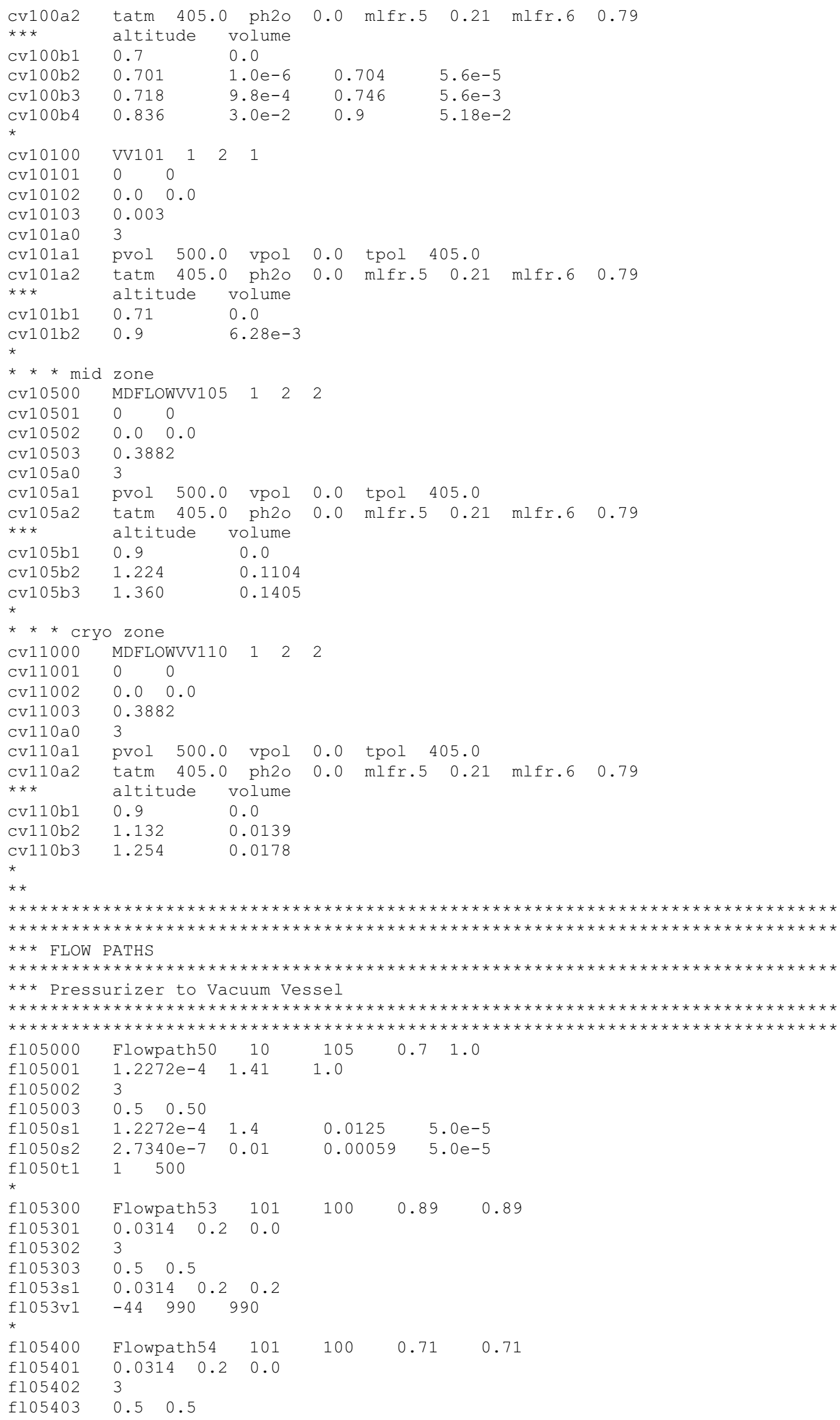




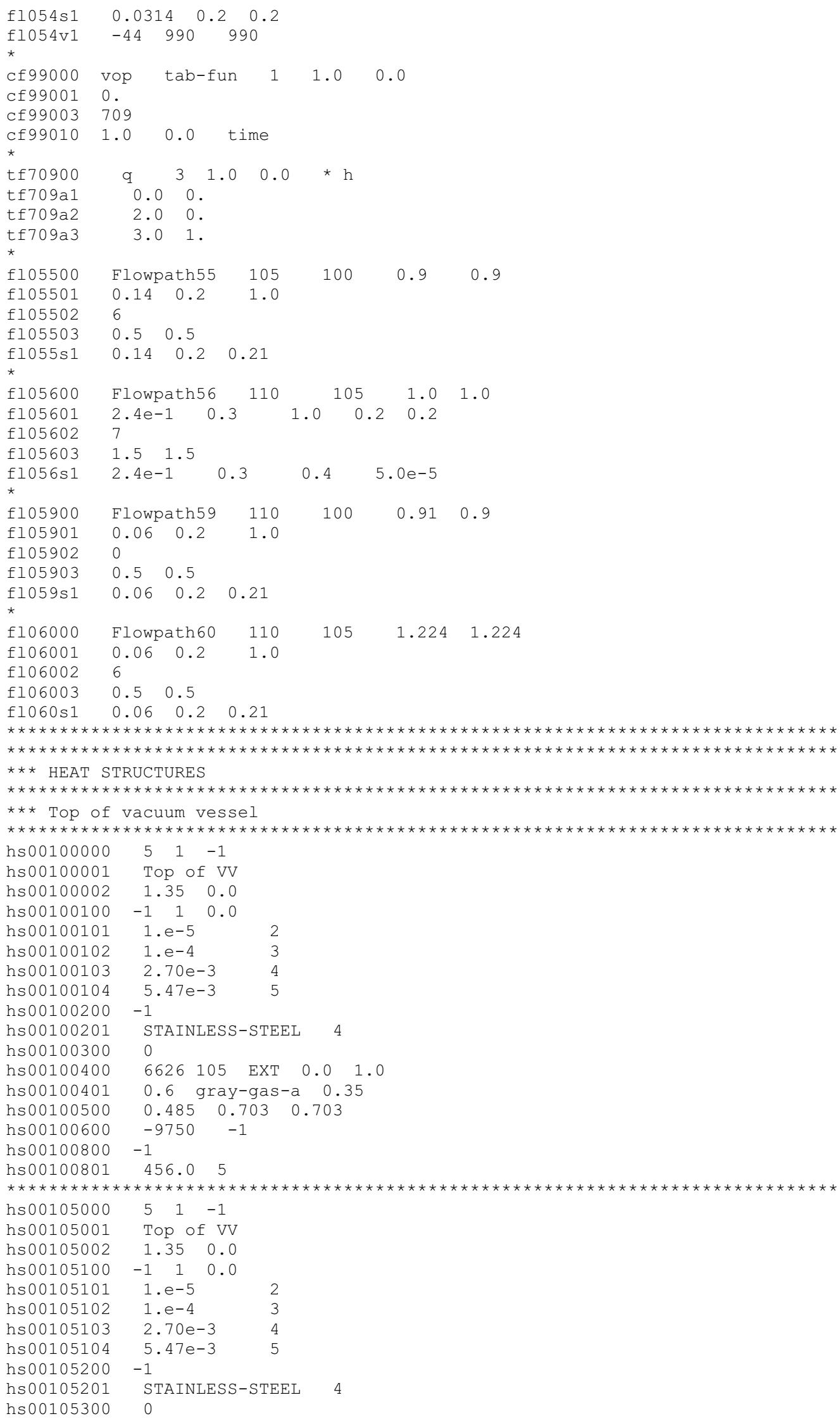




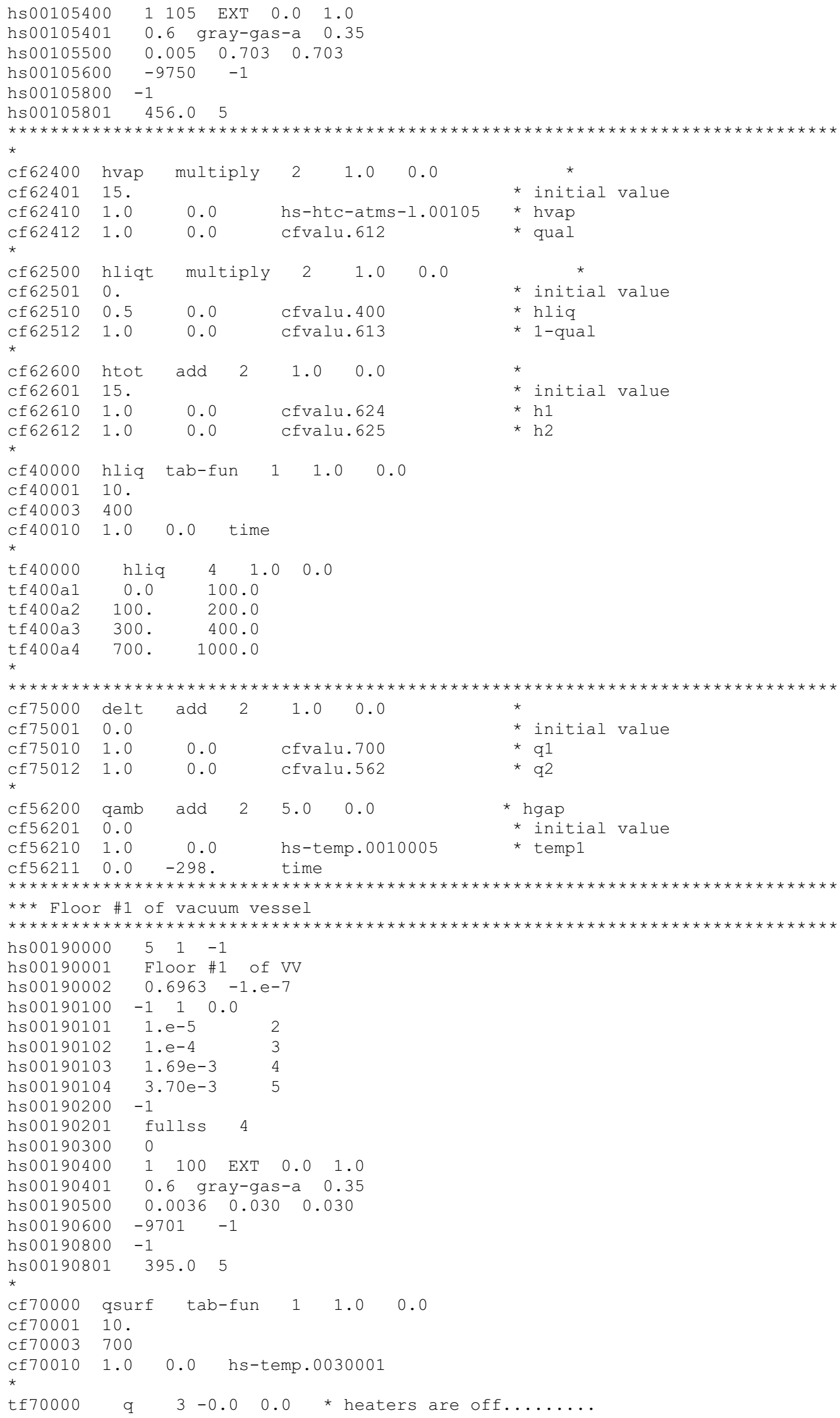




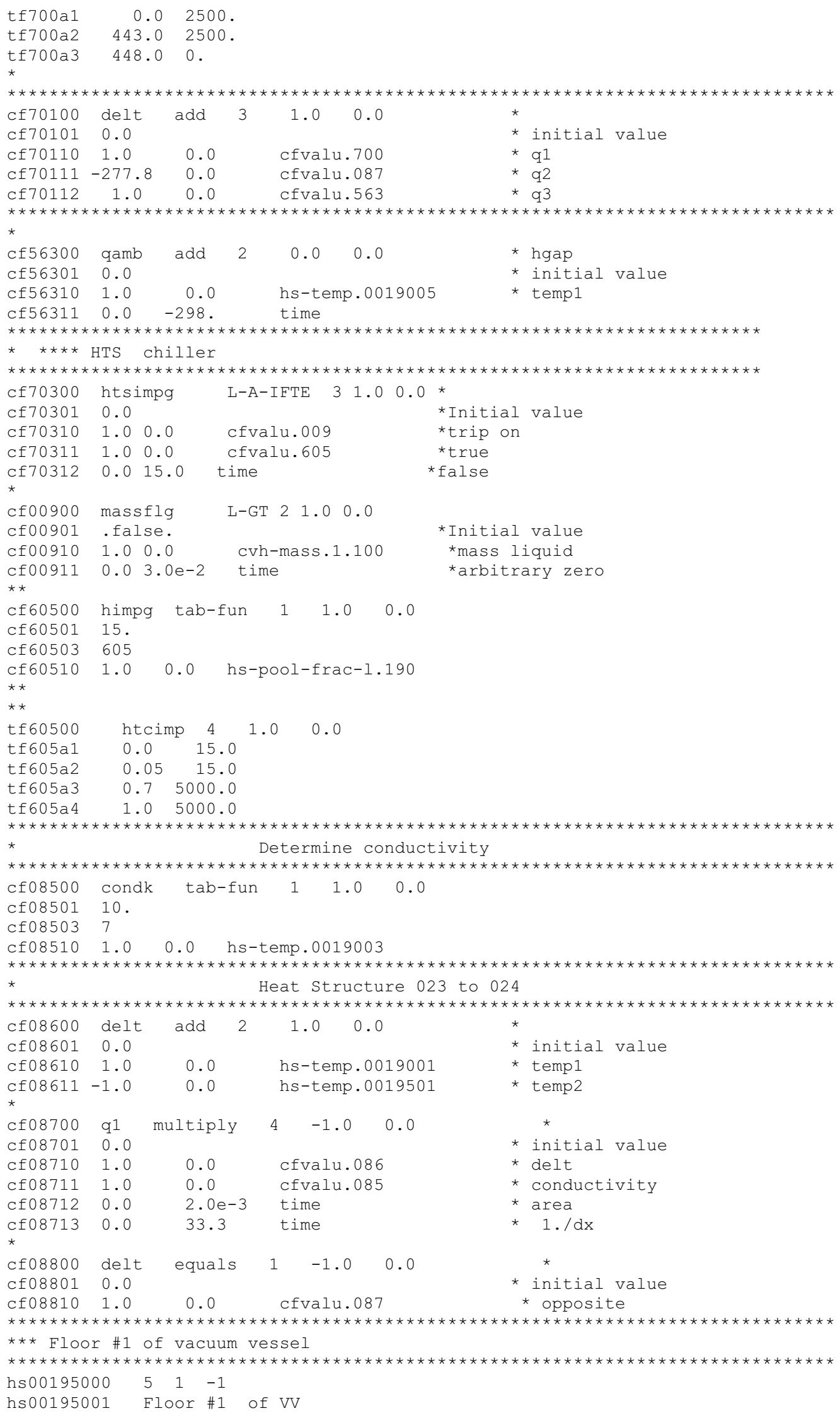




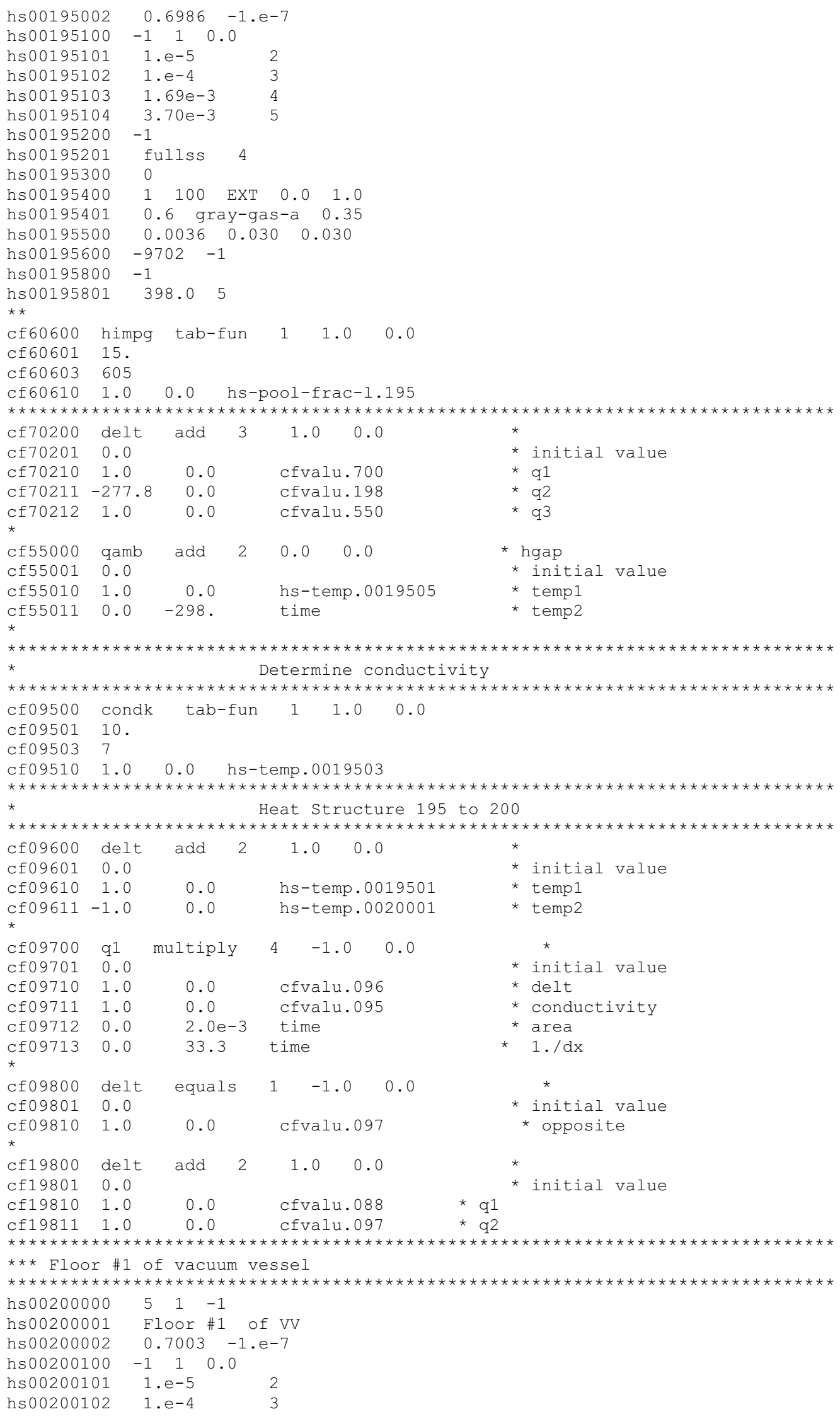




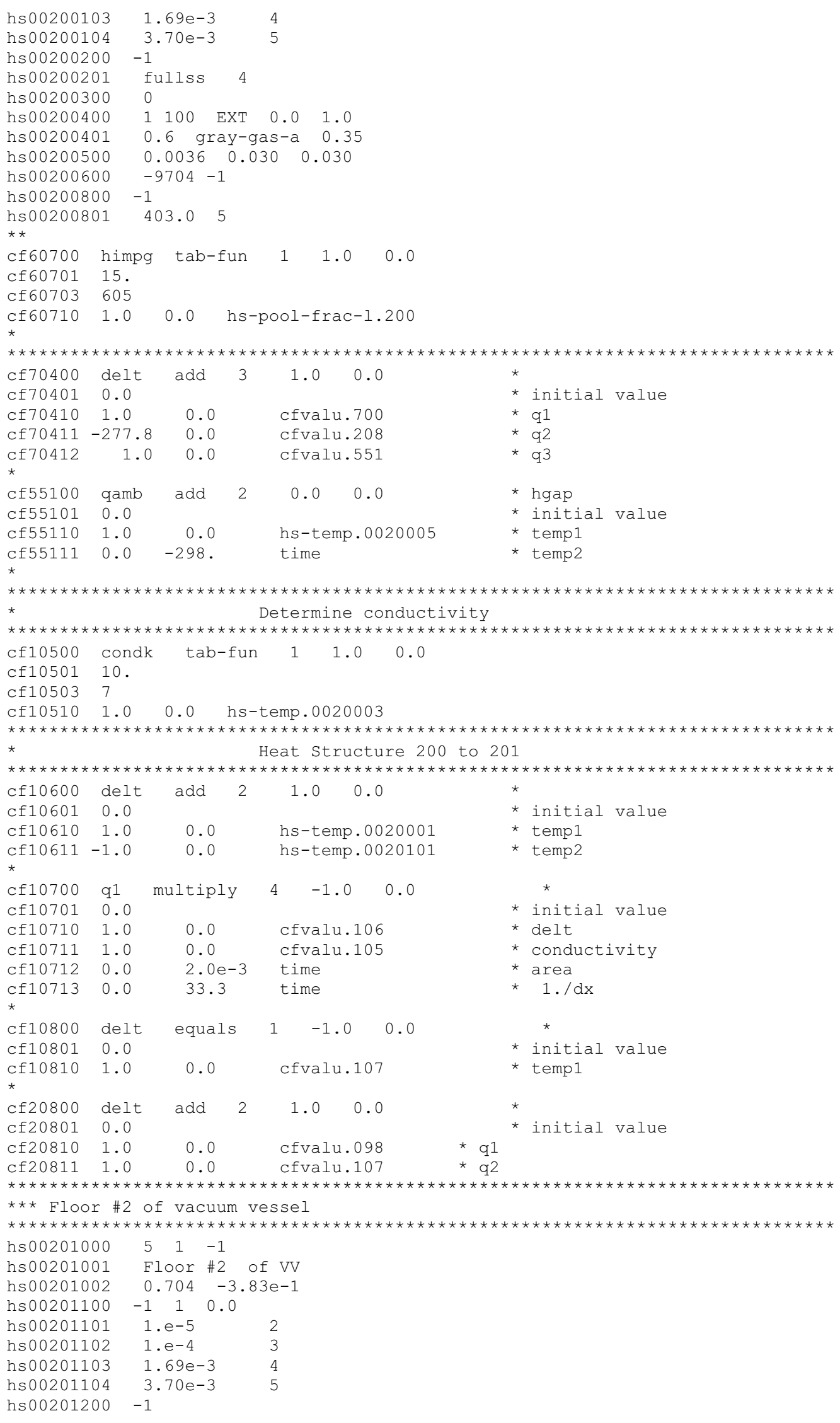




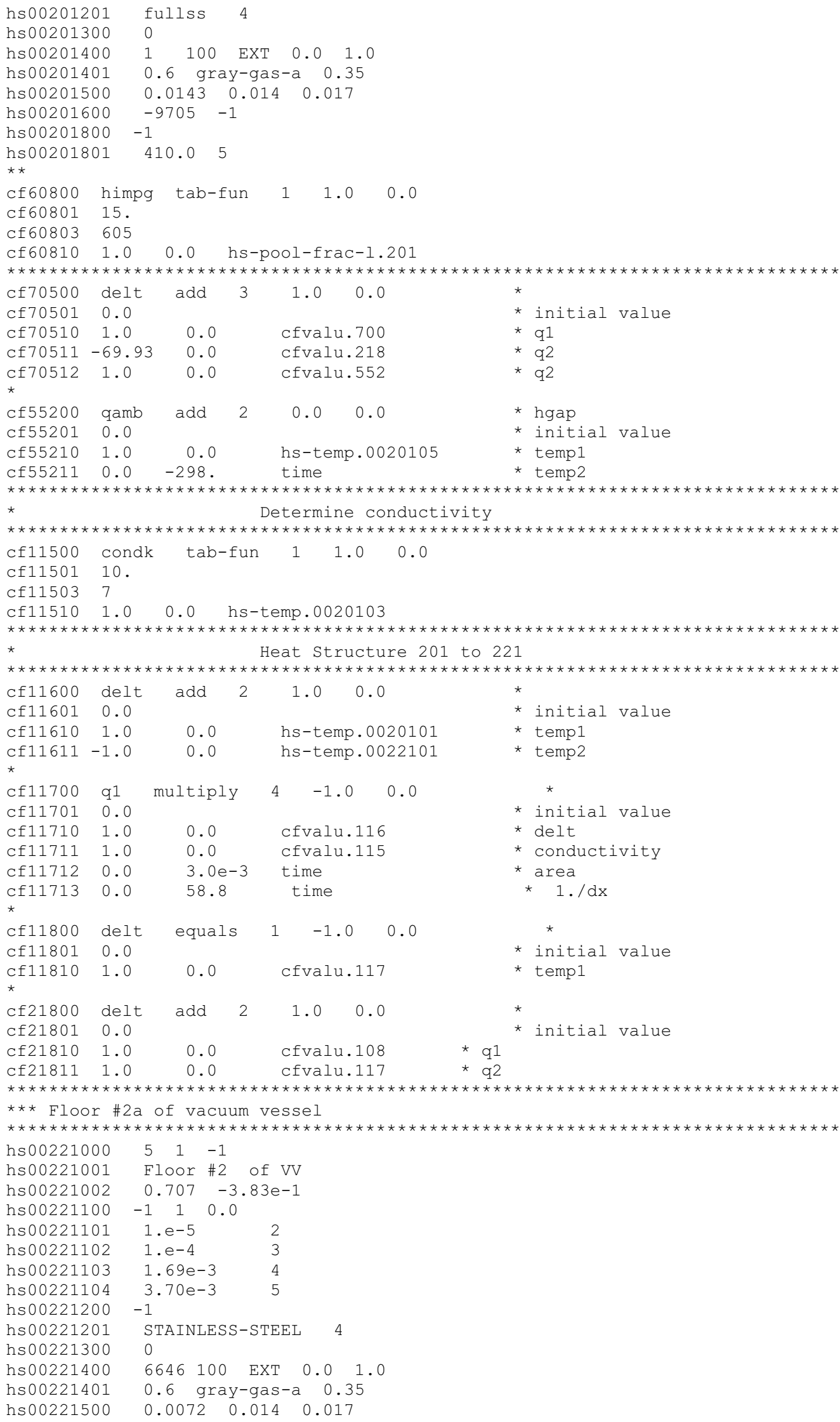




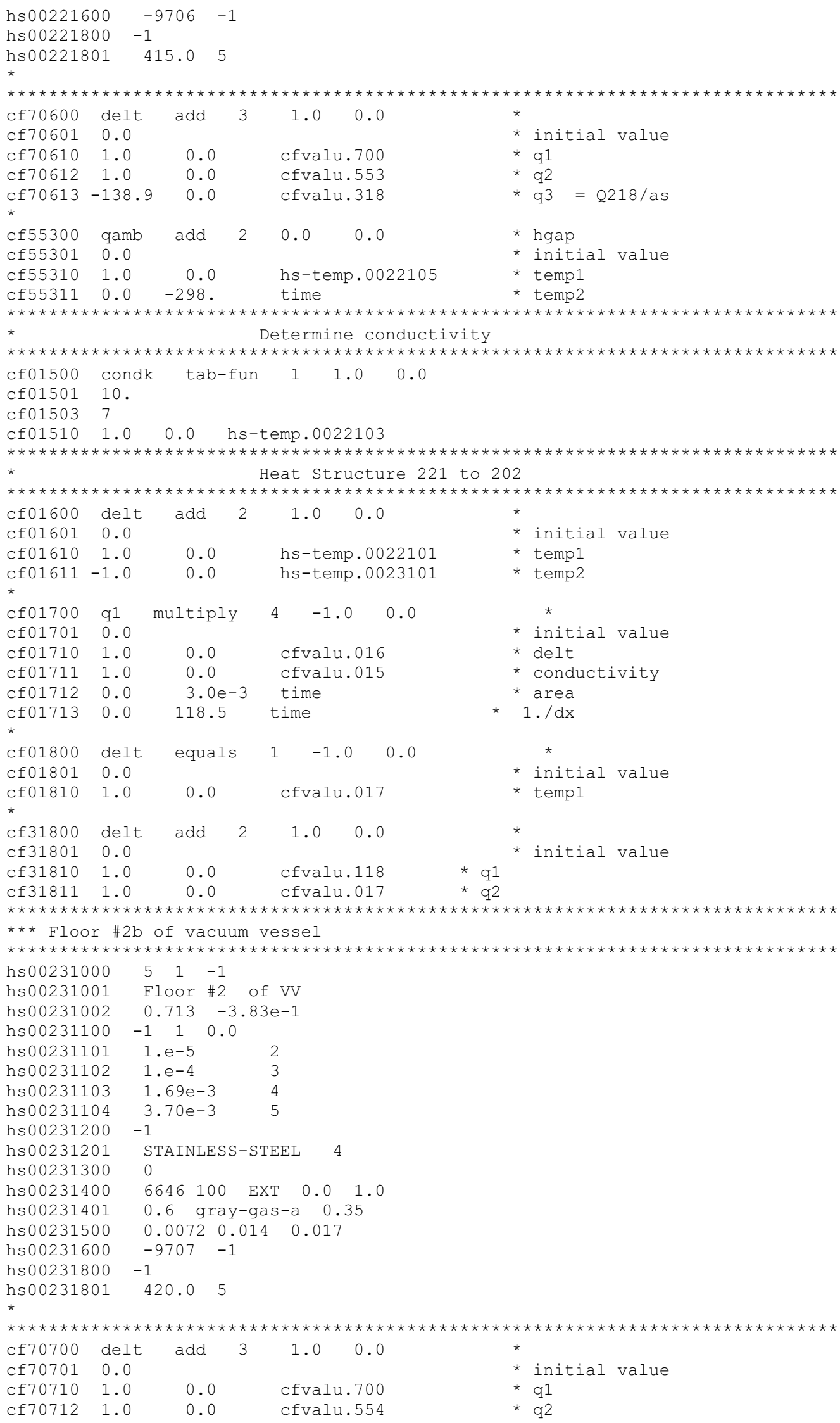




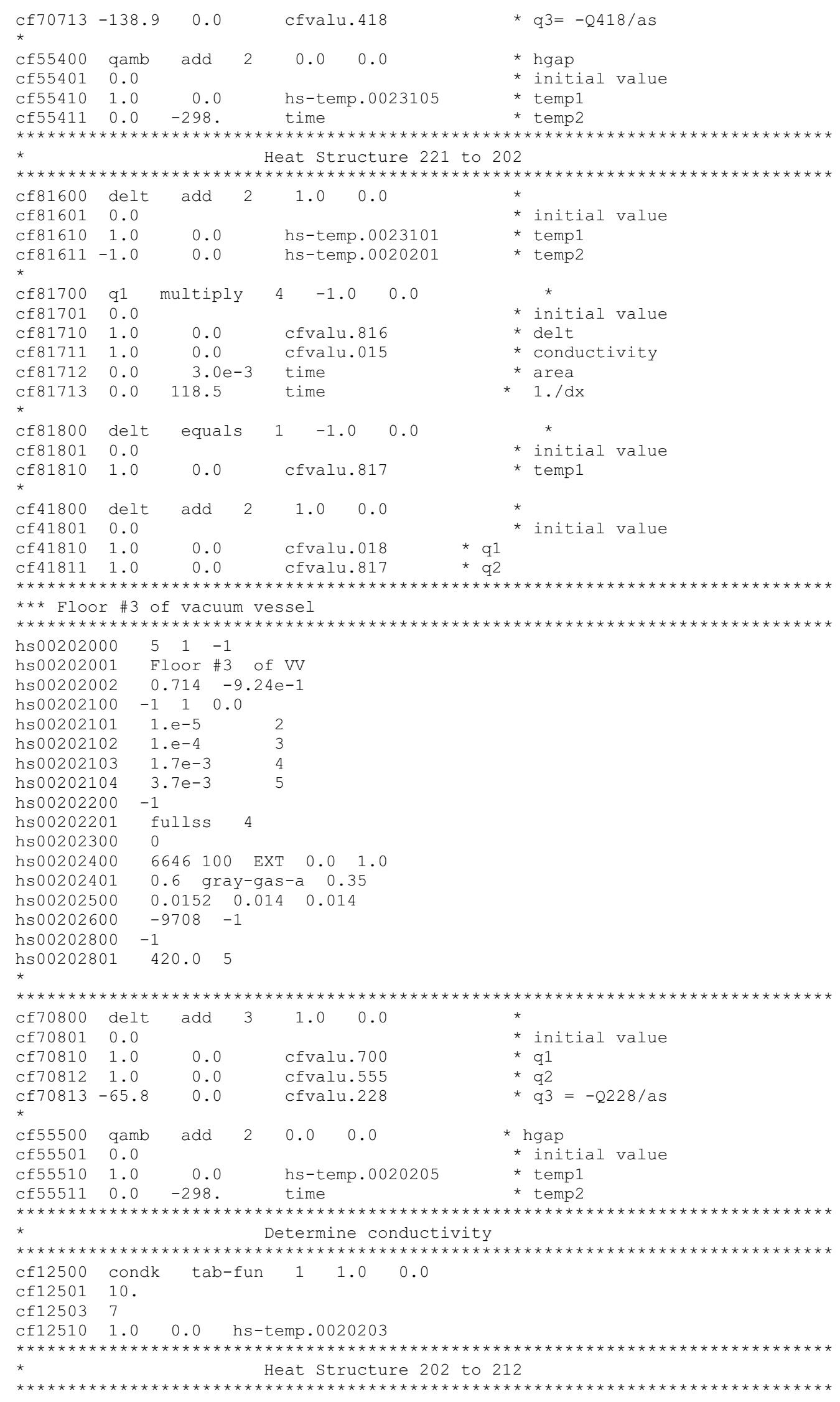




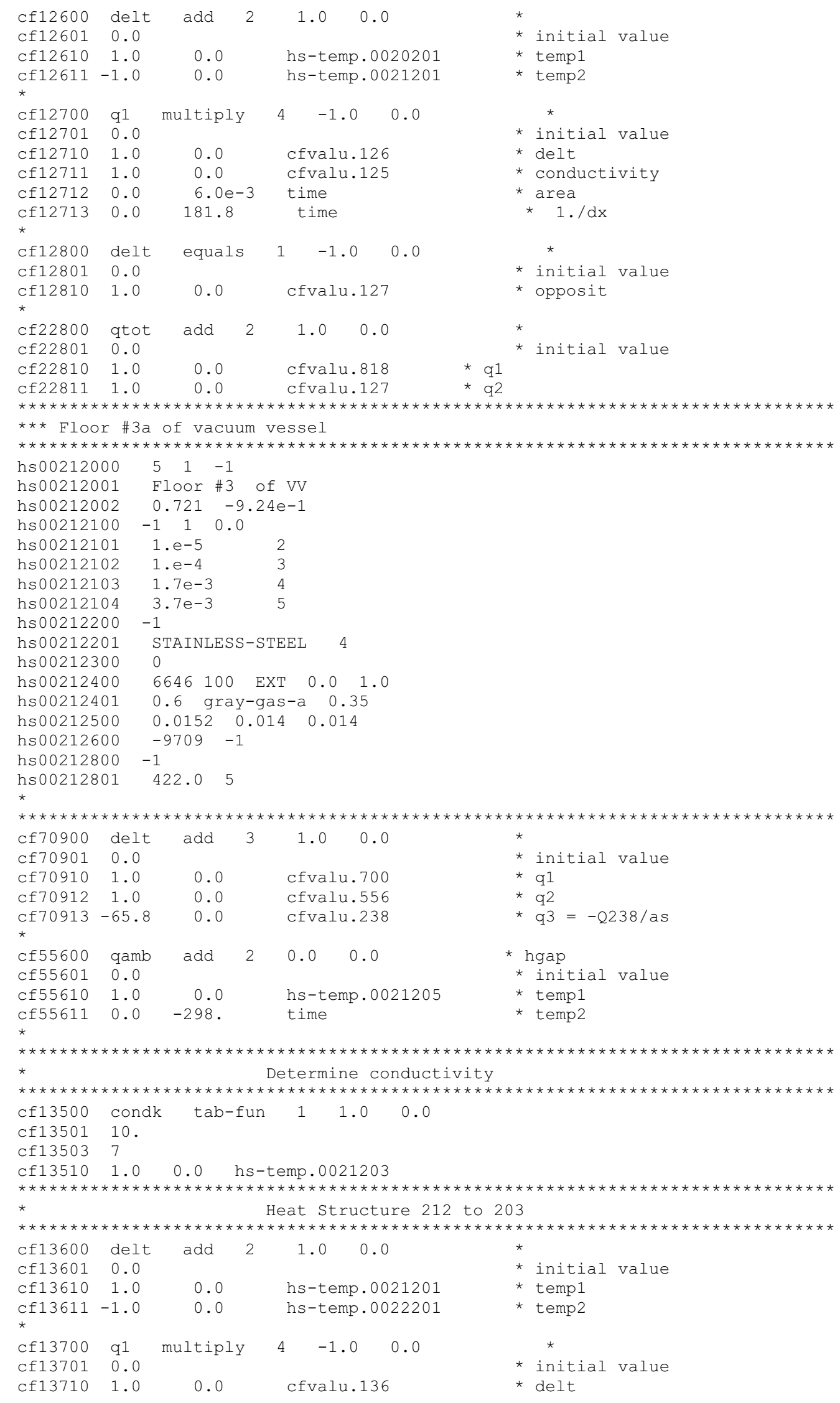




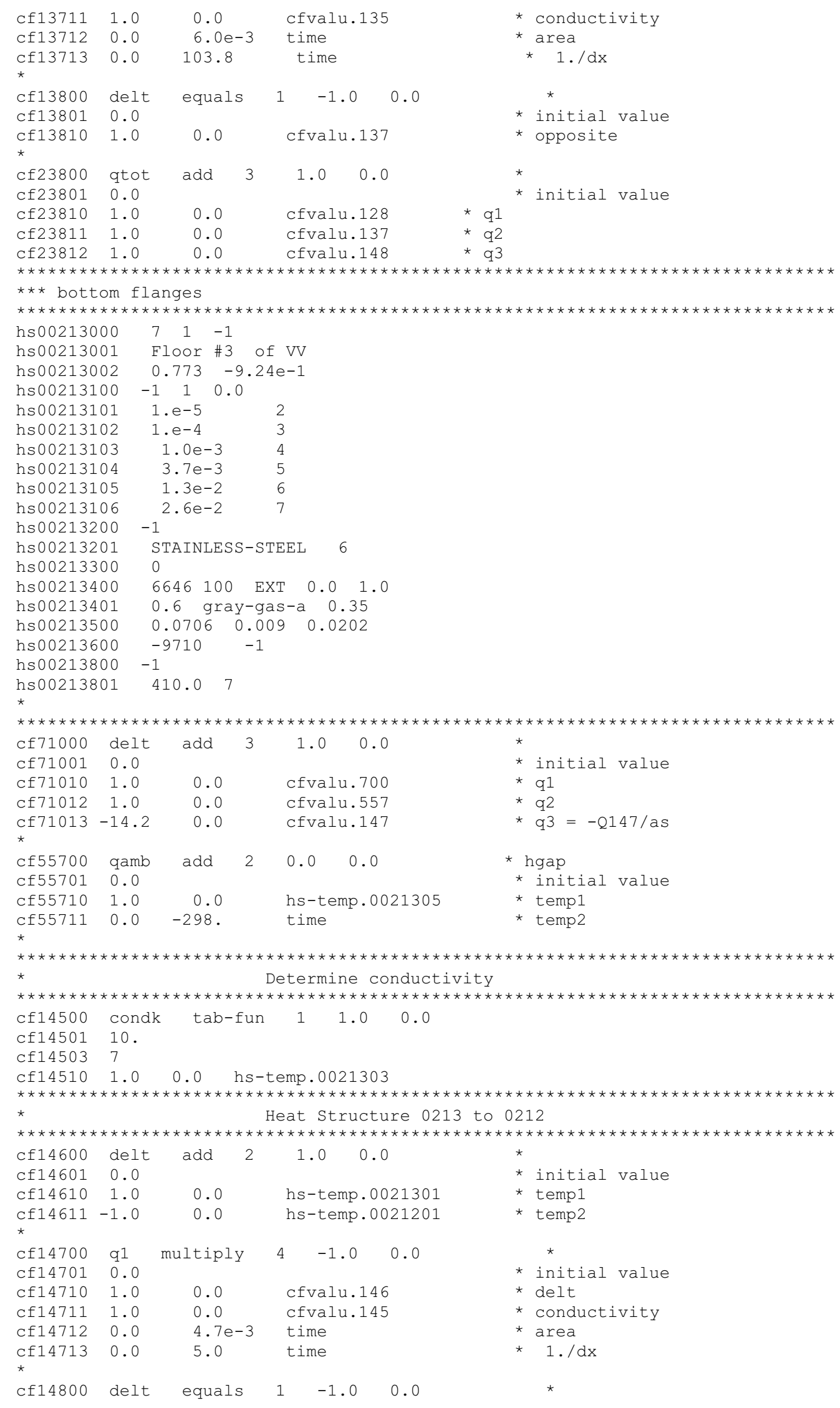




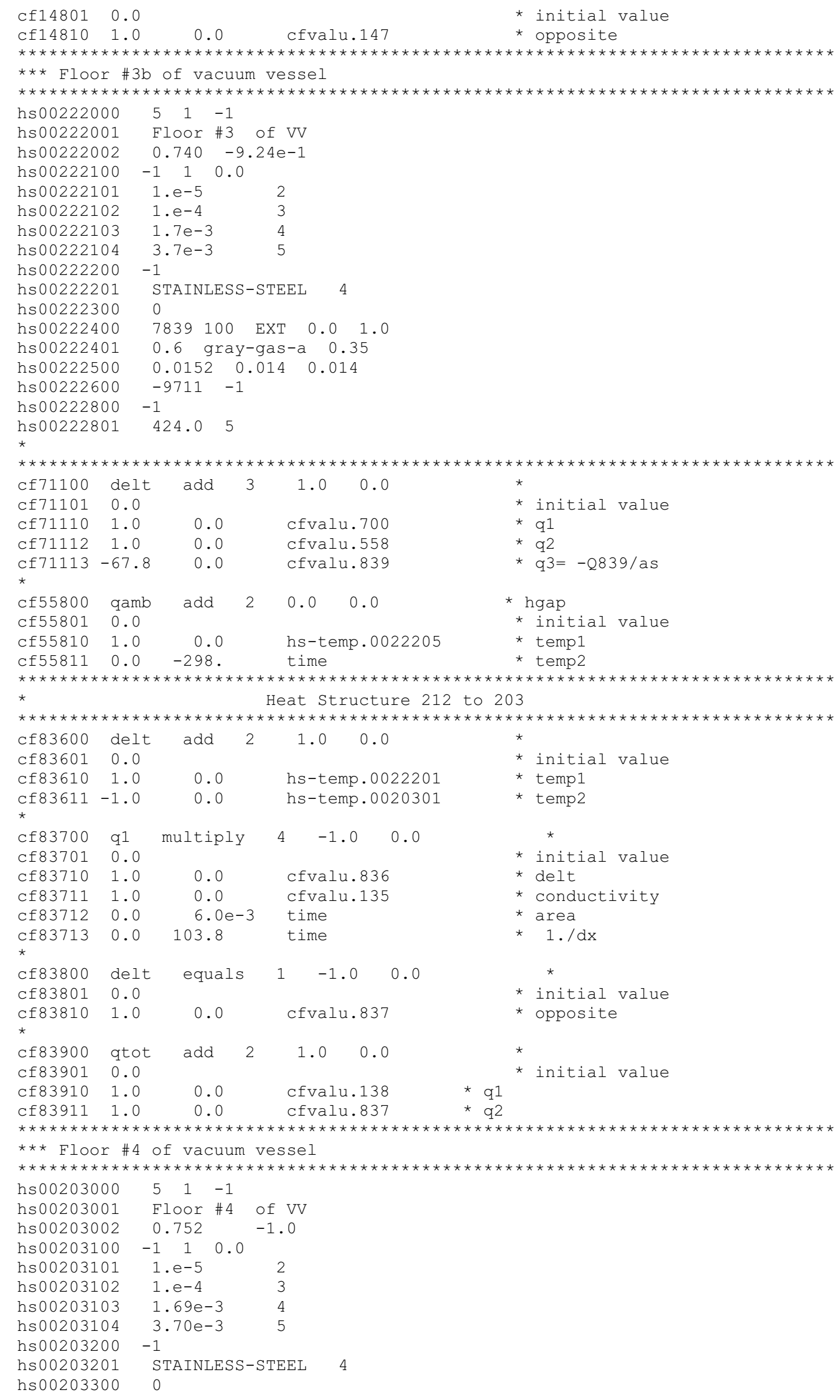




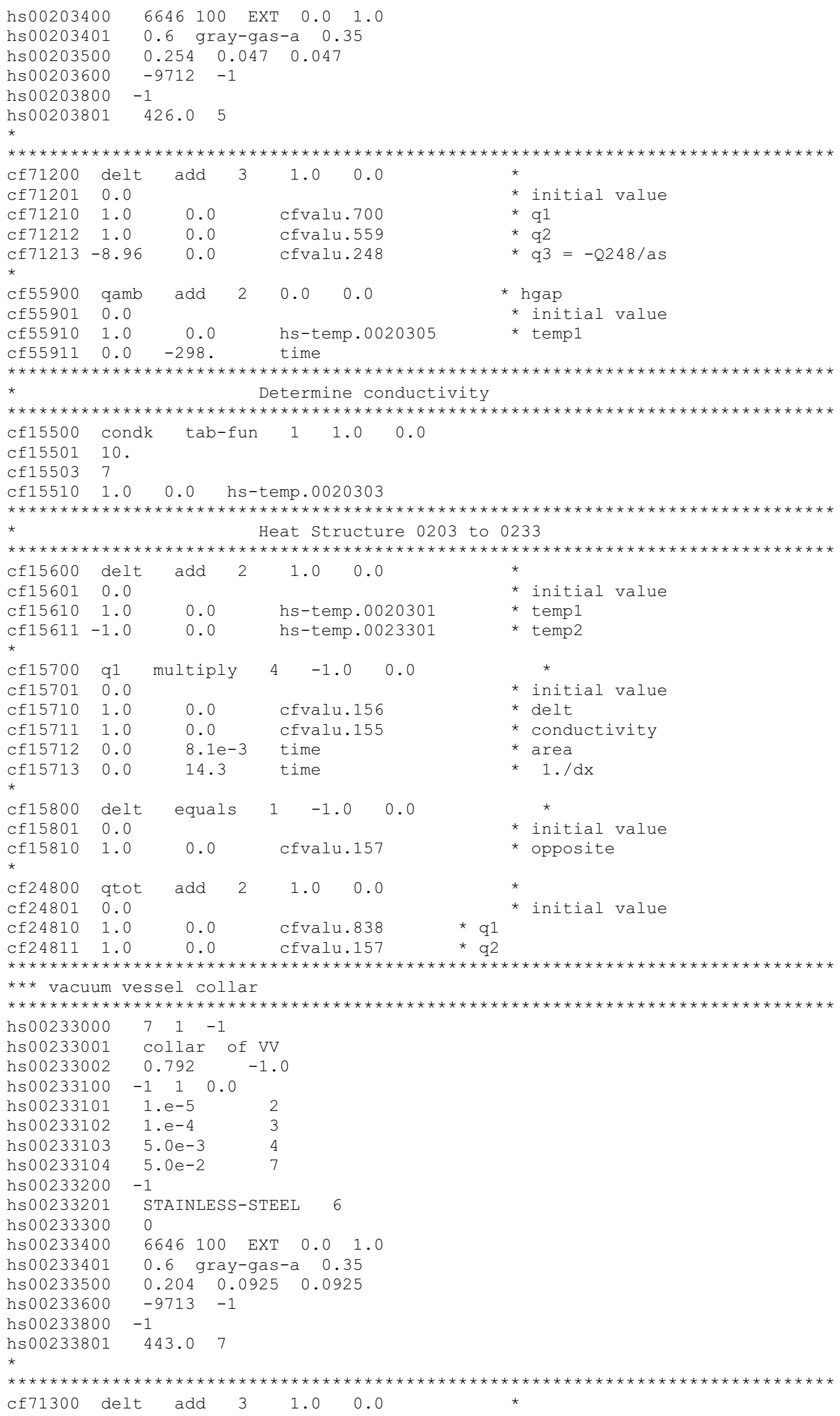




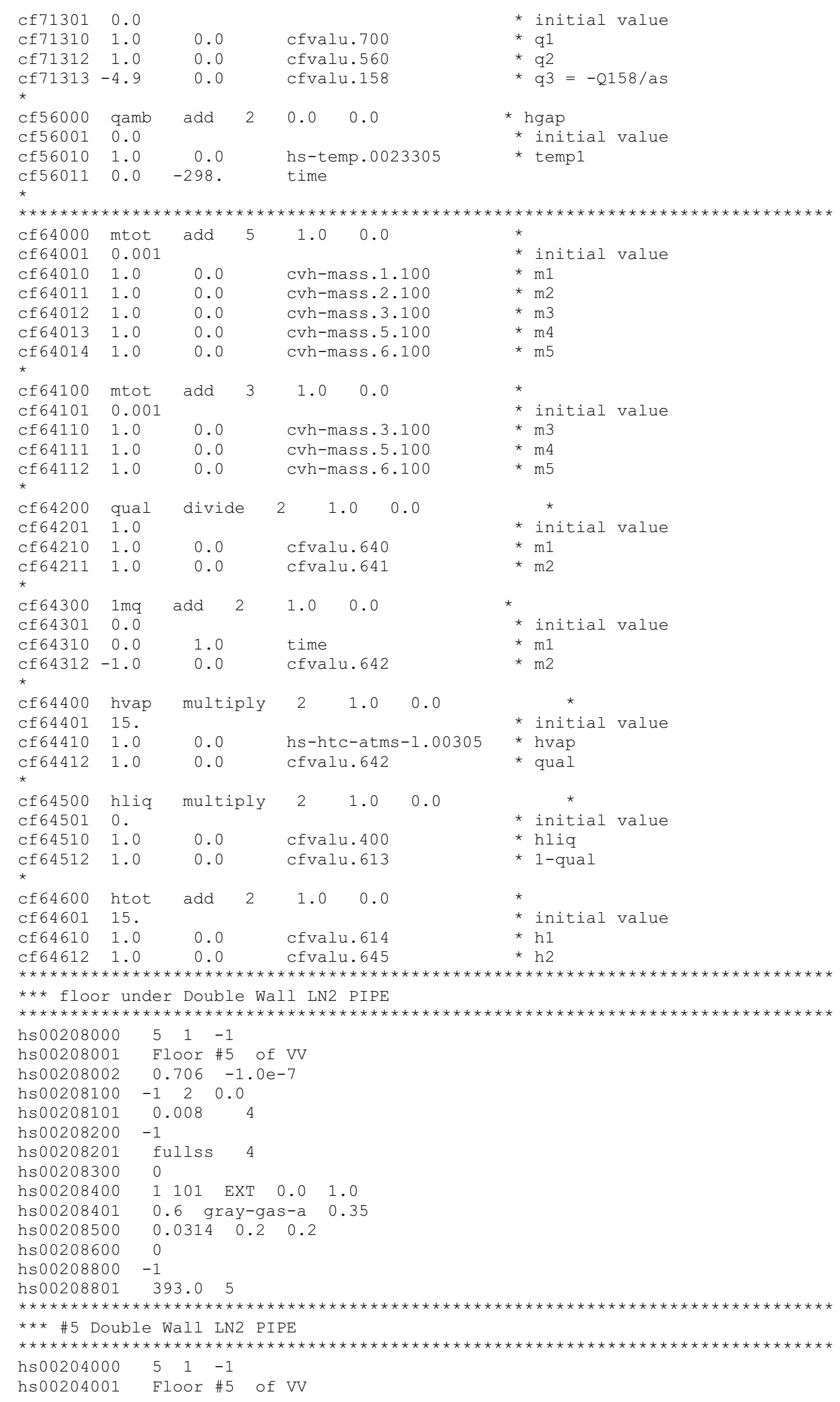




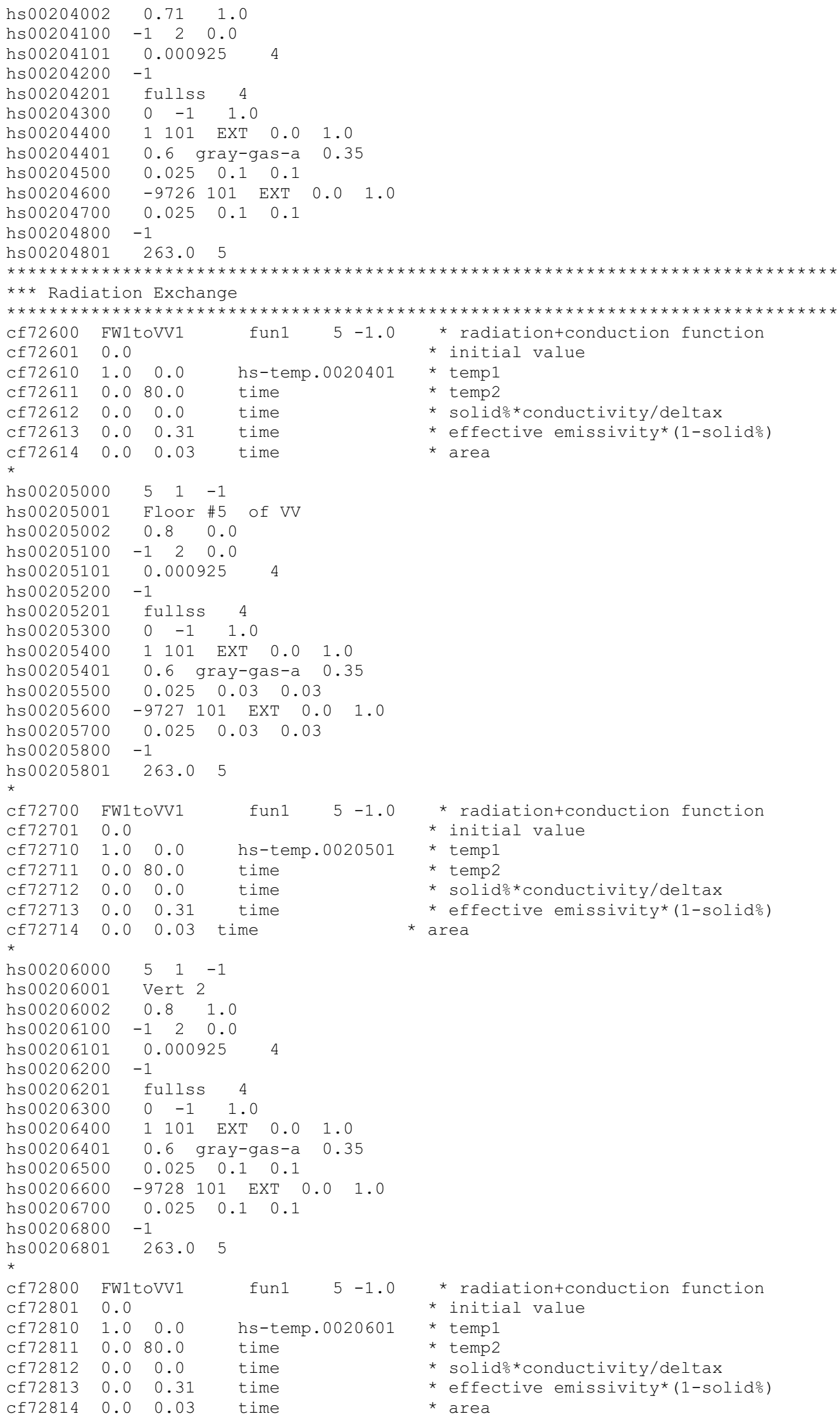




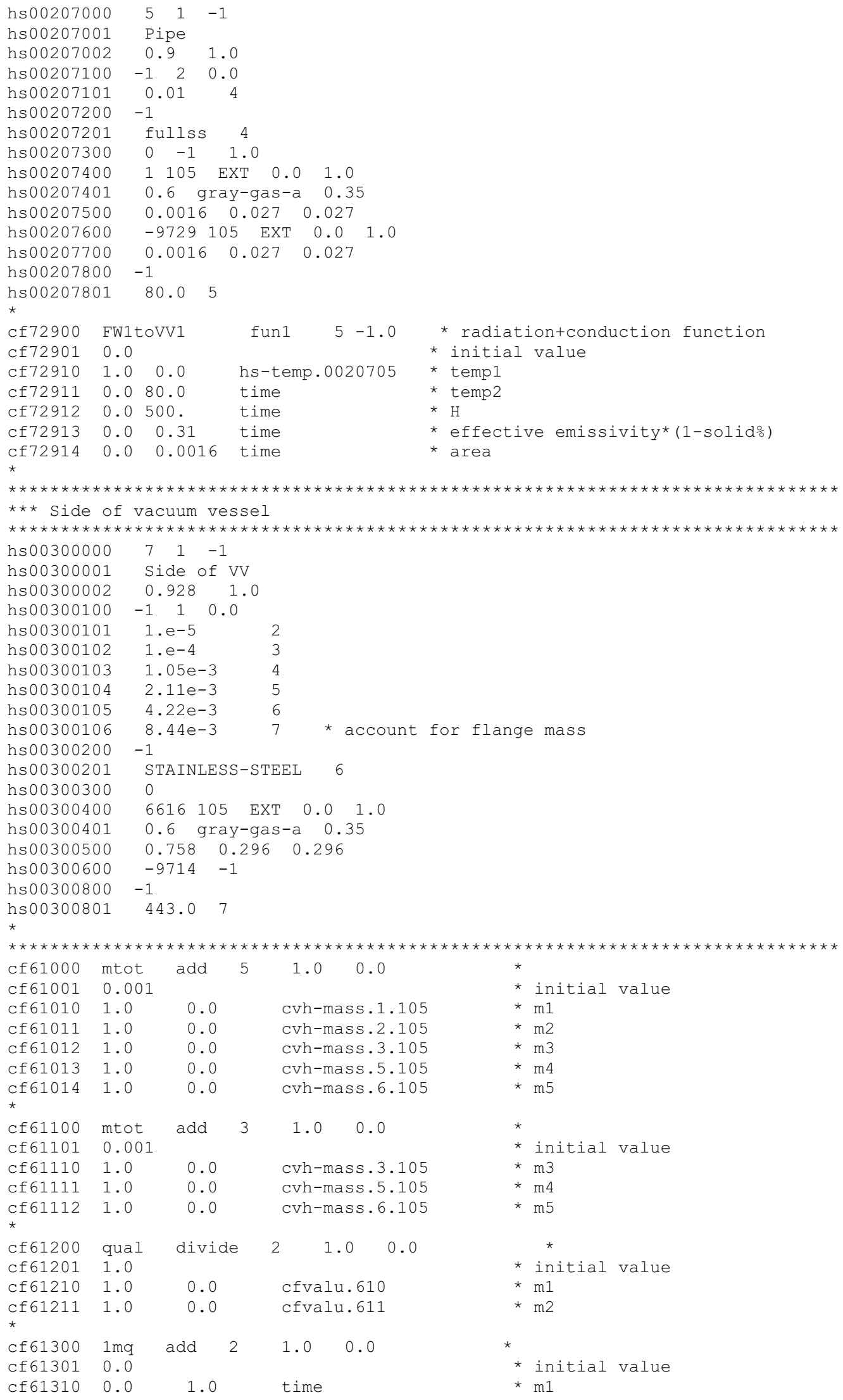




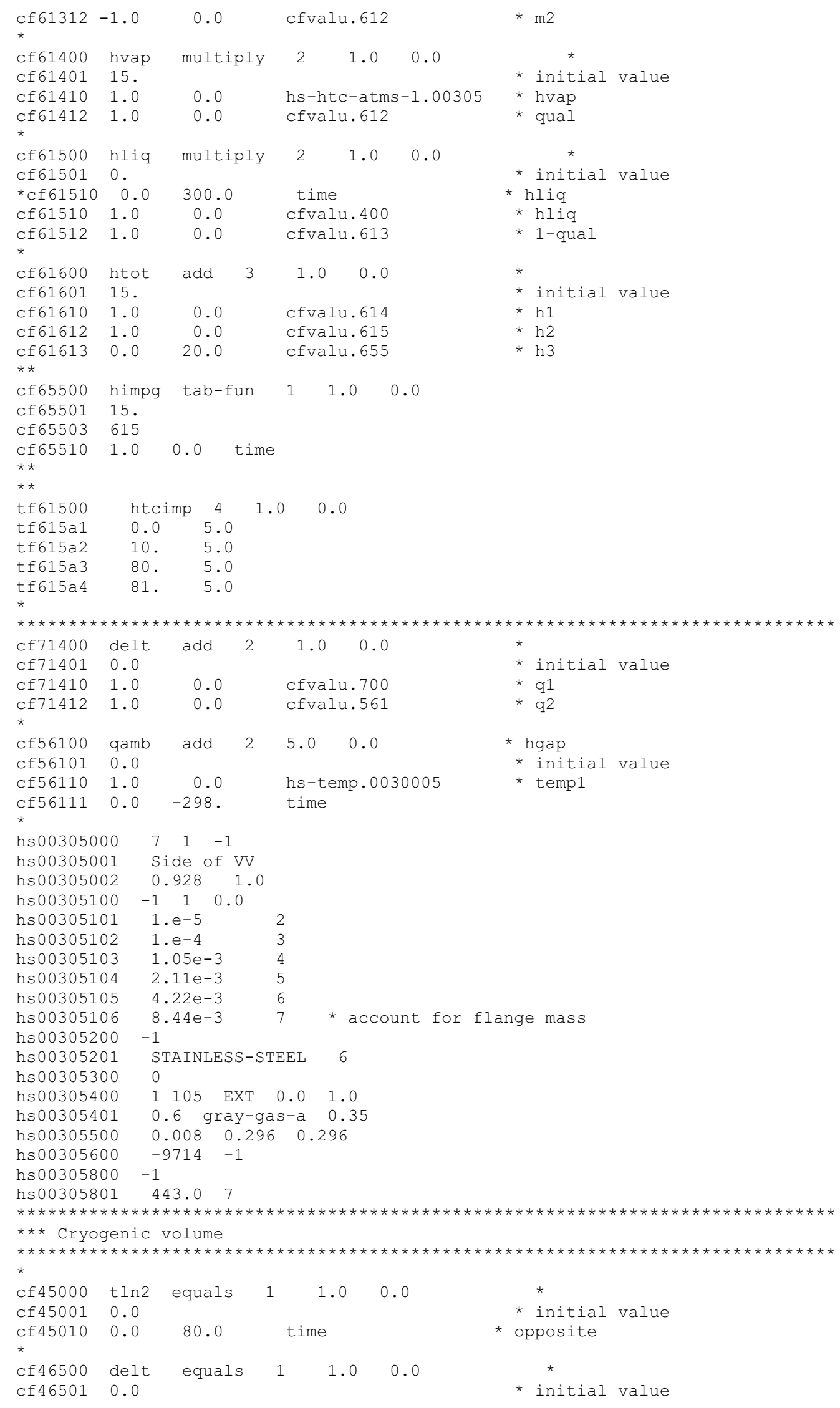




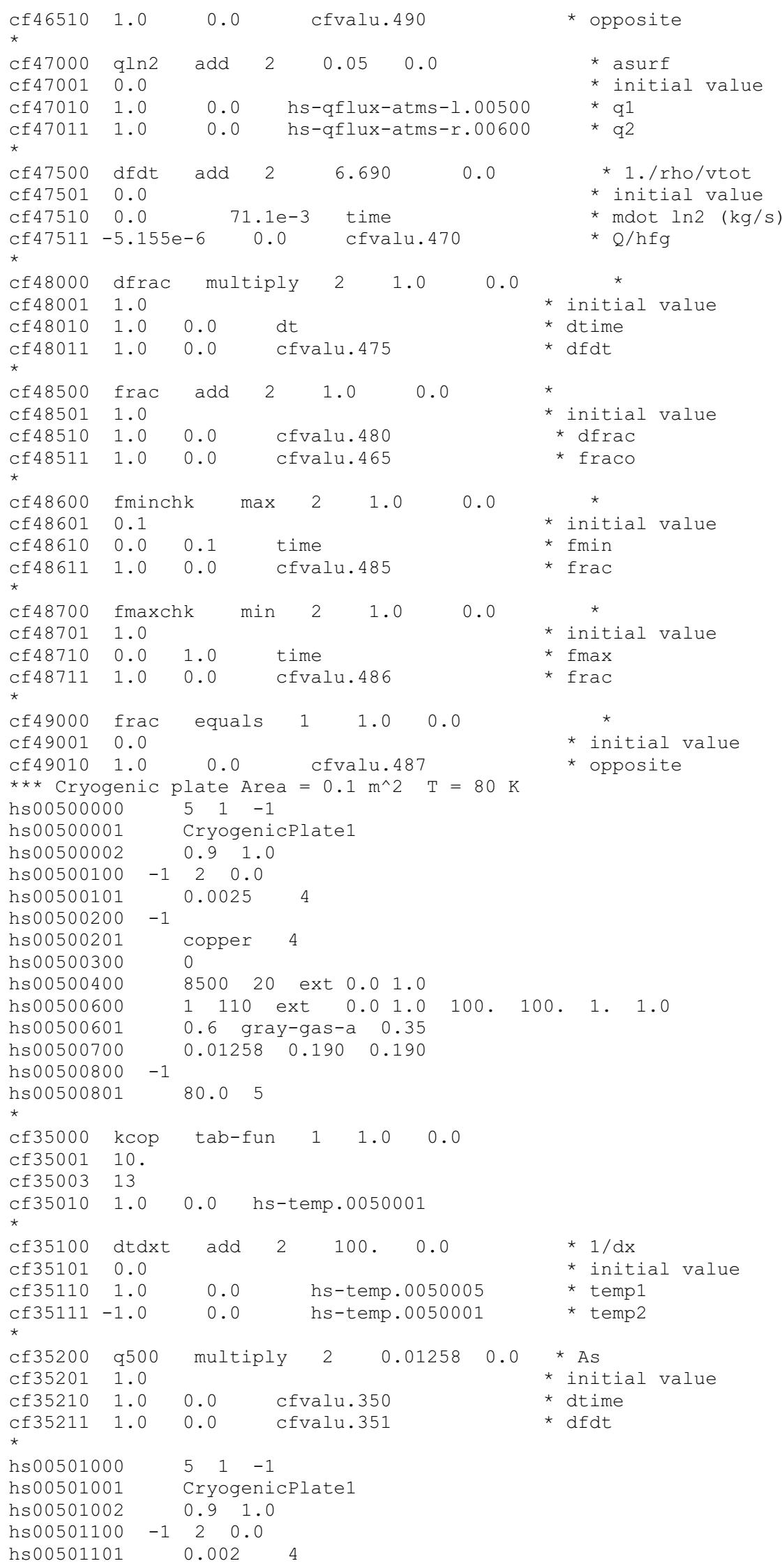




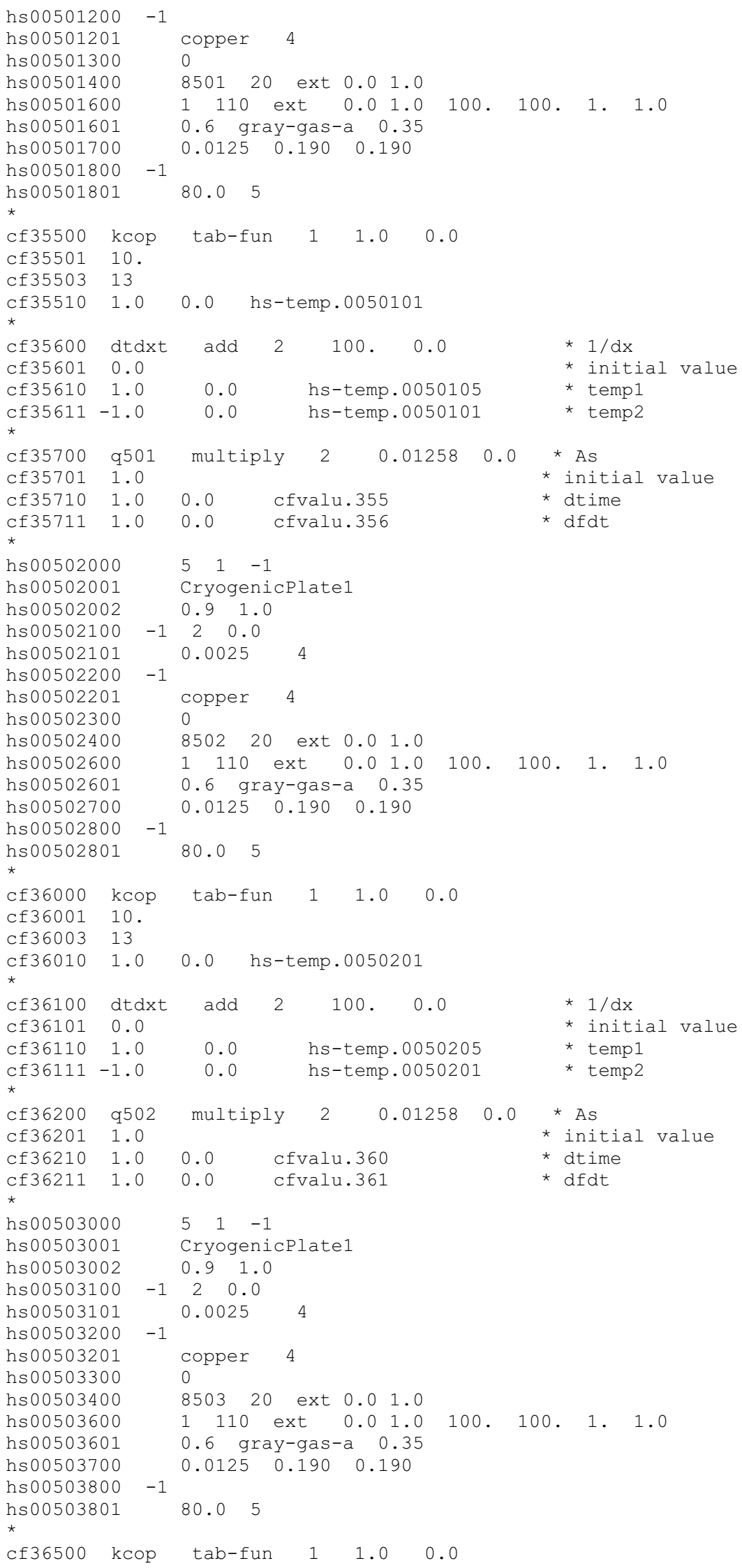




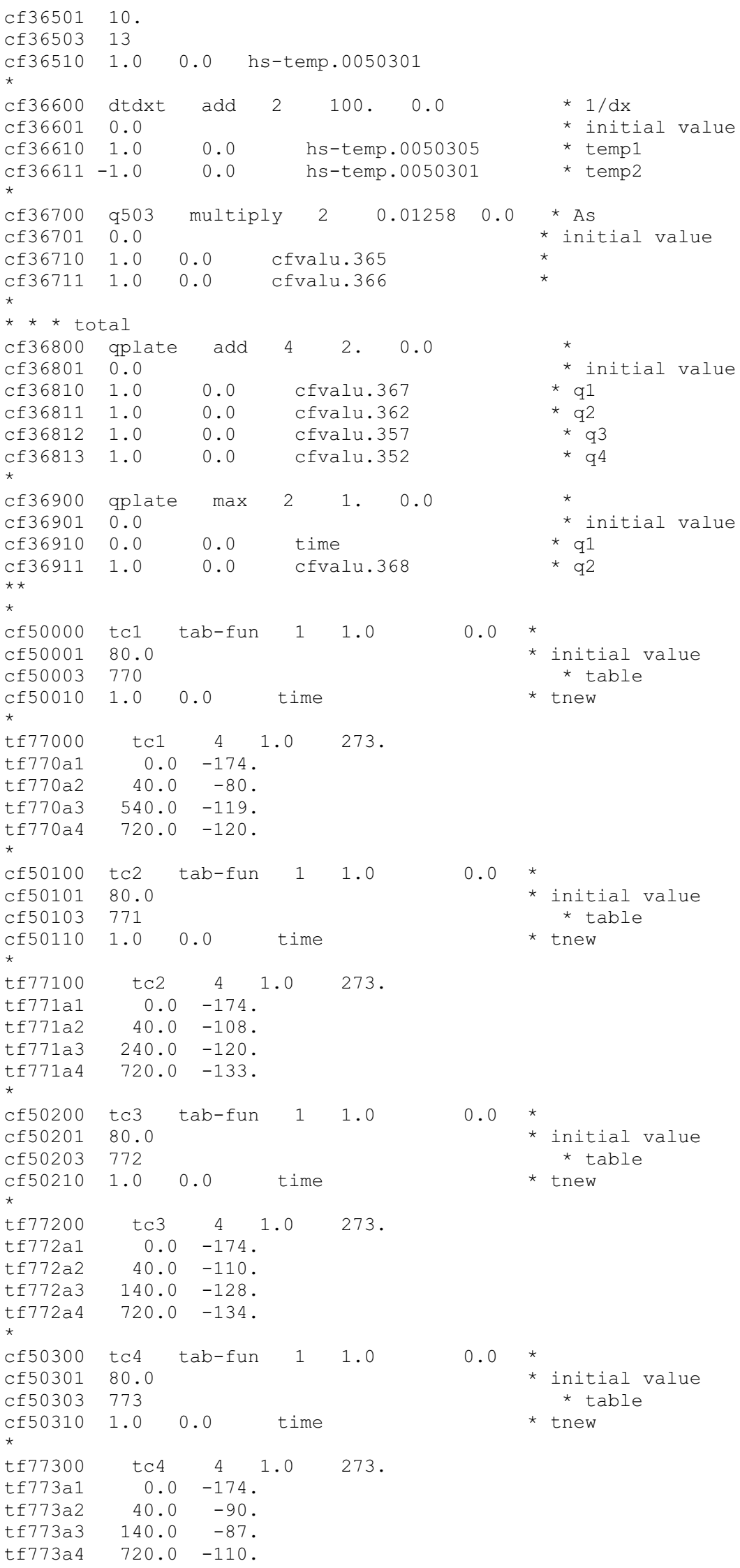




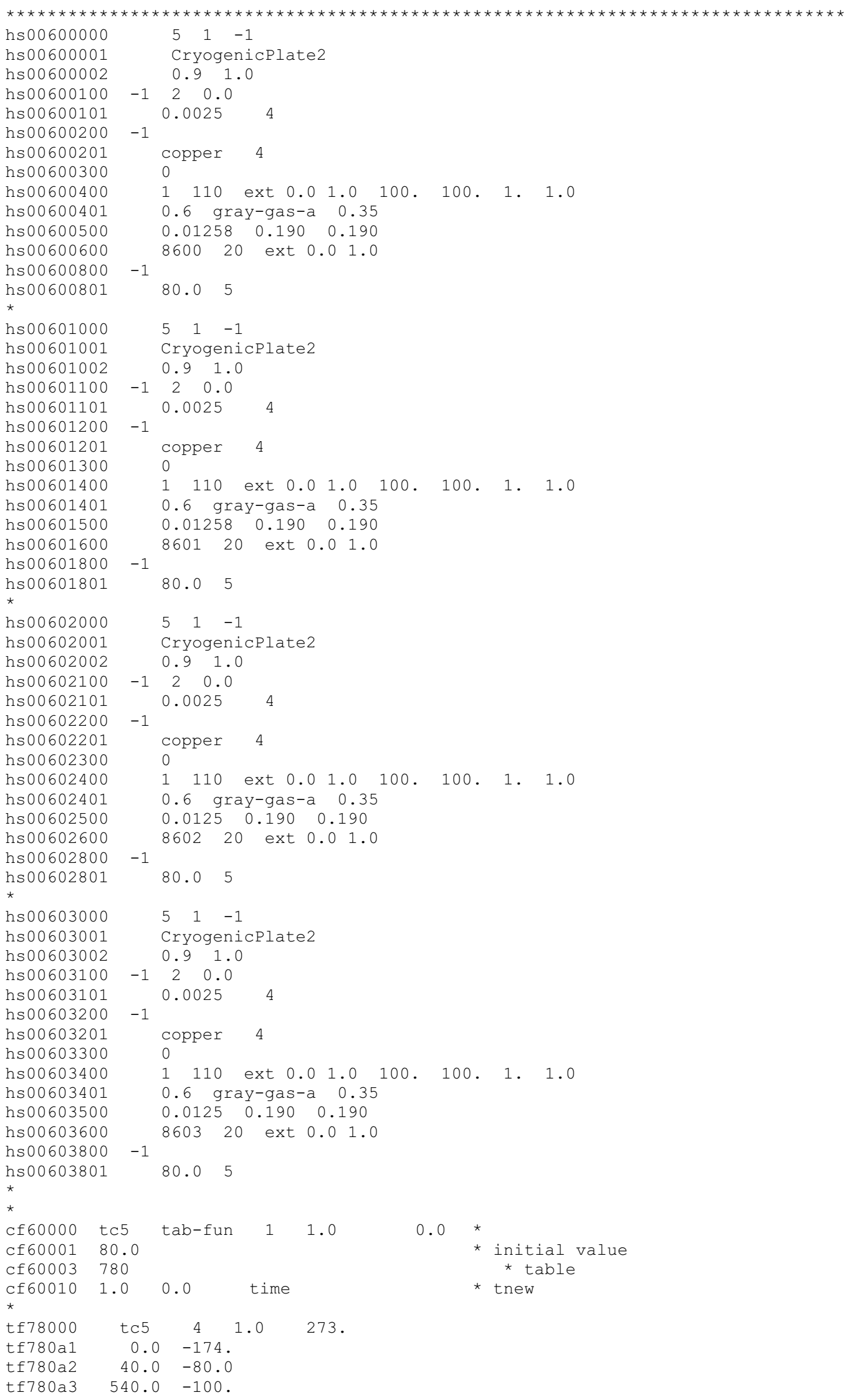




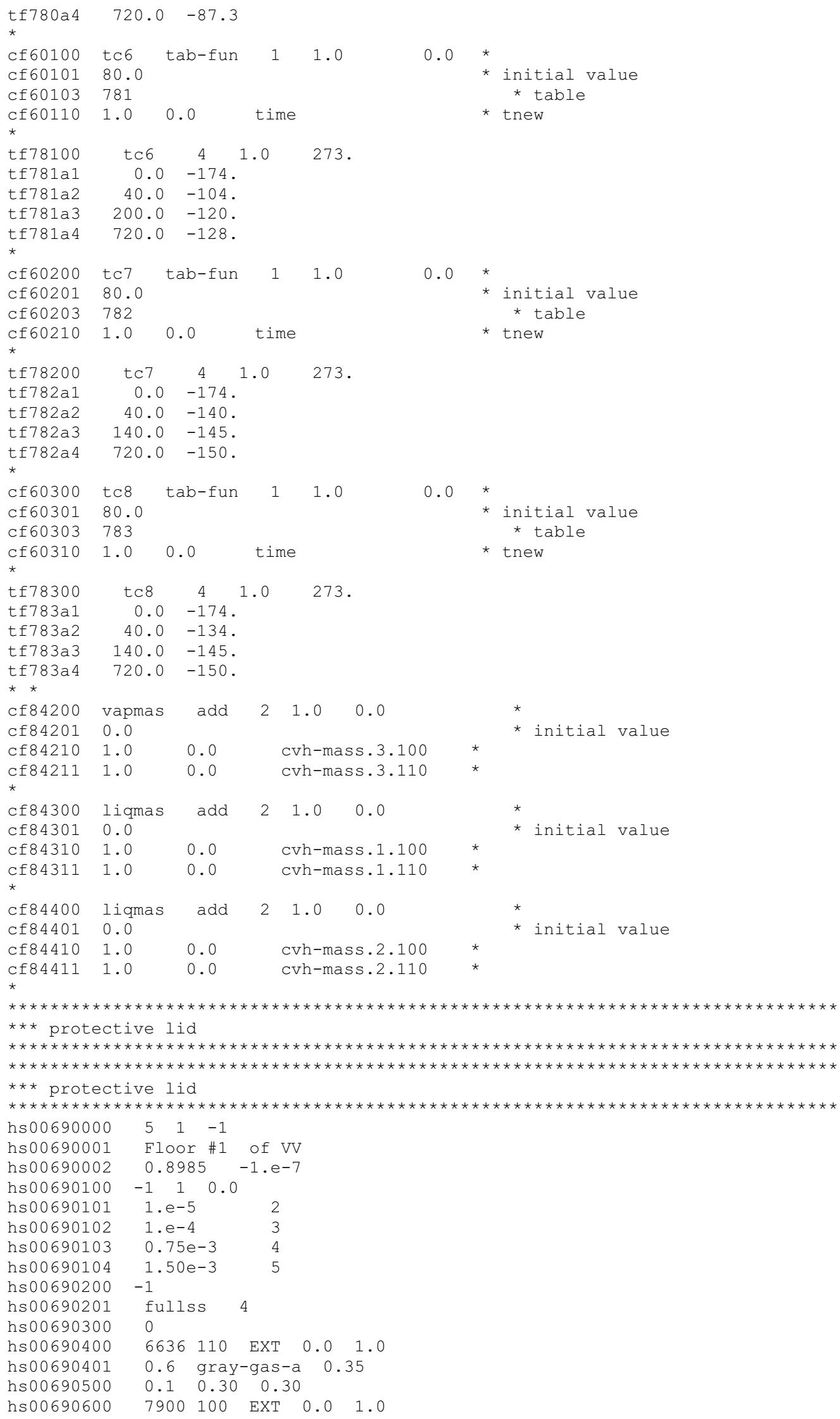




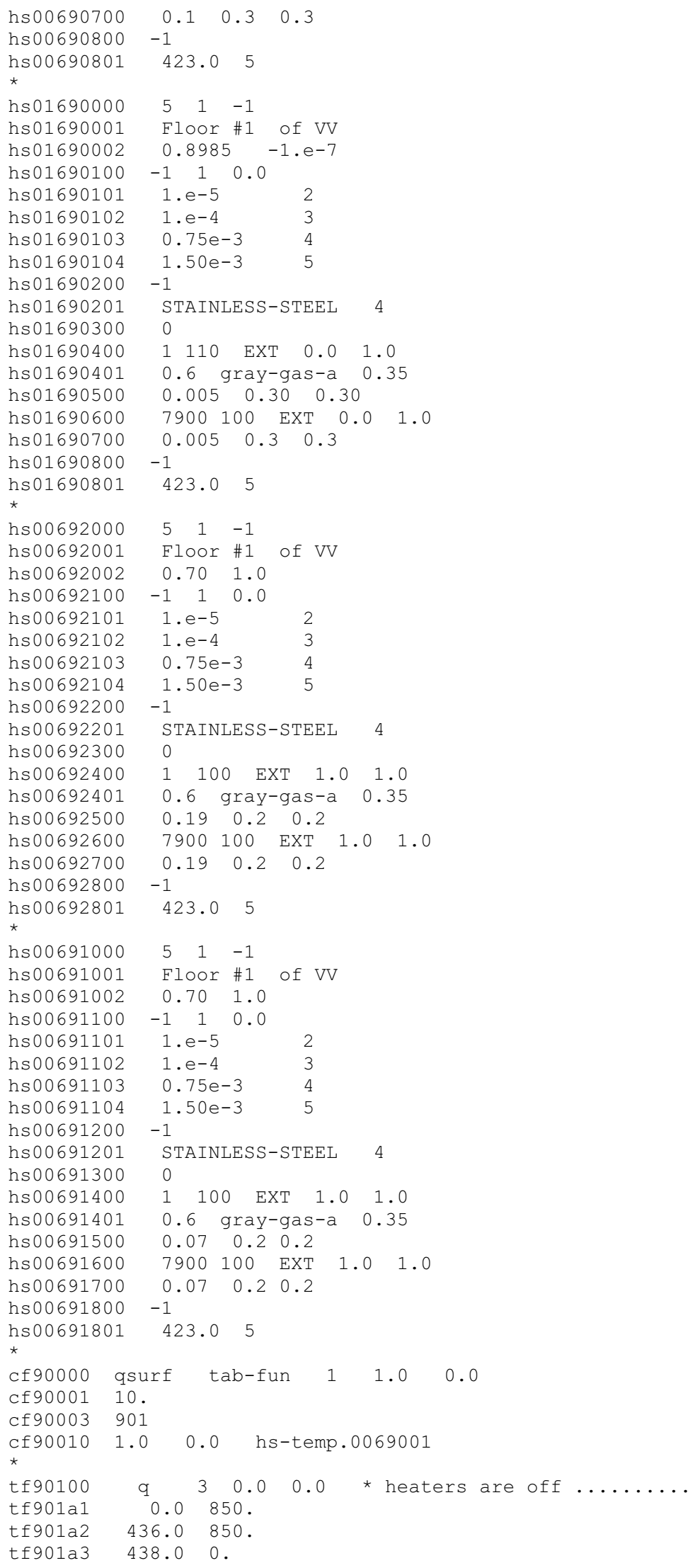




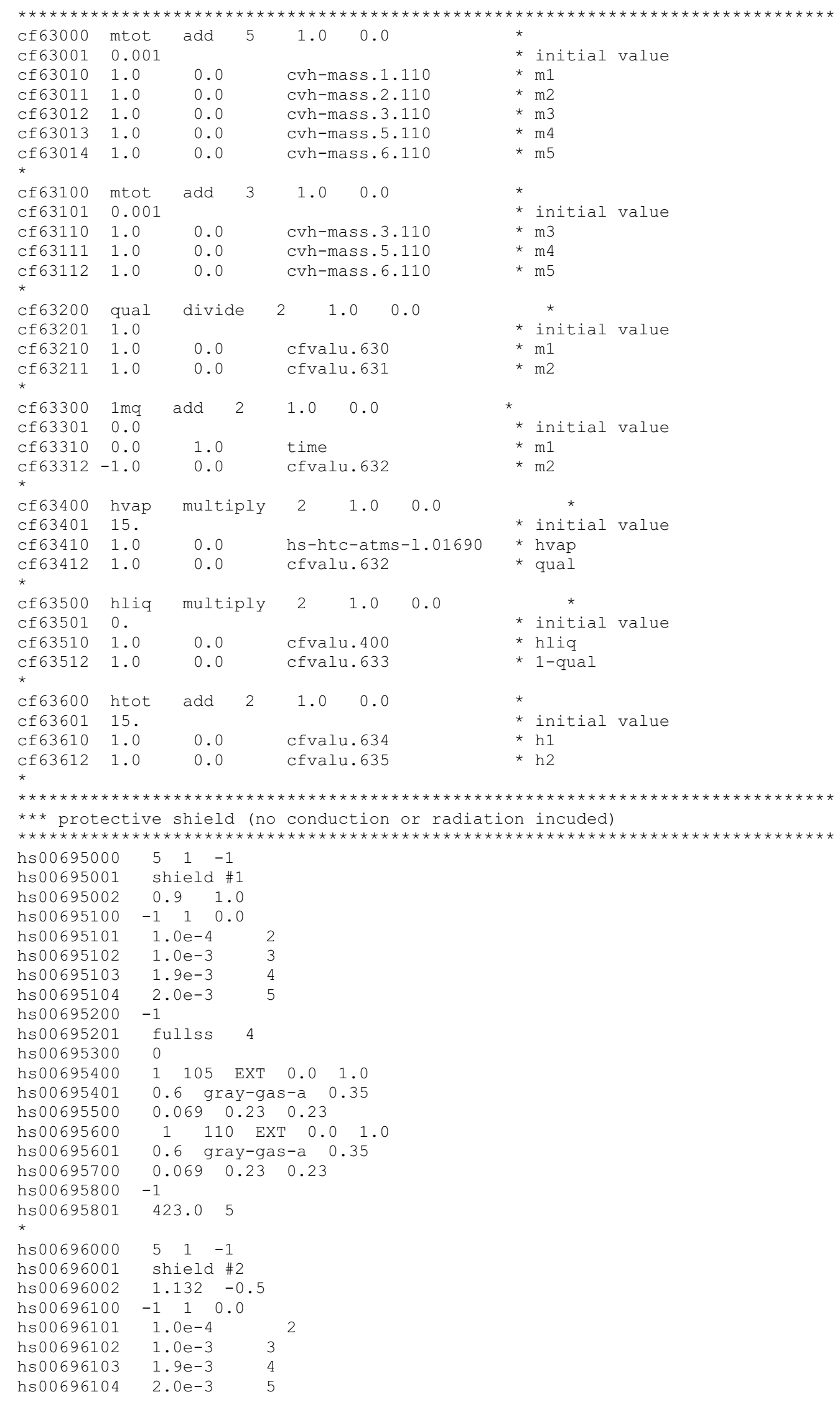




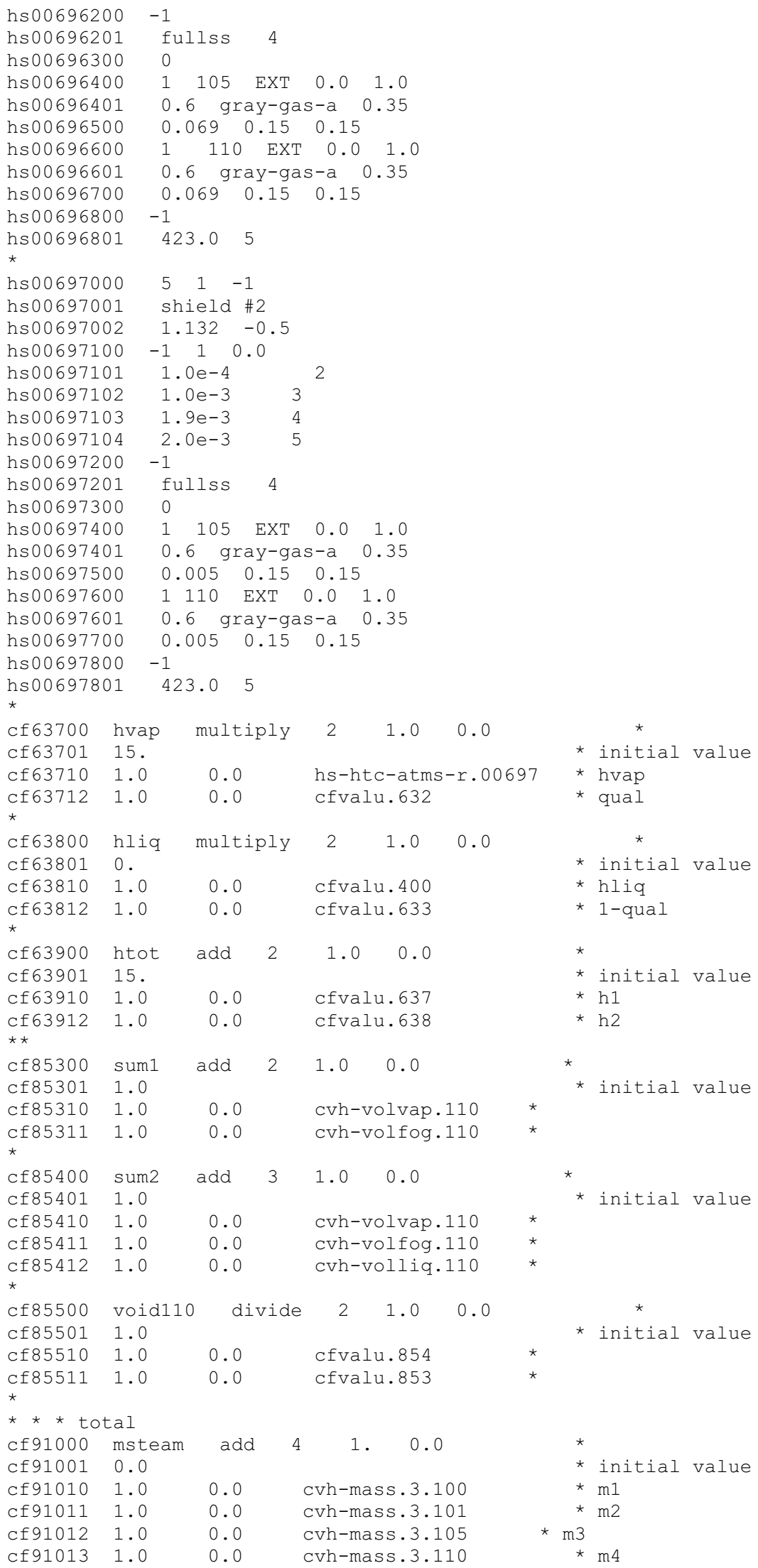




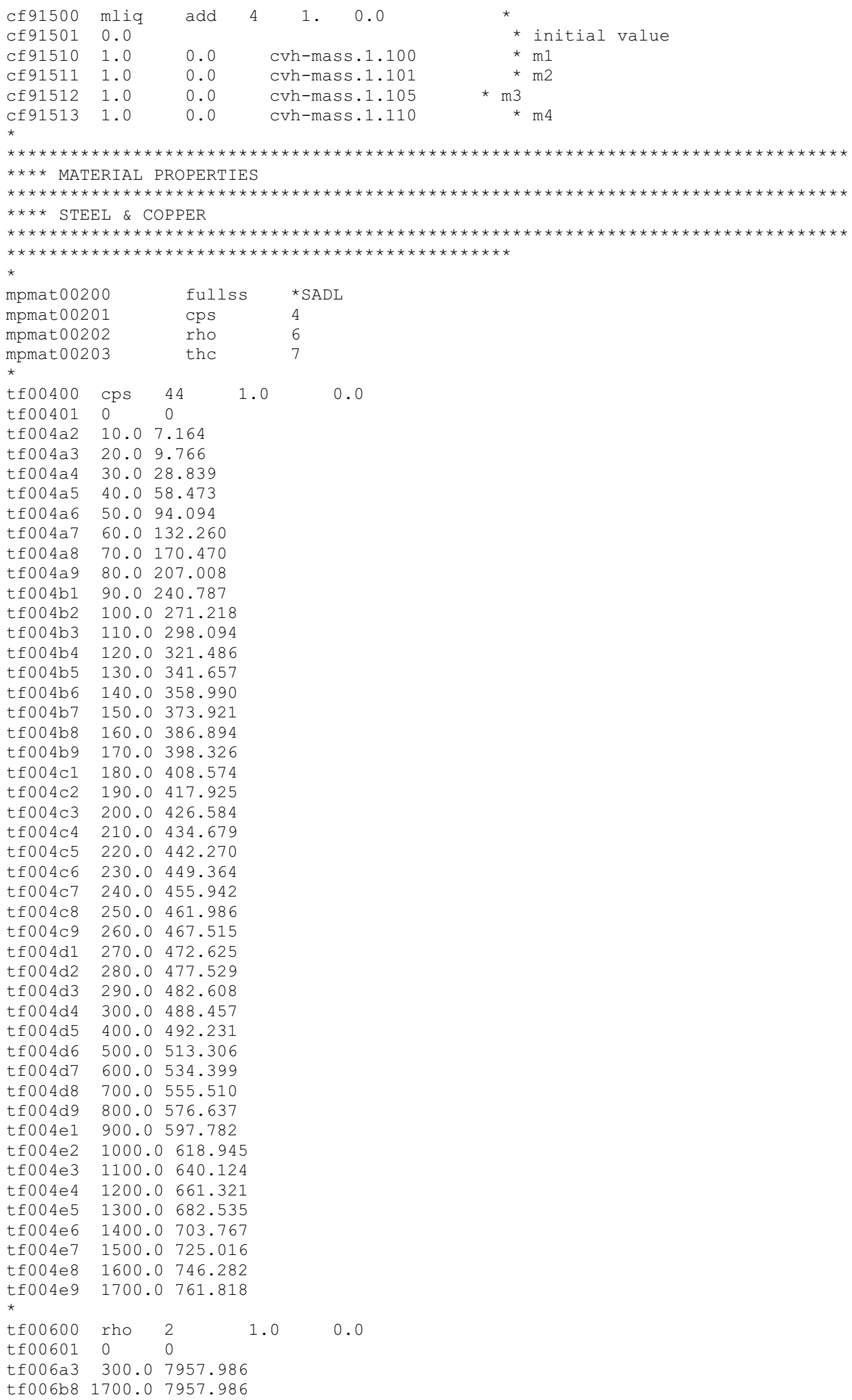




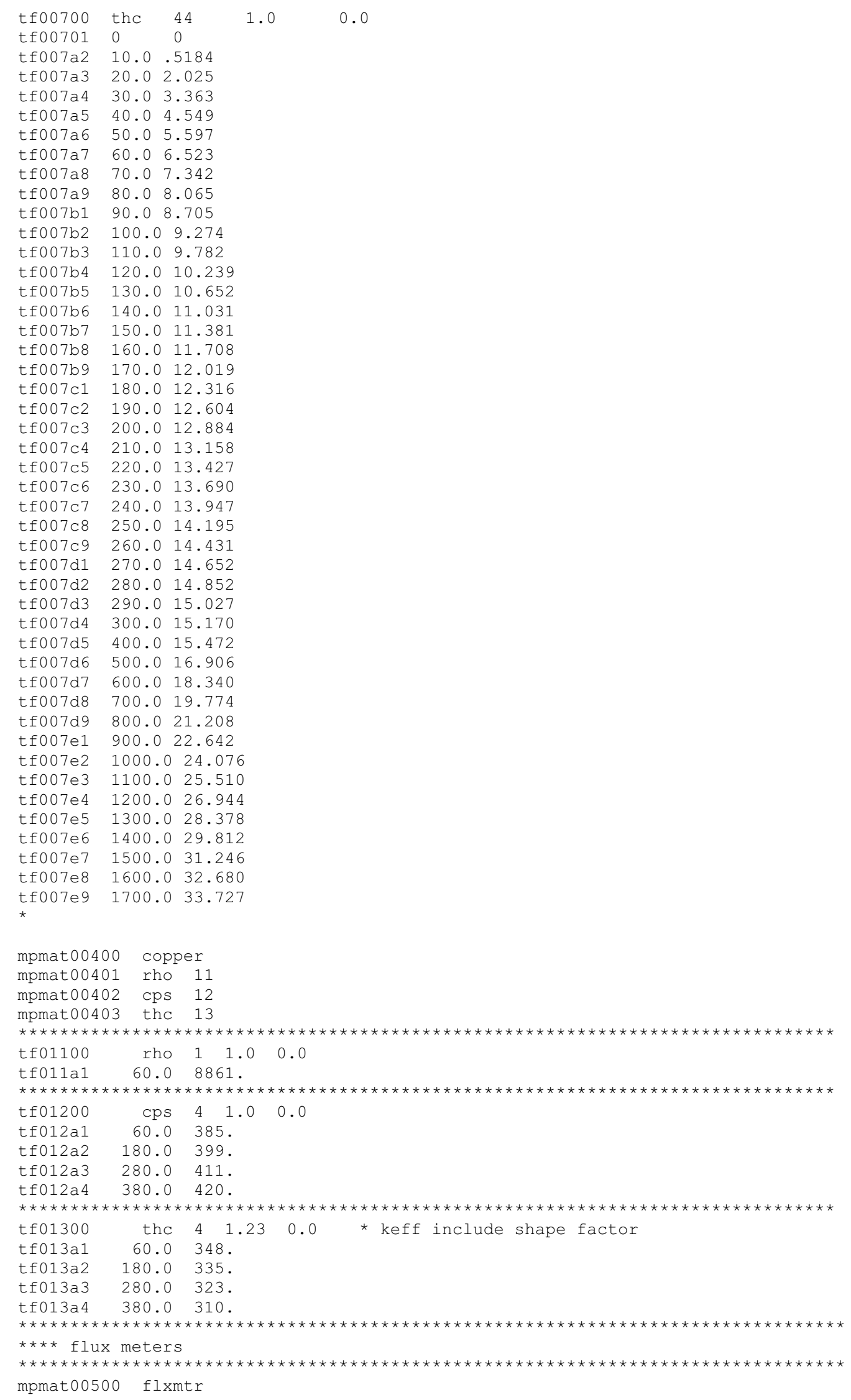




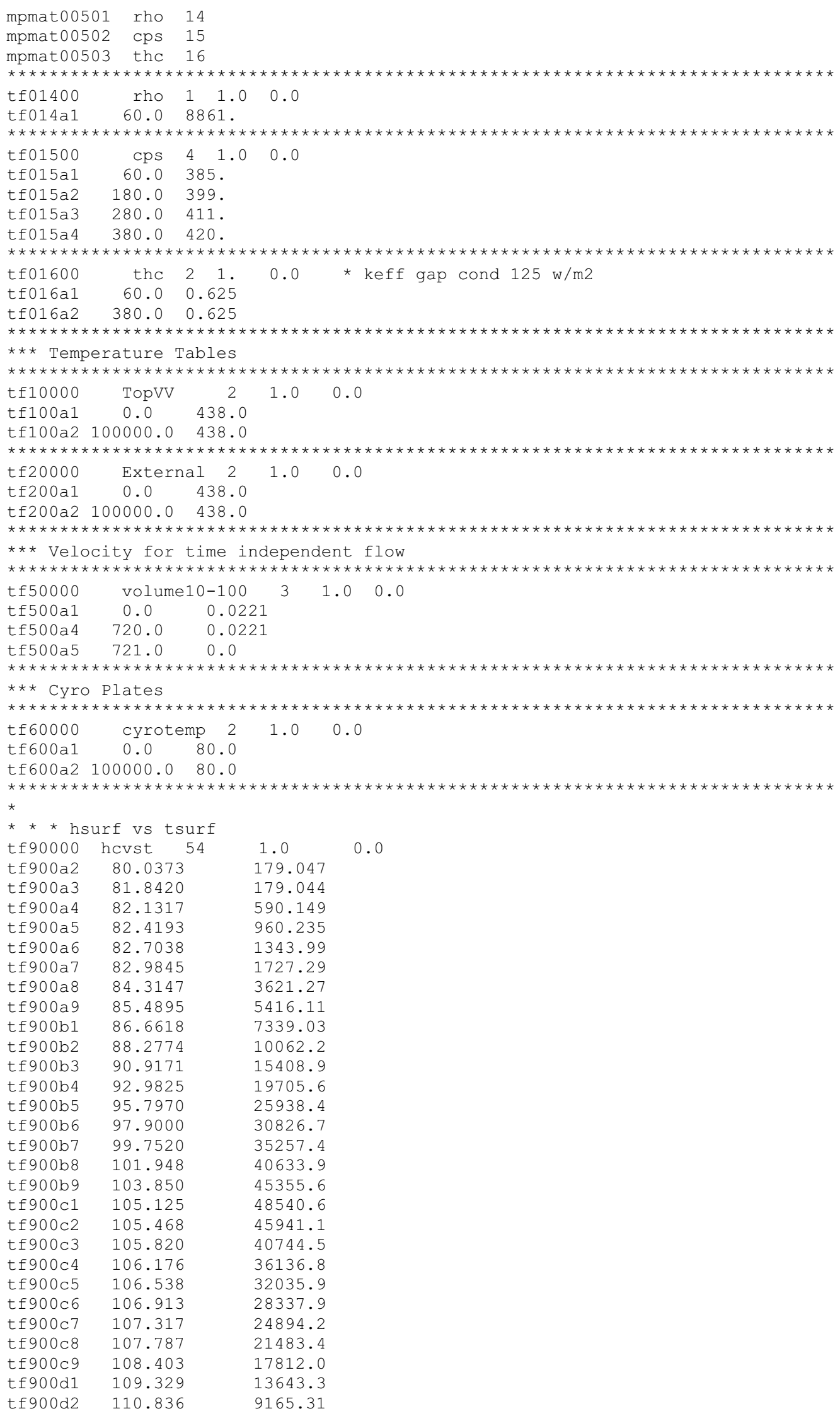




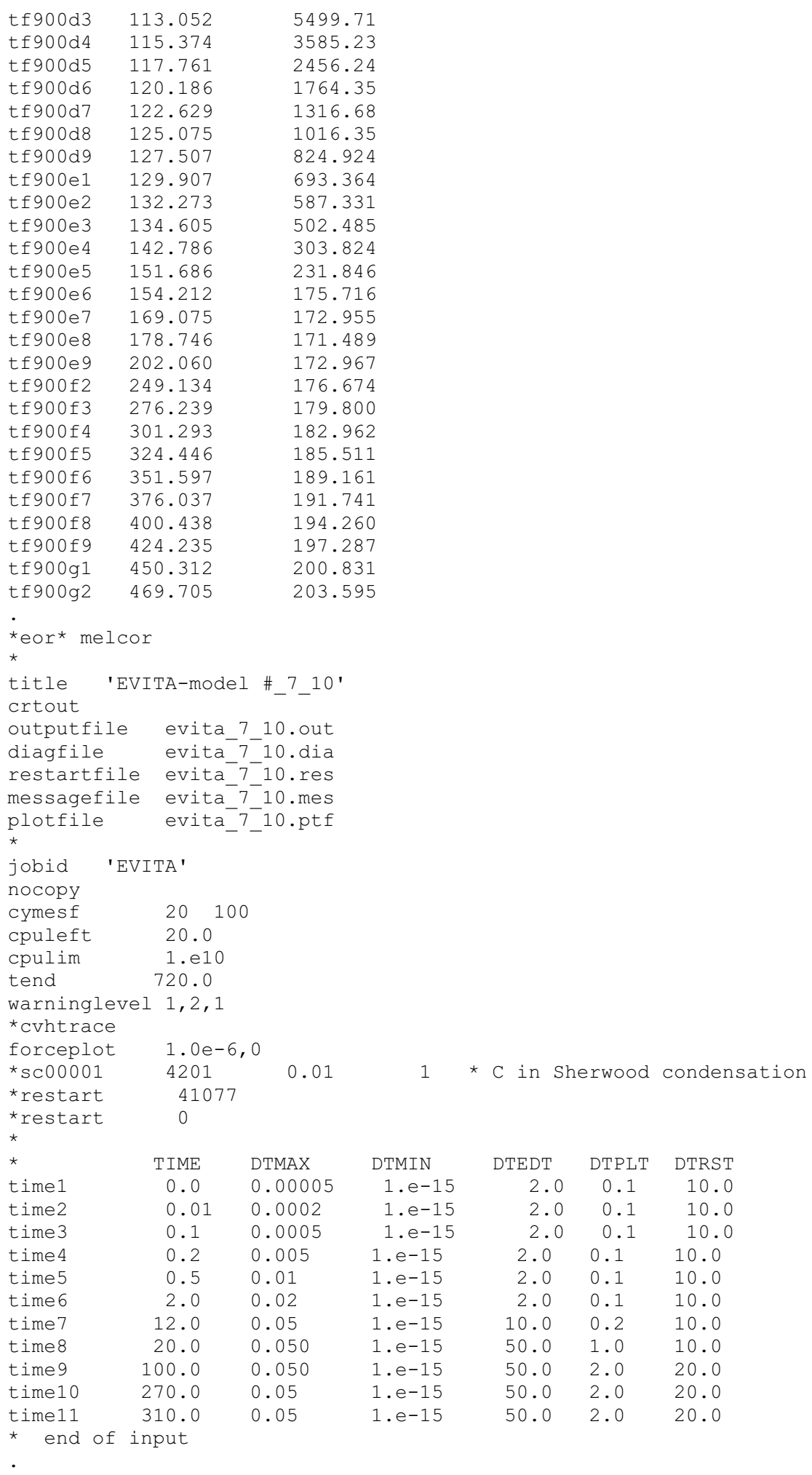

